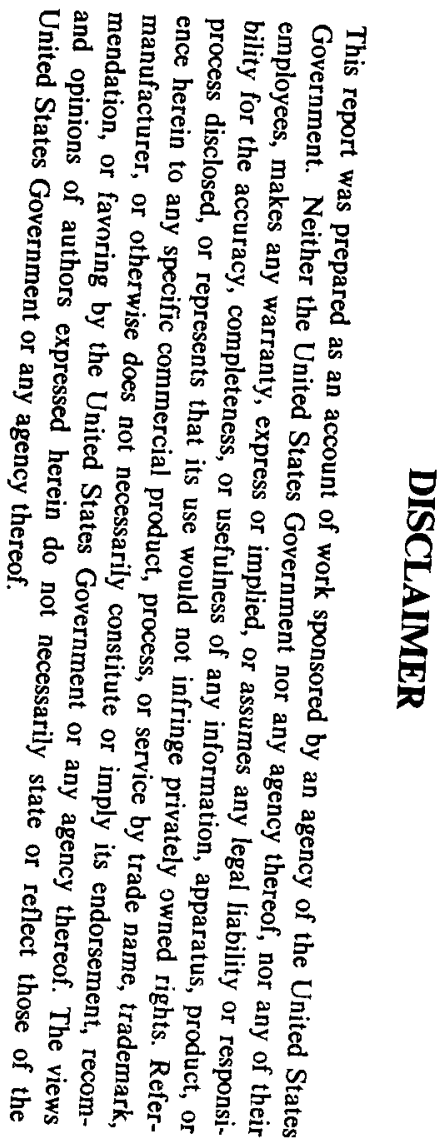

\title{
Testing and Analysis of Immersed Heat Exchangers
}

\author{
SERI/TR- $-253-2866$ \\ DE86 010742
}

Robert B. Farrington

Carl E. Bingham

August 1986

Prepared under Task No. 3016.31

FTP No. 01-526-85

Solar Energy Research Institute

A Division of Midwest Research Institute

1617 Cole Boulevard

Golden, Colorado 80401

Prepared for the

U.S. Department of Energy

Contract No. DE-AC02-83CH10093 


\section{DISCLAIMER}

This report was prepared as an account of work sponsored by an agency of the United States Government. Neither the United States Government nor any agency Thereof, nor any of their employees, makes any warranty, express or implied, or assumes any legal liability or responsibility for the accuracy, completeness, or usefulness of any information, apparatus, product, or process disclosed, or represents that its use would not infringe privately owned rights. Reference herein to any specific commercial product, process, or service by trade name, trademark, manufacturer, or otherwise does not necessarily constitute or imply its endorsement, recommendation, or favoring by the United States Government or any agency thereof. The views and opinions of authors expressed herein do not necessarily state or reflect those of the United States Government or any agency thereof. 


\section{DISCLAIMER}

Portions of this document may be illegible in electronic image products. Images are produced from the best available original document. 


\section{PREFACE}

In keeping with the national energy policy goal of fostering an adequate supply of energy at a reasonable cost, the U.S. Department of Energy (DOE) supports a variety of programs to promote a balanced and mixed energy resource system. The mission of the DOE Solar Buildings Research and Development Program is to support this goal by providing for the development of solar technology alternatives for the buildings sector. It is the goal of the program to establish a proven technology base to allow industry to develop solar products and designs for buildings that are economically competitive and can contribute significantly to building energy supplies nationally. Toward this end, the program sponsors research activities related to increasing the efficiency, reducing the cost, and improving the long-term durability of passive and active solar systems for buildings water and space heating, cooling, and daylighting applications. These activities are conducted in four major areas: (1) Advanced Passive Solar Materials Research, (2) Collector Technology Research, (3) Cooling Systems Research, and (4) Systems Analysis and Applications Research.

Advanced Passive Solar Materials Research--This activity area includes work on new aperture materials for controlling solar heat gains and for enhancing the use of daylight for building interior lighting. It also encompasses work on low-cost thermal storage materials that have high thermal storage capacity and can be integrated with conventional building elements, and work on materials and methods to transport thermal energy efficiently between any building exterior surface and the building interior by nonmechanical means.

Collertor Technology Research--This activity area encompasses work on advanced 10w- to medium-temperature (up to $80^{\circ} \mathrm{C}\left[180^{\circ} \mathrm{F}\right]$ useful operating temperature) flat-plate collectors for water and space heating applications, and medium- to high-temperature (up to $204^{\circ} \mathrm{C}\left[400^{\circ} \mathrm{F}\right]$ useful operating temperature) evacuatedtube/concentrating collectors for space heating and cooling applications. The focus is on design innovations using new materials and fabrication techniques.

Cooling Systems Research--This activity area involves research on highperformance dehumidifiers and chillers that can operate efficiently with the variable thermal outputs and delivery temperatures associated with solar collectors. It also includes work on advanced passive cooling techniques.

Systems Analysis and Applications Research--This activity area encompasses experimental testing, analysis, and evaluation of solar heating, cooling, and daylighting systems for residential and nonresidential buildings. This involves system integration studies, the development of design and analysis tools, and the establishment of overall cost, performance, and durability targets for various technology or system options.

This report supports Systems Analysis and Applications Research by measuring the performance of immersed heat exchangers commonly used in active solar domestic hot water systems. Such heat exchangers are thought to perform much lower than expected. This work documents the actual performance of four immersed heat exchangers over a wide range of operating conditions. 
The authors gratefully acknowledge the assistance of Douglas Powell, James Pruett, and Kirk Lindahl, who assisted with the experiments, and Charles Kutscher and Ren Anderson for their considerable help with the analytical studies. Michael Connolly performed the work for and wrote the appendix on the detailed numerical model. This report was reviewed at SERI by Ren Anderson, Michael Connolly, Charles Kutscher, Allan Lewandowski, and Mary Linskens. The authors are grateful to those reviewers and to $\mathrm{S}$. Karaki (Colorado State University), K. May (Industrial Solar Technology), and $\mathrm{J}$. Mitchell (University of Wisconsin), all of whom contributed useful comments on the report.

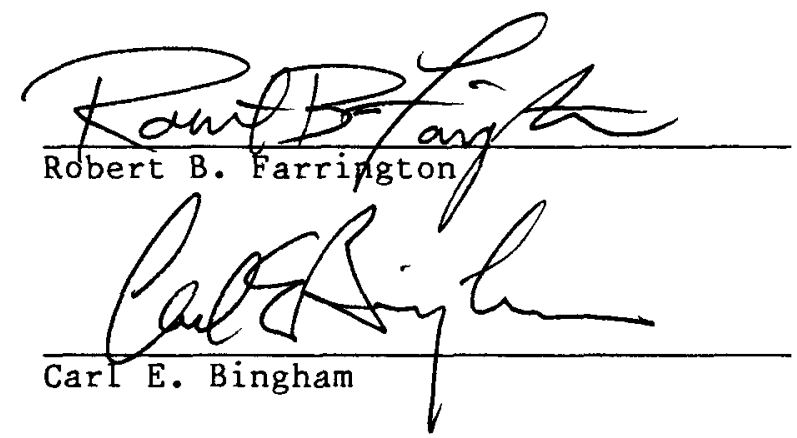

Approved for

SOLAR ENERGY RESEARCH INSTITUTE

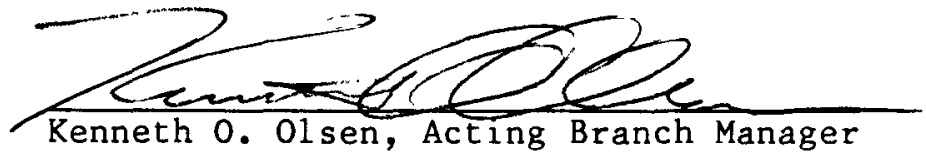

Kenneth 0. Olsen, Acting Branch Manager

Buildings Research Branch

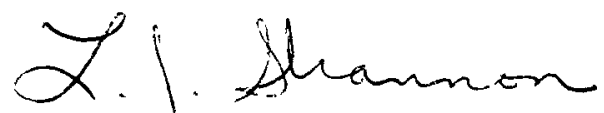

L. J. Shannon, Director

Solar theat Research Division 


\section{SUMMARY}

\section{Objectives}

The objectives of this work were to determine the performance of four immersed, supply-side* heat exchangers used in solar domestic hot water (SDHW) systems; to examine the effects of flow rate, temperature difference, and coil configuration on performance; and to develop a simple model to predict immersed heat exchanger performance.

\section{Discussion}

We tested four immersed heat exchangers: a smooth coil, a finned spiral, a single-wall bayonet, and a double-wall bayonet. We developed two analytical models and a simple finite difference model.

\section{Conclusions}

We experimentally verified that the performance of these heat exchangers is dependent on the flow rate through them and showed that the temperature difference between the inlet of the heat exchanger and the storage tank can strongly affect heat exchanger performance. The heat exchanger effectiveness dropped to very low values at low temperature differences, which is a significant finding since previous studies have concluded that the effectiveness is not very sensitive to temperature differences. These low effectiveness values may lead to improper selection of turn-off differentials for control systems. The turn-off differentials for some indirect systems should be as high as $4.2^{\circ} \mathrm{C}\left(7.6^{\circ} \mathrm{F}\right)$ to prevent uneconomical pump operation. We also compared the effects of the heat exchanger configuration and correlated Nusselt and Rayleigh numbers for each heat exchanger tested. The smooth coil consistently had a higher effectiveness than the others, while the double-wall bayonet heat exchanger had a very low effectiveness. The smooth-coil heat exchanger we built had a heat-transfer area of $0.9 \mathrm{~m}^{2}\left(10 \mathrm{ft}^{2}\right)$ and yet performed nearly as well as a commercially available finned-coil heat exchanger with twice as much heat-transfer area.

There was good agreement among the models as well as with experimental data, provided we accounted for the inside film coefficient and film efficiency. The temperature drop between the heat exchanger fluid and the tube wall was significant for the heat exchangers with an outside heat-transfer area much larger than the inside heat-transfer area--for example, finned heat exchangers where the outside area is approximately five times the inside heat-transfer area.

We still do not know the long-term effectiveness of heat exchangers when there is scale accumulation. Another unknown is the effect of very low flow rates

*By "supply-side" we mean the energy source is on the tube side of the heat exchanger. In particular, this refers to either collector loop fluid or space heating storage water flowing through the heat exchanger. The former case can also be referred to as "collector-side" heat exchangers. 
on heat exchanger performance. Heat exchanger effectiveness can vary significantly over typical operating parameters of solar energy systems. Designers often need one effectiveness value. An hourly simulation should be run where the effectiveness varies with the operating conditions to determine the impact varying effectiveness has on annual system performance. 


\section{TABLE OF CONTENTS}

$\underline{\text { Page }}$

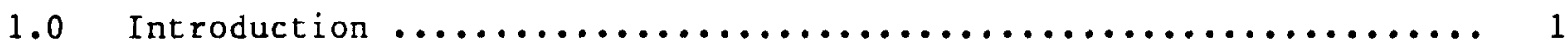

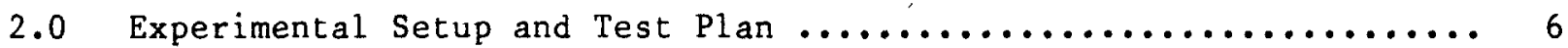

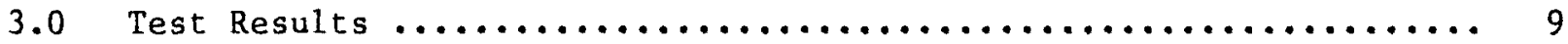

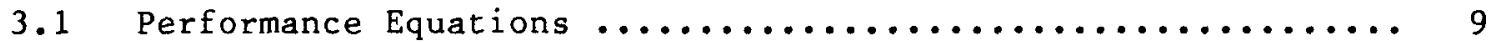

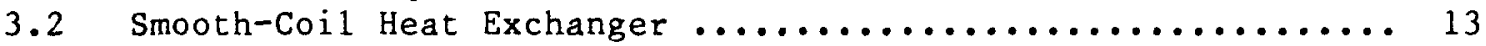

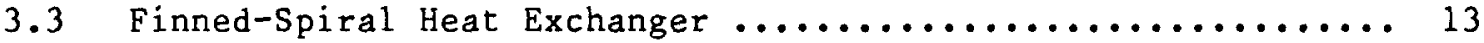

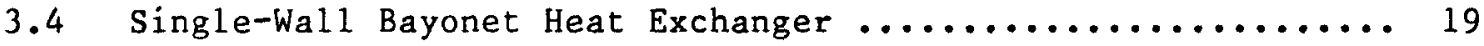

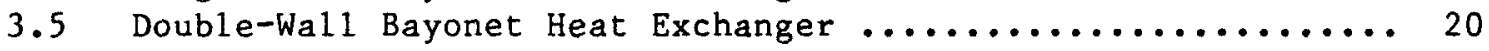

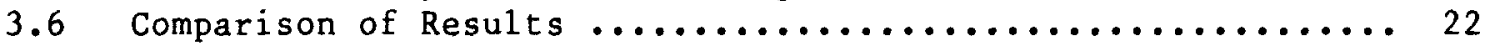

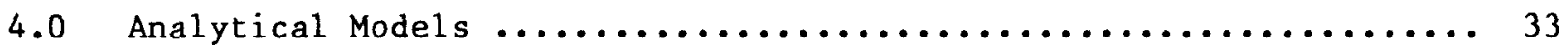

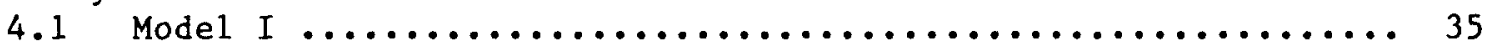

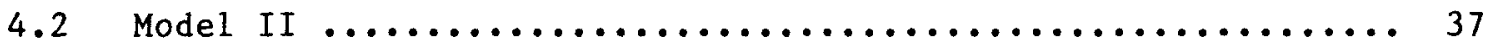

4.3 Model III--Finite Difference Model ................. 39

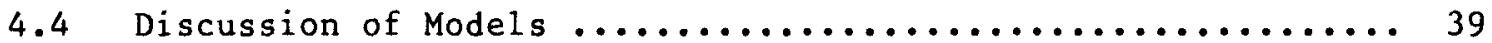

4.5 Comparison of Models with Experimental Results ........... 43

5.0 Conclusions and Recommendations $\ldots \ldots \ldots \ldots \ldots \ldots \ldots \ldots \ldots \ldots \ldots$

$6.0 \quad$ References $\ldots \ldots \ldots \ldots \ldots \ldots \ldots \ldots \ldots \ldots \ldots \ldots \ldots \ldots \ldots \ldots \ldots \ldots \ldots \ldots$

$7.0 \quad$ Bibliography $\ldots \ldots \ldots \ldots \ldots \ldots \ldots \ldots \ldots \ldots \ldots \ldots \ldots \ldots \ldots \ldots \ldots \ldots \ldots$

Appendix A Measurement Uncertainty Analysis .................. 52

Appendix B System Parameters for Figure $3-3 \ldots \ldots \ldots \ldots \ldots \ldots \ldots \ldots \ldots \ldots \ldots$

Appendix C Detailed Numerical Model ........................ 62

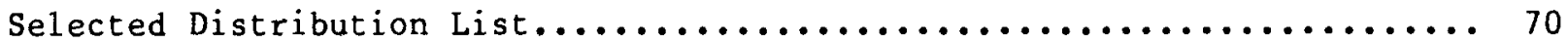


1-1 Internal Heat Exchanger Types $\ldots \ldots \ldots \ldots \ldots \ldots \ldots \ldots \ldots \ldots \ldots \ldots \ldots$

1-2 Photographs of Heat Exchangers Tested $\ldots \ldots \ldots \ldots \ldots \ldots \ldots \ldots \ldots \ldots \ldots$

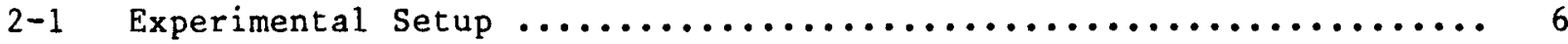

3-1 Solar Fraction as a Function of Collector/Storage Tank Heat Exchanger Effectiveness ............................. 10

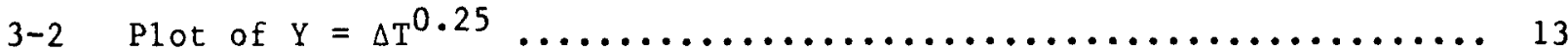

3-3 Smooth-Coil Heat Exchanger Geometry .................... 14

3-4 Smooth-Coil Heat Exchanger Test Results .................. 15

3-5 Finned-Spiral Heat Exchanger Geometry $\ldots \ldots \ldots \ldots \ldots \ldots \ldots \ldots \ldots$

3-6 Finned-Spiral Heat Exchanger Performance versus Time ......... 17

3-7 Finned-Spiral Heat Exchanger Test Results $\ldots \ldots \ldots \ldots \ldots \ldots \ldots \ldots \ldots 18$

3-8 Single-Wall Bayonet Heat Exchanger Geometry ................ 19

3-9 Single-Wall Bayonet Heat Exchanger Test Results .............. 21

3-10 Double-Wall Bayonet Heat Exchanger Geometry ............... 22

3-11 Double-Wal1 Bayonet Heat Exchanger Test Results .............. 23

3-12 Comparison of Reverse Flow in Double-Wall Bayonet Heat Exchanger .. 24

3-13 Comparison of All Heat Exchangers Tested ................. 25

3-14 Nusselt-Rayleigh Results by Heat Exchanger Type for All

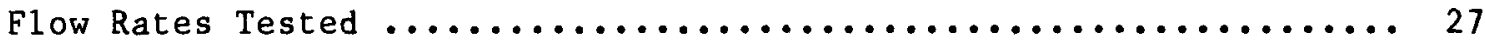

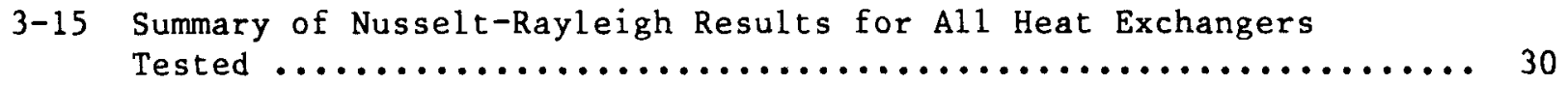

3-16 C Factor Variations for Each Heat Exchanger Type ............. 32

4-1 Immersed-Coil Heat Exchanger Types $\ldots \ldots \ldots \ldots \ldots \ldots \ldots \ldots \ldots \ldots \ldots$

4-2 Finite Difference Model Parametric Variation for Immersed-Coil Heat Exchanger ........................ 41

4-3 Parametric Variations for Immersed-Coil Heat Exchanger ........ 42

C-1 Thermal Model of Nodal Schematic DHW Tank/Heat Exchanger ........ 65 


\section{LIST OF FIGURES (Concluded)}

C-2 System Temperature versus Time $\ldots \ldots \ldots \ldots \ldots \ldots \ldots \ldots \ldots \ldots \ldots \ldots \ldots$

C-3 Heat Exchanger Temperature versus Time $\ldots \ldots \ldots \ldots \ldots \ldots \ldots \ldots \ldots \ldots$

C-4 Heat Exchanger Heat Transfer Rate versus LMTD .............. 67

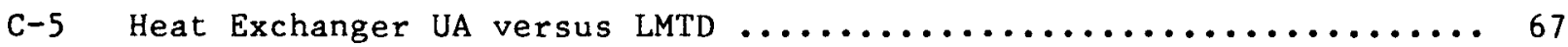

C-6 Heat Exchanger Effectiveness versus LMTD $\ldots \ldots \ldots \ldots \ldots \ldots \ldots \ldots \ldots$

C-7 Heat Exchanger Effectiveness versus Temperature Difference ...... 68

\section{LIST OF TABLES}

$\underline{\text { Page }}$

1-1 TVA Heat Exchanger Test Results $\ldots \ldots \ldots \ldots \ldots \ldots \ldots \ldots \ldots \ldots \ldots \ldots \ldots$

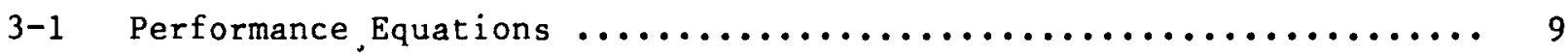

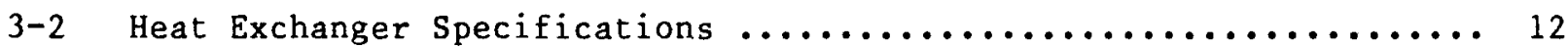

3-3 Nusselt Numbers at Selected Rayleigh Numbers ............... 29

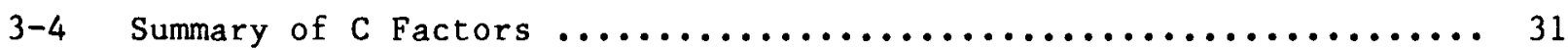

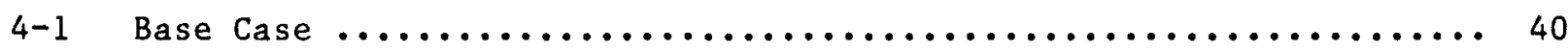

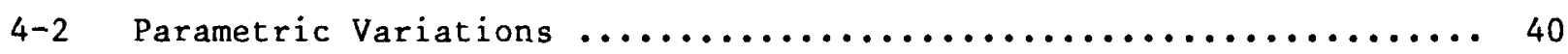

$4-3$ Comparisons of Models I, II, and III $\ldots \ldots \ldots \ldots \ldots \ldots \ldots \ldots \ldots$

4-4 Comparison of Analytical Results to Measured Performance

of Smooth-Coil Heat Exchanger ........................ 45

4-5 Comparison of Measured and Predicted Effectiveness for Finned, Single-Wall Bayonet Heat Exchanger at $10 \mathrm{~L} / \mathrm{min} \ldots \ldots \ldots \ldots \ldots \ldots \ldots 45$

A-1 Elemental Errors $\ldots \ldots \ldots \ldots \ldots \ldots \ldots \ldots \ldots \ldots \ldots \ldots \ldots \ldots \ldots \ldots \ldots \ldots$

A-2 Total Sensor Measurement Uncertainty $\ldots \ldots \ldots \ldots \ldots \ldots \ldots \ldots \ldots$

A-3 Summary of Bias Limits and Random Errors $\ldots \ldots \ldots \ldots \ldots \ldots \ldots \ldots \ldots$

A-4 Measurement Uncertainty Summary $\ldots \ldots \ldots \ldots \ldots \ldots \ldots \ldots \ldots \ldots$

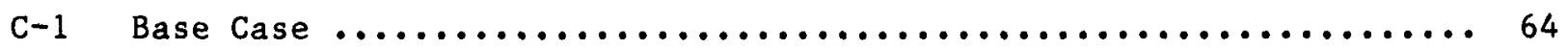




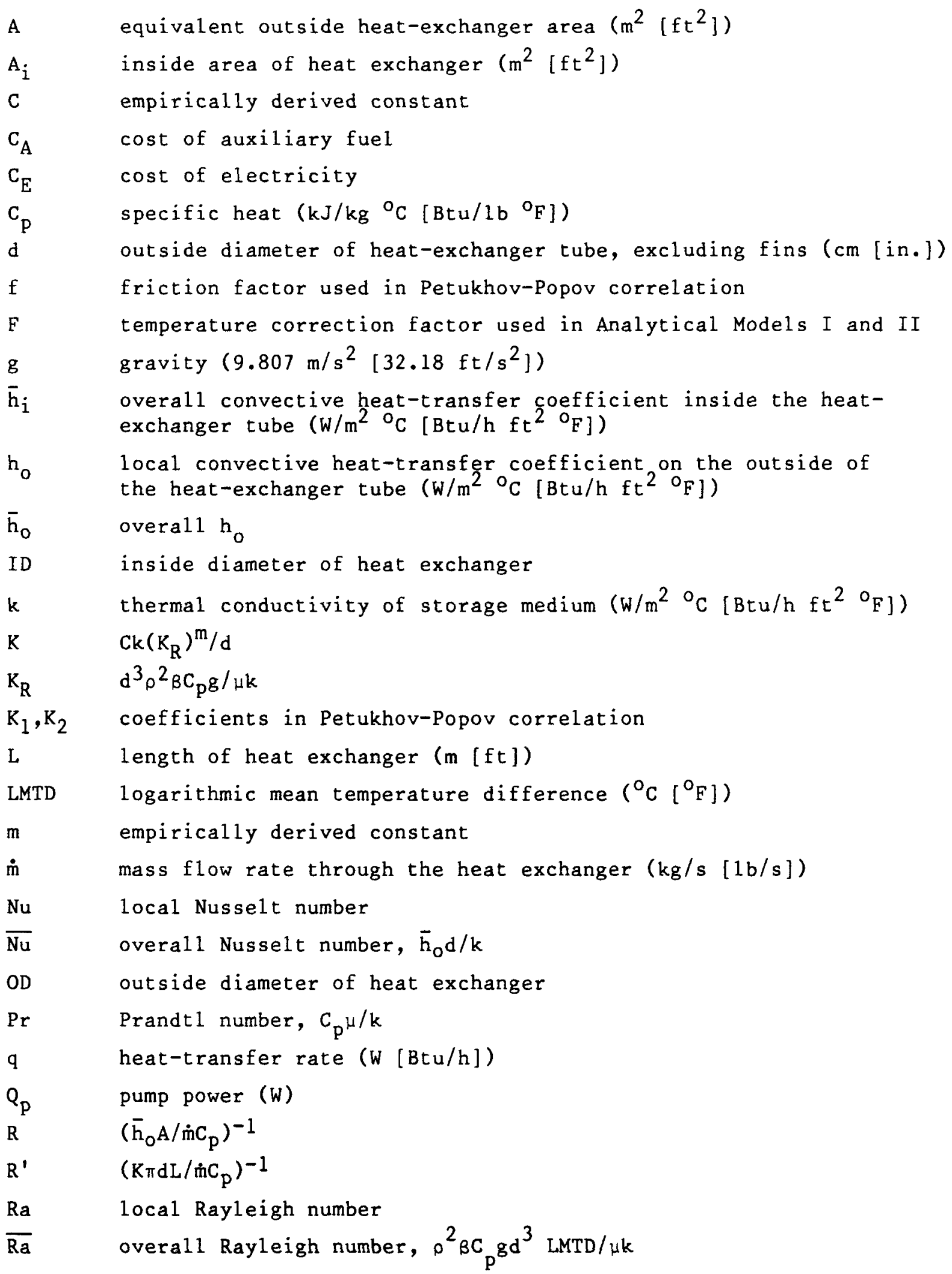




\section{NOMENCLATURE (Concluded)}

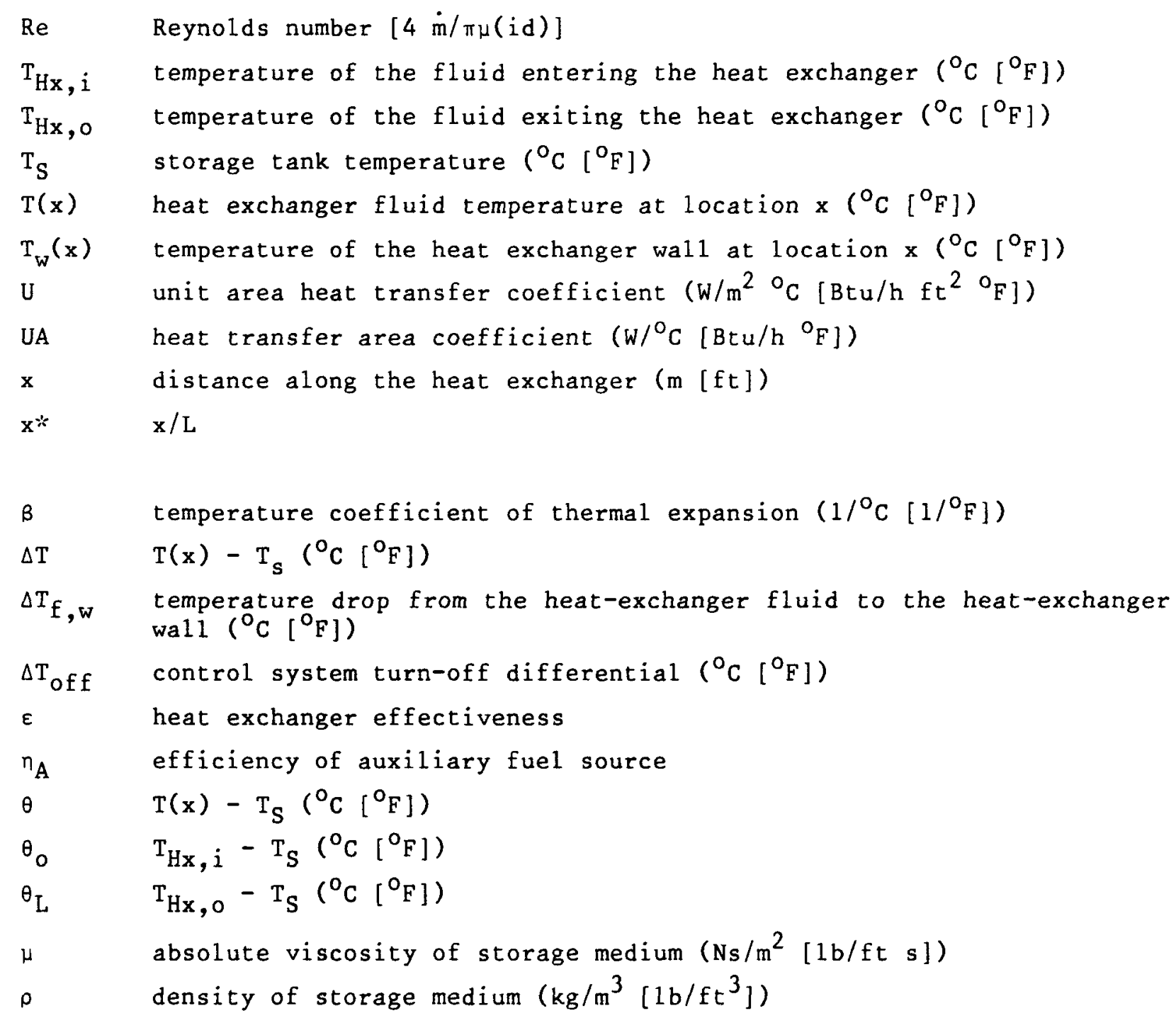


SERI*

$$
\begin{aligned}
& \text { - MPOREILS } \\
& \because \because \text { inu }
\end{aligned}
$$




\subsection{INTRODUCTION}

Solar energy systems often perform less efficiently than expected. This can be attributed to many causes, including poor heat exchanger performance. Results from the Tennessee Valley Authority (TVA), shown in Table 1-1, reveal that the measured effectiveness of heat exchangers (defined as the ratio of the actual heat transfer to the maximum theoretical possible) is significantly below the specified performance (Chaffin et al. 1982). The impact of supplyside heat exchanger effectiveness on system performance is significant if the effectiveness drops below about 0.4; the exact value depends on the system configuration (Mumma et al. 1978). We anticipate that the results of this work will lead to a better understanding of natural convective heat transfer from immersed heat exchangers and eventually to better heat exchanger designs and more accurate performance predictions.

The typical engineering approach to poor heat exchanger performance is to increase the heat exchanger area. However, increasing the heat exchanger area may not significantly contribute to better performance but may only increase the initial cost of the system, since the heat transfer from a combination of tubes is not equivalent to the sum of the heat transfer from each tube by itself because of the complex interaction between the tubes. In FY 1983 we began to analytically investigate the performance of immersed heat exchangers and developed a simple finite difference model to identify important performance parameters. In FY 1984 and 1985 we constructed a test loop and measured the performance of four types of immersed heat exchangers: smooth coil, finned spiral, single-wall bayonet, and double-wall bayonet. In FY 1985, we also began to develop a detailed numerical model to predict heat exchanger performance.

Table 1-1. TVA Heat Exchanger Test Results

\begin{tabular}{|c|c|c|c|}
\hline \multicolumn{2}{|c|}{ Heat Exchanger } & \multirow{2}{*}{$\begin{array}{c}\text { Specified } \\
\text { Effectiveness }\end{array}$} & \multirow{2}{*}{$\begin{array}{c}\text { Measured } \\
\text { Effectiveness }\end{array}$} \\
\hline System & Type & & \\
\hline 1 & externa1 DW & 0.53 & 0.37 \\
\hline 2 & internal DW & 0.50 & 0.13 \\
\hline 3 & wrap-around & 0.55 & 0.08 \\
\hline 4 & internal SW & 0.70 & 0.11 \\
\hline 5 & internal SW & 0.70 & 0.23 \\
\hline 6 & external DW & 0.61 & 0.54 \\
\hline \multirow[t]{3}{*}{7} & internal SW & 0.50 & 0.28 \\
\hline & Average (a11 types) & 0.58 & 0.25 \\
\hline & Average (internal) & 0.60 & 0.19 \\
\hline
\end{tabular}

Note: $\mathrm{SW}=$ single wall; $\mathrm{DW}=$ double wall. Source: Chaffin et al. 1982 . 
All indirect solar energy systems use some type of heat exchanger between the collector subsystem and the storage or energy delivery subsystems. The heat exchanger may be external, meaning that it is physically located outside the storage tank, or internal, meaning that convective heat transfer on the tank side is by natural convection (for example, a coil installed inside or wrapped around the outside of the storage). Heat transfer from external heat exchangers is generally from forced convection on both sides of the heat exchanger, which requires pumps on both the hot and cold sides. Some external heat exchangers placed below or beside the storage tank depend on natural convection to transfer heat from the heat exchanger to the storage tank and, likewise, a few use an external heat exchanger and depend on natural convection to transfer heat from the storage tank to the energy delivery subsystem. However, the majority of external heat exchangers depend on pumps to transfer energy.

A heat exchanger can be placed either between the collector and the storage tank or between the storage tank and the energy delivery system. We will refer to the former as a "supply-side" heat exchanger and the latter as a "load-side" heat exchanger. A supply-side heat exchanger means that the energy source is on the tube side of the heat exchanger. In particular, it refers to either collector loop fluid or space heating storage water flowing through the heat exchanger. Heat exchangers that have collector loop fluid flowing through them are also known as "collector-side" heat exchangers, but this term does not adequately describe a domestic hot water (DHW) tank heated by water from a solar space-heating storage tank.

Many indirect systems use an internal heat exchanger where the heat exchanger is located, either in or on the storage tank. For a supply-side heat exchanger, heat transfer from the heat exchanger wall to the storage tank side is by natural convection. For the load-side heat exchanger, heat transfer from the storage tank to the heat exchanger wall is by natural convection. In the case of a supply-side heat exchanger, forced convection occurs within the heat exchanger tubes whenever the collector loop pump operates, whereas in a load-side heat exchanger, forced convection occurs inside the heat exchanger tubes only when a load is drawn (unless an extra circulating pump is used). Generally, circulation is fairly continuous through a supply-side heat exchanger, while load-side heat exchangers are one-pass or instantaneous heaters. Solar space heating systems often use supply-side heat exchangers between the space heating storage tank and the DHW tank. Whenever there is a sufficient temperature difference between the two tanks, the DHW pump operates and continually circulates water from the space heating tank, through the heat exchanger in the DHW tank, and back to the space heating tank. For this type of system, the space heating tank is the energy supply or heat source just as a collector array would be in a solar domestic hot water (SDHW) system.

There are many types of internal heat exchangers. Figure 1-1 shows the common types: immersed, wrap-around, and tank-in-tank. Among them, the immersed heat exchanger is probably the most common internal heat exchanger and comes in several varieties, ranging from coils to tightly packed bayonet-type heat exchangers. All transfer heat in the same general way.

An advantage of indirect systems is that they have a type of stratification that direct systems do not have. This was identified by Balcomb (1982). When a load is drawn during the day, the cold water enters the bottom of the tank 


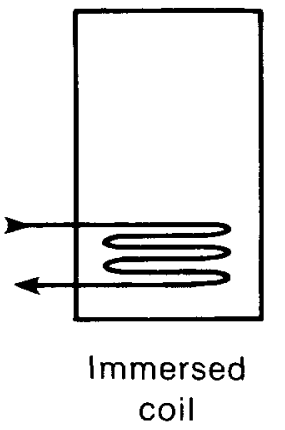

coil

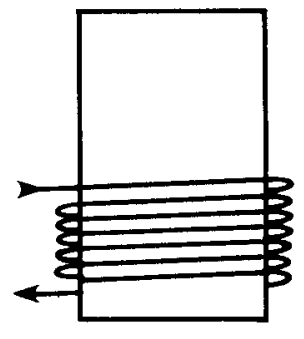

Wrap around

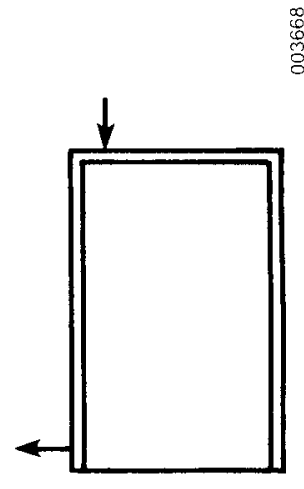

Tank-in-tank

\section{Figure 1-1. Internal Heat Exchanger Types}

and remains there until it is heated by the heat exchanger to a temperature greater than the temperature of the water above it. In a direct system, this water is immediately sent to the collectors and returned near the top of the tank (often about one-third from the top), mixing the tank and cooling water below the collector return. Indirect systems avoid this type of mixing.

Among publications regarding immersed heat exchanger testing, three are particularly relevant. Feiereisen et al. (1982) tested four heat exchanger configurations with heat exchanger areas ranging from $0.06 \mathrm{~m}^{2}\left(0.6 \mathrm{ft}^{2}\right)$ to $0.73 \mathrm{~m}^{2}\left(7.9 \mathrm{ft}^{2}\right)$ and examined the effect of tilting the heat exchanger. Feiereisen (1982) experimentally examined the effects of several parameters on heat exchanger performance, including coil position, flow direction, flow rate, temperature difference, parallel versus series flow (using two heat exchangers), enhanced convection techniques, and coil orientation. Klett et al. (1983) tested a single-wall and a double-wall bayonet heat exchanger, each with a heat exchanger area of $1.95 \mathrm{~m}^{2}\left(21 \mathrm{ft}^{2}\right)$, as a function of flow rate and temperature difference at two different tank volumes.

Feiereisen et al. (1982) concluded that "effectiveness is found to be nearly independent of temperature difference" but that "effectiveness is found to vary significantly over the range of flow rates tested." They also concluded that closely spaced fins ( $4 \mathrm{fins} / \mathrm{cm}$ for their study) appear to reduce the convection heat transfer coefficient.

Klett et al. (1983) concluded that although the effectiveness of immersed coils was a function of both flow rate and temperature difference, an average effectiveness could be selected for a given flow rate and an intermediate value of the temperature difference.

All of the above tests were conducted at a temperature difference above $7^{\circ} \mathrm{C}$ $\left(13^{\circ} \mathrm{F}\right)$ with most of the data in the Klett et al. (1983) tests taken at temperature differences above $10^{\circ} \mathrm{C}\left(18^{\circ} \mathrm{F}\right)$.

Our test results show that at sufficiently high temperature differences, the heat exchanger effectiveness tends to level off. High temperature differences 
may be encountered in a combination solar space-heating and DHW system but not constantly. Depending on the control system, the DHW pump may operate at low temperature differences in a combination system as well as at high differences. If the DHW load is drawn when the temperature of the space heating storage is low, the DHW heat exchanger will operate at a low temperature difference. If the DHW load is drawn when the space heating storage tank is fully charged, then the DHW heat exchanger will operate at a high temperature difference. Consequently, it is likely that the DHW will operate at both low and high temperature differences, which makes selecting an average effectiveness difficult.

In a DHW system, the heat exchanger will generally operate at temperature differences between the turn-on and turn-off differential of the controller, although a well-designed system or one with stratification devices or using low collector flow rates will operate above the turn-on differential. The collector loop pump will begin operating when the turn-on differential (generally the collector outlet temperature minus the temperature at the bottom of the storage tank) has been exceeded. This temperature is typically between $5^{\circ} \mathrm{C}\left(9^{\circ} \mathrm{F}\right)$ and $11^{\circ} \mathrm{C}\left(20^{\circ} \mathrm{F}\right)$. The collector loop pump will continue to operate until the temperature is less than the turn-off differential, typically $0.5^{\circ}-$ $3^{\circ} \mathrm{C}\left(1^{\circ}-5^{\circ} \mathrm{F}\right)$. If the collector loop is well-insulated then the heat exchanger inlet temperature will be approximately the same as the collector outlet temperature. Therefore, the temperature difference $\left(\mathrm{T}_{\mathrm{Hx}}, \mathrm{i}-\mathrm{T}_{\mathrm{S}}\right)$ can be as low as the turn-off differential of the controller. Our test results show that the heat exchanger effectiveness can be very low at low temperature differences. If there is a temperature difference of $3^{\circ} \mathrm{C}\left(5^{\circ} \mathrm{F}\right)$ between the heat exchanger inlet and tank temperature, then the heat exchanger effectiveness may be as low as 0.20 , which leads to a temperature drop across the hot side of the heat exchanger of $0.6^{\circ} \mathrm{C}\left(1^{\circ} \mathrm{F}\right)$. In a steady-state situation with no pipe losses, the temperature drop across the heat exchanger inlet and outlet will equal the temperature rise across the collectors. Therefore, the temperature rise across the collector will be $0.6^{\circ} \mathrm{C}$, which equals a total collected energy of about $210 \mathrm{~W}(716 \mathrm{Btu} / \mathrm{h})$ at $5 \mathrm{~L} / \mathrm{min}(1.3 \mathrm{gal} / \mathrm{min})$.

An immersed heat exchanger in a typical solar domestic water heater will therefore operate at temperature differences between the controller turn-off differential and some temperature above or below the controller's turn-on differentials, which makes it very difficult to choose an average effectiveness.

As alluded to by Feiereisen (1982), the strong dependence of heat exchanger effectiveness on flow rate makes it very difficult to easily predict the performance of SDHW systems with immersed heat exchangers using proportional controllers that vary the flow rate during the day.

This report discusses our test plan, experimental setup, and the results from testing four different immersed heat exchangers (Figure 1-2). We calculated the heat transfer, effectiveness, and $U A$ value at 5,10 , and $15 \mathrm{~L} / \mathrm{min}(1.3$, 2.6 and $4.0 \mathrm{gal} / \mathrm{min}$ ) over a wide range of temperature differences (heat exchanger inlet minus tank temperature) from measured temperatures and flow rates. We also discuss the analytical and numerical models we developed and compare these with our experimental results. 


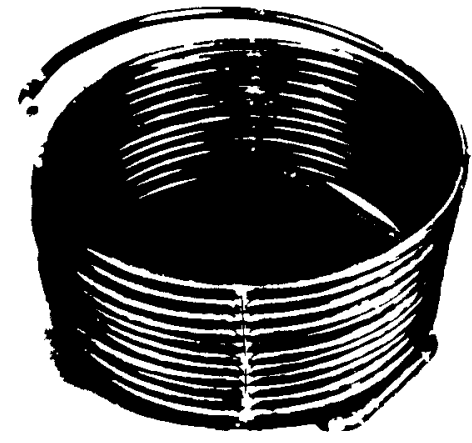

(a) Smooth coll

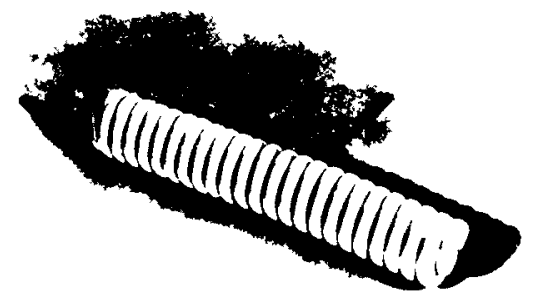

(c) Single-wall bayonet

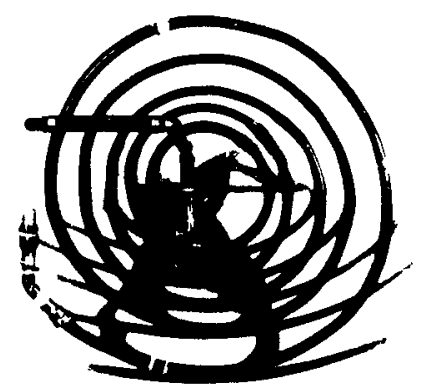

(b) Finned spıral

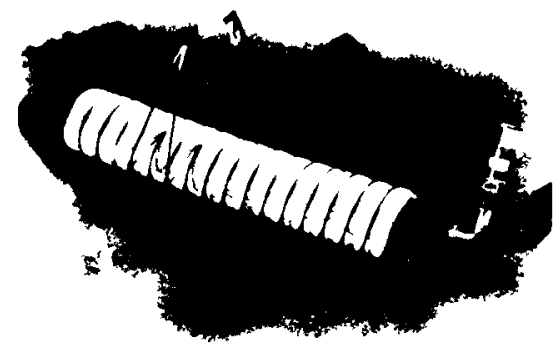

(d) Double-wall bayonet

Figure 1-2. Photographs of Heat Exchangers Tested 


\subsection{EXPERIMENTAL SETUP AND TEST PLAN}

The test $100 \mathrm{p}$ is shown in Figure 2-1 and consisted of two 151-L (40-gal) electric water heaters and one 409-L (108-gal) clear acrylic tank. The acrylic tank had an inside diameter of $58 \mathrm{~cm}(23 \mathrm{in.})$ and an interior height of $152 \mathrm{~cm}$ ( $60 \mathrm{in.})$. It was constructed with removable end caps and was insulated during testing with $15 \mathrm{~cm}$ ( 6 in.) of fiberglass insulation on the sides, $5 \mathrm{~cm}$ ( 2 in.) of foam insulation on the bottom, and $8 \mathrm{~cm}$ ( 3 in.) of foam insulation on top. The tank had a measured heat 1 oss rate of $1.6 \mathrm{~W} /{ }^{\circ} \mathrm{C}$ $\left(3.0 \mathrm{Btu} / \mathrm{h}^{\circ} \mathrm{F}\right)$. The top end cap of the acrylic tank had small holes to eliminate air during filling and to allow for thermal expansion of the water. Water was removed from the top of the tank by an overflow tube.

The temperature profile inside the tank was measured with four thermistors immersed in the center of the tank and placed near the top, halfway down, three-fourths down, and near the bottom of the tank. The thermistors, suspended by their leads, were specified with an accuracy of $\pm 0.5^{\circ} \mathrm{C}\left( \pm 0.9^{\circ} \mathrm{F}\right)$ and a response time of $18 \mathrm{~ms}$ in a cold water splash test. These thermistors read

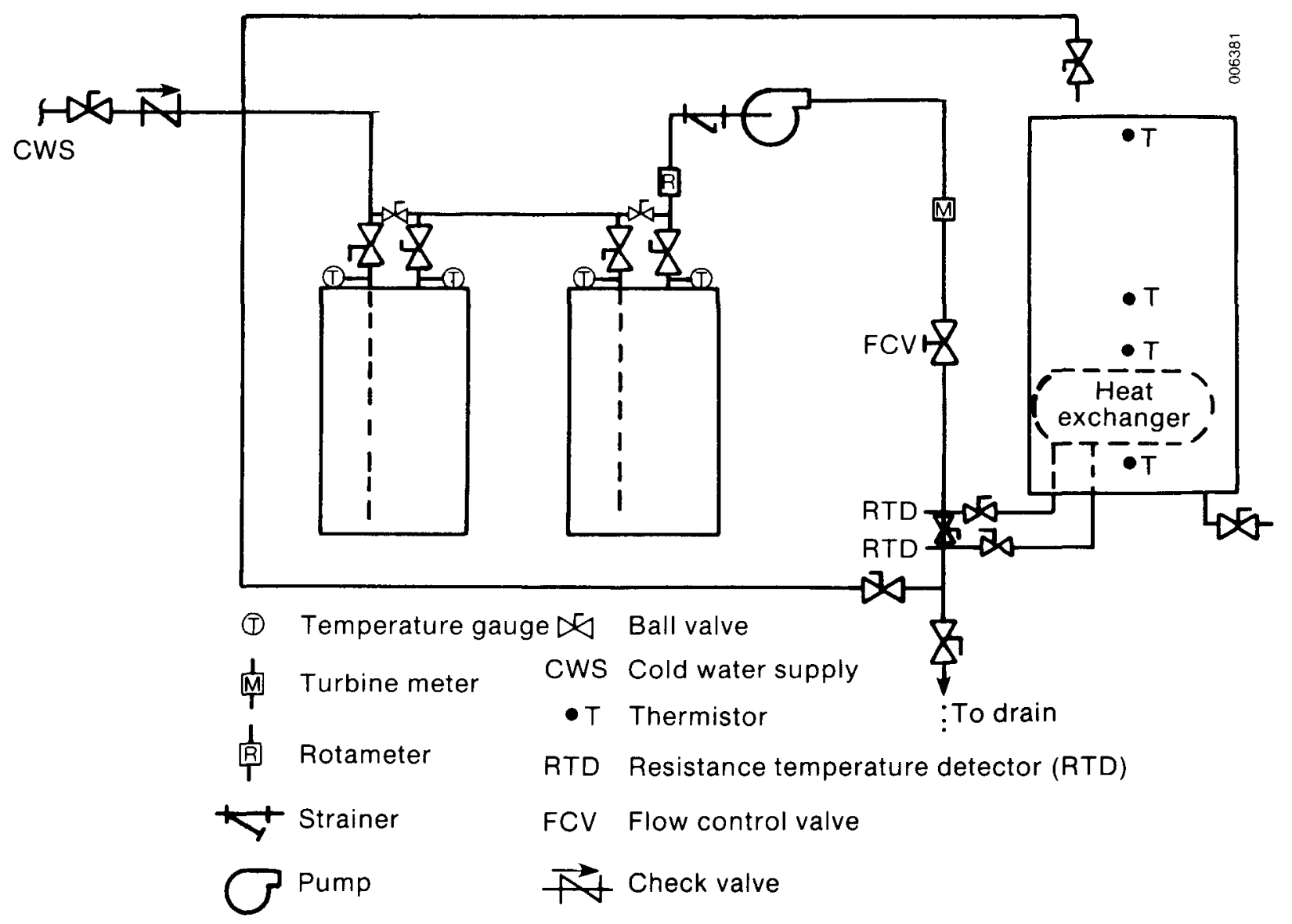

Figure 2-1. Experimental Setup 
within $\pm 0.1^{\circ} \mathrm{C}\left( \pm 0.2^{\circ} \mathrm{F}\right)$ of each other when the tank was well-mixed. We accounted for the measured lead resistance of these sensors in our data acquisition computer program.

The temperatures of the heat exchanger inlet and outlet were measured with four-wire, platinum-wound resistance temperature detectors (RTD) calibrated in the SERI Metrology Laboratory. We performed an end-to-end check of the RTDs after their installation using a stirred ice-bath monitored with two digital quartz thermometers. The heat exchanger inlet RTD read $0.023^{\circ} \mathrm{C}$ below and the heat exchanger outlet RTD read within $0.001^{\circ} \mathrm{C}$ of the digital quartz thermometers. The RTDs had sheaths mounted in the center of the flow with the entire sheath parallel to the flow. The RTD mounting heads were wellinsulated.

The flow rate was monitored visually with a rotameter and measured with a turbine meter $1.2 \mathrm{~cm}(0.5 \mathrm{in.})$ in diameter that had flow straighteners and 40 pipe diameters of unobstructed flow upstream and downstream of the turbine meter. We used the factory calibration and corrected the viscosity for temperature effects.

We calculated the random uncertainty of each sensor (thermistors, RTDs, and turbine meter) by calculating the standard deviation of 100 readings at steady state. The random fluctuations were always significantly less than $1 \%$ of the mean. Thermistor and RTD resistances were measured with a Hewlett-Packard (HP) HP3456A digital voltmeter that was calibrated by HP at the start of the test period. Its next calibration was scheduled after our testing was completed.

Scanning and frequency measurements were accomplished by an HP3497A scanner and an HP3498 extender box.

The acquisition of data was controlled by an HP9816s computer that collected data every $30 \mathrm{~s}$, calculated necessary results, and printed both tabular and graphic results. Both raw data and reduced data were stored on magnetic disks for easy retrieval and manipulation. The data acquisition system, with the exception of the computer, was left on continuously to avoid waiting during warm-up periods.

The following test procedure was used:

1. Pressurize the electrically heated tanks and heat them to $71^{\circ} \mathrm{C}$ $\left(160^{\circ} \mathrm{F}\right)$. Circulate flow through the electrically heated tanks, bypassing the heat exchanger, to mix the electric tanks.

2. Prepare the acrylic tank by slowly filling it with cold water, making sure to eliminate any air bubbles on the heat exchanger or at the top of the tank. Replace the foam insulation on top of the tank.

3. While bypassing the heat exchanger, set the flow to the desired rate (5, 10 , or $15 \mathrm{~L} / \mathrm{min}[1.3,2.6$, or $4.0 \mathrm{gal} / \mathrm{min}])$ plus approximately $0.5 \mathrm{~L} / \mathrm{min}(0.1 \mathrm{gal} / \mathrm{min})$ to account for the additional pressure drop through the heat exchanger. 
4. Close the heat exchanger bypass and open the heat exchanger isolation valves. Adjust the flow rate until it is within approximately $1 \%$ of the desired value.

5. Allow the heat exchanger outlet temperature to register the effect of the circulation and then begin the data acquisition program.

6. Continue the test until the heat exchanger inlet temperature is within approximately $1^{\circ} \mathrm{C}\left(2^{\circ} \mathrm{F}\right)$ of the tank temperature.

There were some exceptions to this procedure. For many of the tests, we connected other storage tanks to the loop to provide a larger source of hot water. On some tests we shut off the cold-water supply (CwS) to the electric heaters because large pressure fluctuations were affecting our flow rate. On some tests, we were unable to maintain a constant flow rate, and the flow rate gradually declined to as $10 \mathrm{w}$ as $3 \%$ below the desired value. On some of the heat exchanger designs, we were unable to achieve $15 \mathrm{~L} / \mathrm{min}$ in a recirculation mode because of the unavailability of larger pumps used in other experiments. In this case we dumped the water from the heat exchanger outlet down the drain and used the city water pressure to achieve the desired flow rate.

We also attempted to obtain a visual indication of natural convection flow patterns inside the tank. To do this, we removed the top and side insulation and injected dye with a long, removable probe that penetrated the top of the tank. We generally injected dye along the heat exchanger and at cross sections of the tank.

We circulated water rather than a freeze-tolerant fluid through the heat exchangers for several reasons: (1) water has we11-known and documented properties; (2) water is easy to use and can be heated easily in large quantities; and (3) water is a common heat transfer fluid for these heat exchangers used in drainback systems and solar space heating systems. 


\subsection{TEST RESULTS}

\subsection{Performance Equations}

We used the equations given in Table 3-1 to determine the performance of the heat exchangers. Those equations are explained in detail in many heat transfer texts (e.g., Kreith 1973).

The importance of an effective heat exchanger is easy to understand. The temperature of the fluid to the inlet of the collectors is approximately equal to the temperature of the fluid leaving the heat exchanger. Therefore, the collector efficiency is directly related to heat exchanger outlet temperature. In a highly effective heat exchanger, the outlet temperature closely approaches the tank temperature, which is generally the lowest temperature in the system. Figure 3-1 shows that system performance is significantly affected if the heat exchanger effectiveness drops below about 0.4 , the exact value depending on the system configuration and parameters. The inputs for the systems modeled in Figure 3-1 are given in Appendix $B$.

However, system performance is not optimized by maximizing the heat exchanger effectiveness. Maximum heat exchanger effectiveness would occur at a flow

\section{Table 3-1. Performance Equations}

\begin{tabular}{|c|c|c|}
\hline Quantity & Equation" & $\begin{array}{l}\text { Equation } \\
\text { Number }\end{array}$ \\
\hline Effectiveness & $\varepsilon=\frac{\mathrm{T}_{\mathrm{Hx}, \mathrm{i}}-\mathrm{T}_{\mathrm{Hx}, \mathrm{o}}}{\mathrm{T}_{\mathrm{Hx}, \mathrm{i}}-\mathrm{T}_{\mathrm{S}}}$ & $(3-1)$ \\
\hline Heat transfer rate & $\mathrm{q}=\dot{\mathrm{m}} \mathrm{C}_{\mathrm{p}}\left(\mathrm{T}_{\mathrm{Hx}, \mathrm{i}}-\mathrm{T}_{\mathrm{Hx}, \mathrm{o}}\right)$ & $(3-2)$ \\
\hline $\begin{array}{l}\text { Overall heat transfer } \\
\text { area coefficient }\end{array}$ & $\mathrm{UA}=\mathrm{q} / \mathrm{LMTD}$ & $(3-3)$ \\
\hline $\begin{array}{l}\text { Logarithmic mean } \\
\text { temperature difference }\end{array}$ & LMTD $=\frac{\left.\mathrm{Hx}_{\mathrm{i}}-\mathrm{Hx}_{\mathrm{O}}\right)}{\ln \left[\frac{\left.\left(\mathrm{T}_{\mathrm{Hx}, \mathrm{i}}-\mathrm{T}_{\mathrm{S}}\right)\right]}{[\mathrm{T}}\right]}$ & $(3-4)$ \\
\hline Overall Nusselt number & $\overline{\mathrm{Nu}}=\bar{h}_{\mathrm{o}} \mathrm{d} / \mathrm{k}$ & $(3-5)$ \\
\hline $\begin{array}{l}\text { Outside convective heat } \\
\text { transfer coefficient }\end{array}$ & $\bar{h}_{0}=q /(A)($ LMTD $)$ & $(3-6)$ \\
\hline Overall Rayleigh number & $\overline{\mathrm{Ra}}=\frac{\rho^{2} B C_{p} g}{\mu k} d^{3}$ (LMTD) & $(3-7)$ \\
\hline
\end{tabular}




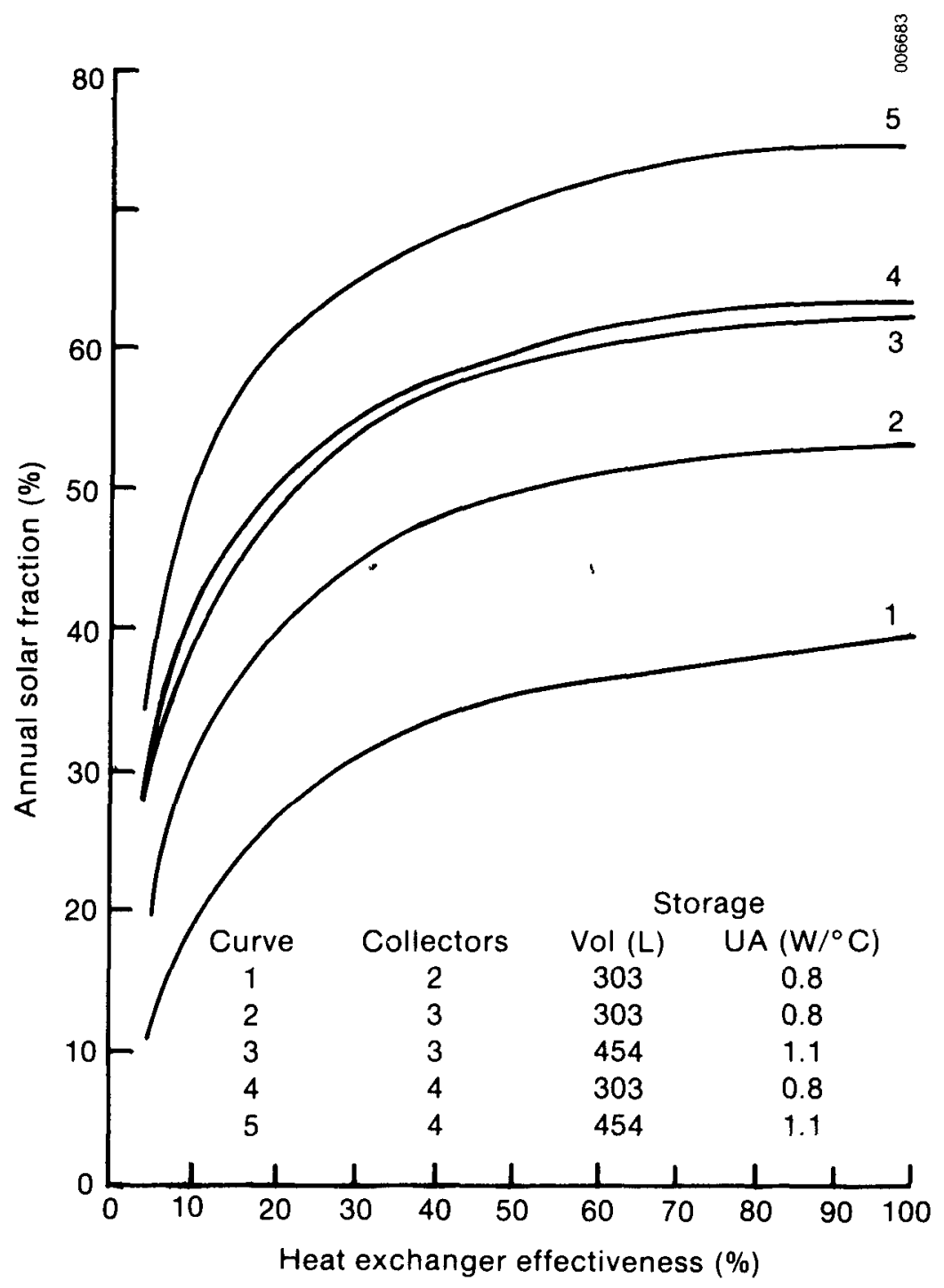

Figure 3-1. Solar Fraction as a Function of Collector/Storage Tank Heat Exchanger Effectiveness

rate approaching no flow, which would minimize the heat transfer rate. The heat transfer rate is not optimized by maximizing the flow rate since the temperature of the fluid leaving the heat exchanger is a function of the effectiveness.

The heat exchanger UA can be reduced from Eqs. 3-3 and 3-4 to

$$
\mathrm{UA}=\dot{\mathrm{m}} \mathrm{C}_{\mathrm{p}} \ln \frac{\left(\mathrm{T}_{\mathrm{Hx}, \mathrm{i}}-\mathrm{T}_{\mathrm{S}}\right)}{\left(\mathrm{T}_{\mathrm{Hx}, \mathrm{O}}-\mathrm{T}_{\mathrm{S}}\right)}
$$

and is the slope of the 1 ine when the heat transfer rate is plotted as a function of logarithmic mean temperature difference (LMTD) (see Eq. 3-3). 
We defined $\overline{\mathrm{Ra}}$ and $\overline{\mathrm{h}}$ (and therefore $\overline{\mathrm{Nu}}$ ) as a function of LMTD following the method used by Felereisen (1982). We originally based our results on $\left(\mathrm{T}_{\mathrm{Hx}, \mathrm{i}}-\mathrm{T}_{\mathrm{S}}\right)$, but this method did not reflect the dynamics of the heat exchanger since it did not depend on the temperature of the fluid leaving the heat exchanger. In Section 3.6 we discuss an approach to correct the LMTD so that the temperature of the heat exchanger surface is used in the correlations.

We defined the characteristic dimension used in the Nusselt and Rayleigh numbers to be the outside diameter of the tube, excluding any fins. This gave us results consistent with previous experimental data and led to Nusselt and Rayleigh numbers in the range we expected. Nusselt and Rayleigh numbers based on other dimensions can be easily calculated from the information given in Table 3-2.

We defined the storage tank temperature $T_{S}$ to be the temperature at the center of the tank. The tank was well-mixed, as expected (since it was heated from the bottom), except for a cool layer of water beneath the heat exchanger.

By manipulating the equations in Table 3-1 we can show that a steep drop in heat exchanger effectiveness is expected at low temperature differences (or low LMTDs). Using the definition of effectiveness, which is the ratio of the actual heat transfer to the maximum theoretical possible, leads to

$$
\varepsilon=\frac{\overline{\mathrm{h}}_{\mathrm{O}} \mathrm{A}(\mathrm{LMTD})}{\left(\dot{\mathrm{m}}_{\mathrm{p}}\right)_{\mathrm{Hx}}\left(\mathrm{T}_{\mathrm{Hx}, \mathrm{i}}-\mathrm{T}_{\mathrm{S}}\right)}
$$

Solving Eq. 3-5 for $\vec{h}_{0}$ and substituting it into Eq. 3-9 results in

$$
\varepsilon=\frac{\mathrm{A}(\mathrm{LMTD})}{\left(\dot{\mathrm{m}}_{\mathrm{p}}\right)_{\mathrm{Hx}}\left(\mathrm{T}_{\mathrm{Hx}, \mathrm{i}}-\mathrm{T}_{\mathrm{S}}\right)} \frac{\mathrm{k}}{\mathrm{d} u} .
$$

If we assume that the natural convective heat transfer can be approximated as laminar flow around a horizontal tube, then the following correlation exists (McAdams 1954):

$$
\overline{\mathrm{Nu}}=\mathrm{C}(\overline{\mathrm{Ra}})^{0.25}
$$

If we substitute Eqs. 3-7 and 3-11 into Eq. 3-10 we get

$$
\varepsilon=\frac{\mathrm{A} \text { (LMTD) }}{\left(\dot{\mathrm{m}}_{\mathrm{p}}\right)_{\mathrm{Hx}}\left(\mathrm{T}_{\left.\mathrm{Hx}, \mathrm{i}-\mathrm{T}_{\mathrm{S}}\right)}\right.} \frac{\mathrm{k}}{\mathrm{d}} \mathrm{C}\left[\frac{\rho^{2} \mathrm{CC}_{\mathrm{p}} g}{\mu \mathrm{k}} \mathrm{d}^{3} \text { (LMTD) }\right] 0.25 \text {. }
$$

Although $\varepsilon$ is dependent on LMTD and $\left(\mathrm{T}_{\mathrm{Hx}}, \mathrm{i}-\mathrm{T}_{\mathrm{S}}\right)$, it is LMTD 0.25 that dominates at low temperature differences. Figure 3-2 shows the influence of the temperature difference (or LMTD) to the one-quarter power. 
Table 3-2. Heat Exchanger Specifications

\begin{tabular}{|c|c|c|c|c|c|c|c|c|}
\hline Heat Exchanger & $\begin{array}{l}\text { Surface Area } \\
\left(\mathrm{m}^{2} / \mathrm{m}\left[\mathrm{ft} t^{2} / \mathrm{ft}\right]\right)\end{array}$ & $\begin{array}{l}\text { Length } \\
(\mathrm{m}[\mathrm{ft}])\end{array}$ & $\begin{array}{l}\text { Tota1 Area } \\
\left(\mathrm{m}^{2}\left[\mathrm{ft}^{2}\right]\right)\end{array}$ & $\begin{array}{c}\text { ID } \\
(\mathrm{mm}[\mathrm{in} \cdot])\end{array}$ & $\begin{array}{l}\text { OD } \\
(\mathrm{mm}[\mathrm{in} \cdot])\end{array}$ & $\begin{array}{l}\text { Fin Height } \\
(\mathrm{mm}[\mathrm{in.}])\end{array}$ & $\begin{array}{c}\text { Fins/cm } \\
\text { (fins/in.) }\end{array}$ & Comments \\
\hline Smooth coil & $\begin{array}{l}0.050 \\
(0.164)\end{array}$ & $\begin{array}{l}18.6 \\
(60.9)\end{array}$ & $\begin{array}{r}0.93 \\
(10.0)\end{array}$ & $\begin{array}{l}12.7 \\
(0.50)\end{array}$ & $\begin{array}{l}15.9 \\
(0.63)\end{array}$ & $\begin{array}{l}0 \\
0\end{array}$ & $\begin{array}{l}0 \\
0\end{array}$ & $\begin{array}{l}\text { Added } 56-\mathrm{cm}\left(22-i n_{0}\right) \\
\mathrm{PB}^{\mathrm{b}} \text { fittings }\end{array}$ \\
\hline Finned spiral & $\begin{array}{c}0.177 \\
(0.581)\end{array}$ & $\begin{array}{c}5.1 \\
(16.7)\end{array}$ & $\begin{array}{r}0.90 \\
(9.7)\end{array}$ & $\begin{array}{l}10.9 \\
(0.43)\end{array}$ & $\begin{array}{l}12.4 \\
(0.49)^{a}\end{array}$ & $\begin{array}{l}3.2 \\
(0.13)\end{array}$ & $\begin{array}{c}4 \\
(11)\end{array}$ & $\begin{array}{l}\text { Added } 53-\mathrm{cm}(21-\mathrm{in.}) \\
\mathrm{PB} \text { and } 15-\mathrm{cm}\left(6-i \mathrm{n}_{\bullet}\right) \\
\text { copper fittings }\end{array}$ \\
\hline $\begin{array}{l}\text { Single-wall } \\
\text { bayonet }\end{array}$ & $\begin{array}{c}0.177 \\
(0.581)\end{array}$ & $\begin{array}{c}4.9 \\
(16.0)\end{array}$ & $\begin{array}{r}0.86 \\
(9.3)\end{array}$ & $\begin{array}{l}10.9 \\
(0.43)\end{array}$ & $\begin{array}{l}12.4 \\
(0.49)^{a}\end{array}$ & $\begin{array}{l}3.2 \\
(0.13)\end{array}$ & $\begin{array}{c}4 \\
(11)\end{array}$ & $\begin{array}{l}\text { Added } 5-\mathrm{cm}(2-i n \cdot) \\
\text { copper fittings }\end{array}$ \\
\hline $\begin{array}{c}\text { Double-wall } \\
\text { bayonet }\end{array}$ & $\begin{array}{c}0.177 \\
(0.581)\end{array}$ & $\begin{array}{c}4.9 \\
(16.0)\end{array}$ & $\begin{array}{r}0.86 \\
(9.3)\end{array}$ & $\begin{array}{l}12.7 \\
(0.50)\end{array}$ & $\begin{array}{l}15.7 \\
(0.62)^{a}\end{array}$ & $\begin{array}{l}3.2 \\
(0.13)\end{array}$ & $\begin{array}{c}4 \\
(11)\end{array}$ & $\begin{array}{l}\text { Added } 5-\mathrm{cm}(2-i a .) \\
\text { copper fittings }\end{array}$ \\
\hline
\end{tabular}

$a_{\text {Excluding fins. }}$

${ }^{b}$ Polybutylene pipe. 


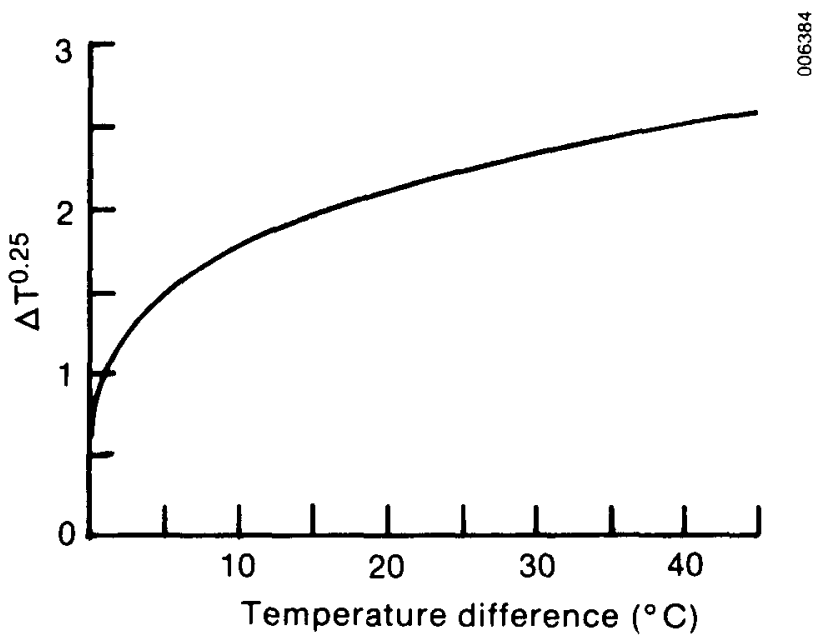

Figure 3-2. Plot of $Y=\Delta T^{0.25}$

\subsection{Smooth-Coil Heat Exchanger}

We manufactured a smooth-coil heat exchanger (i.e., without fins) as shown in Figure 3-3. The coils were set one on the other, with a constant radius about a vertical axis, and held in place by several long pieces of 12-gauge copper wire soldered to the tubes. Flow through the heat exchanger began at the top and went toward the bottom. This produced a type of counterflow heat exchanger in which water heated by natural convection rose upward and water flowing through the heat exchanger went downward.

The results from testing the smooth-coil heat exchanger are shown in Figure 3-4. As with all of the heat exchangers we tested, the effectiveness increased with decreasing flow rate and decreased significantly at low temperature differences. Data were missing for the $10 \mathrm{~L} / \mathrm{min}(2.5 \mathrm{gal} / \mathrm{min})$ case at a temperature difference of about $30^{\circ} \mathrm{C}\left(54^{\circ} \mathrm{F}\right)$ and an LMTD of $18^{\circ} \mathrm{C}\left(32^{\circ} \mathrm{F}\right)$ because of a short interruption in the data collection. The penalty for using higher flow rates was quite substantial for this heat exchanger. At higher flow rates there was less time for the water to be in the heat exchanger and therefore it did not approach the tank temperature very closely. Figure 3-4c shows that this heat exchanger could transfer energy at a very high rate at a large LMTD.

The overall heat transfer area coefficient UA of the heat exchanger varied with LMTD. The unit area heat transfer coefficients at larger LMTDs were approximately $667 \mathrm{~W} / \mathrm{m}^{2}{ }^{\circ} \mathrm{C}\left(117 \mathrm{Btu} / \mathrm{h} \mathrm{ft}^{2}{ }^{\circ} \mathrm{F}\right)$ at $5 \mathrm{~L} / \mathrm{min}(1.3 \mathrm{gal} / \mathrm{min})$, $861 \mathrm{~W} / \mathrm{m}^{2}{ }^{\circ} \mathrm{C}\left(151 \mathrm{Btu} / \mathrm{h} \mathrm{ft}{ }^{\circ}{ }_{\mathrm{F}}\right)$ at $10 \mathrm{~L} / \mathrm{min}(2.6 \mathrm{gal} / \mathrm{min})$, and $968 \mathrm{~W} / \mathrm{m}^{2}{ }^{\circ} \mathrm{C}$ $\left(170 \mathrm{Btu} / \mathrm{h} \mathrm{ft}{ }^{2} \mathrm{O} \mathrm{F}\right)$ at $15 \mathrm{~L} / \mathrm{min}(4.0 \mathrm{gal} / \mathrm{min})$. At an LMTD of $2^{\circ} \mathrm{C}\left(4^{\circ} \mathrm{F}\right)$ the unit area heat transfer coefficients approached $430 \mathrm{~W} / \mathrm{m}^{2}{ }^{\circ} \mathrm{C}$ 


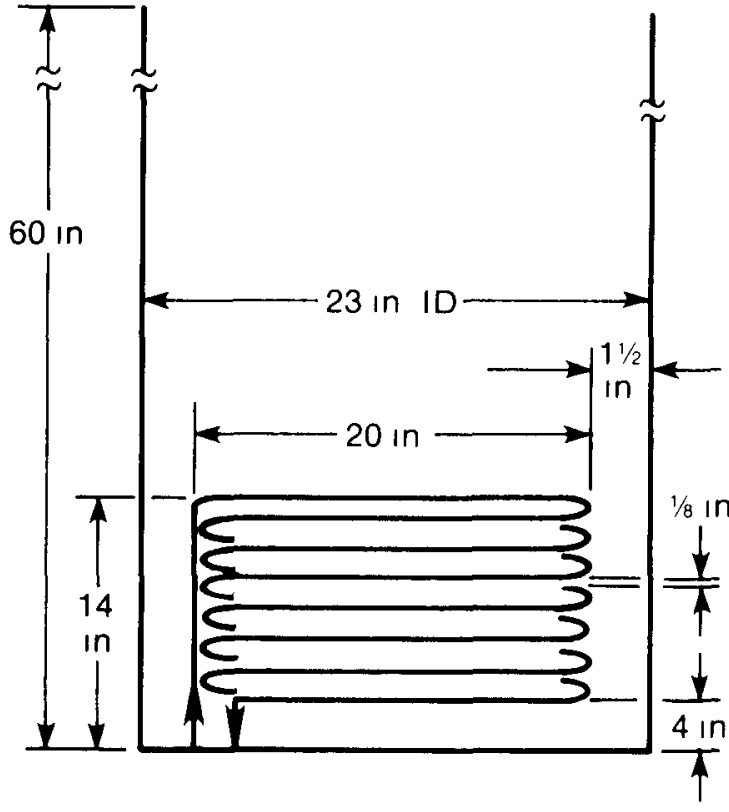

Side view

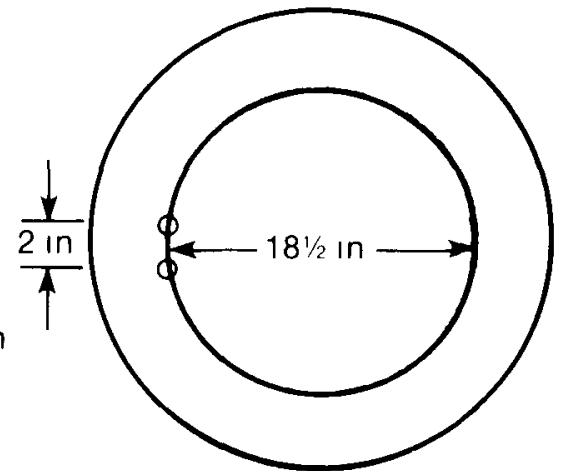

Top view

Figure 3-3. Smooth-Coil Heat Exchanger Geometry

$\left(75 \mathrm{Btu} / \mathrm{h} \mathrm{ft}{ }^{2} \mathrm{O}\right)$. At LMTDs less than $2^{\circ} \mathrm{C}\left(4^{\circ} \mathrm{F}\right)$ the UA values would have approached zero.

We injected dye around the heat exchanger and up and down the tank. We expected to see hot fluid rising from the heat exchanger and cooler fluid dropping in the center of the tank. However, the two-dimensional convection pattern (independent of azimuth angle) we expected did not occur. The convection currents were not easily discernable but appeared to be unstable and threedimensional. We observed swirling in the tank and large volumes of fluid moving in bulk rather than continuous, well-defined paths. However, in general, fluid rose near the tubes and dropped near the center.

The unsteady convection currents may have caused the apparent random fluctuations in our results. As stated earlier, we collected data every $30 \mathrm{~s}$, which was not averaged.

\subsection{Finned-Spiral Heat Exchanger}

We built a finned-tube spiral heat exchanger as shown in Figure 3-5. The concept behind it was twofold. Primarily, we wanted to avoid lower tubes preheating water that rose to the upper tubes. We could have also accomplished this using a flat, two-dimensional spiral heat exchanger that would be installed horizontally near the bottom of the storage tank. We built the heat exchanger with a vertical dimension with the idea that a vertical component of the flow inside the tube would cause swirling around the inside wall of the tube, reducing the boundary layer and enhancing heat transfer on the inside of the tube (Bergles and Webb 1985). However, this effect was probably minimal 


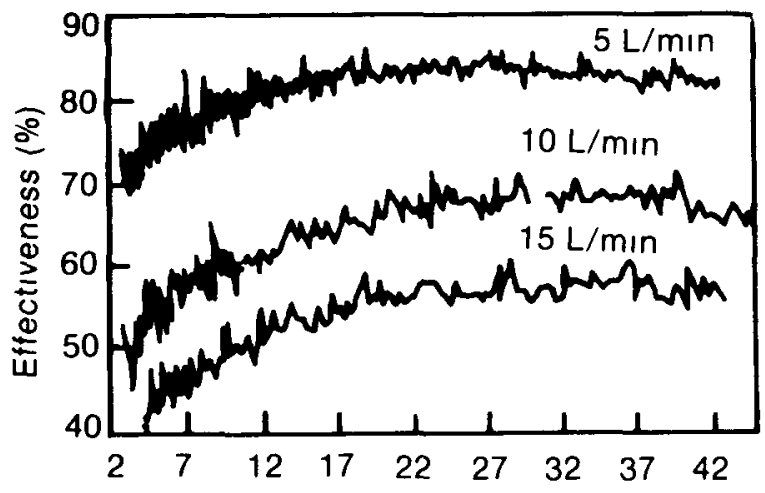

Temperature difference $\left({ }^{\circ} \mathrm{C}\right) \quad\left(T_{H x}-T_{S}\right)$

(a) $H X$ effectiveness versus $\Delta T$

๒ง

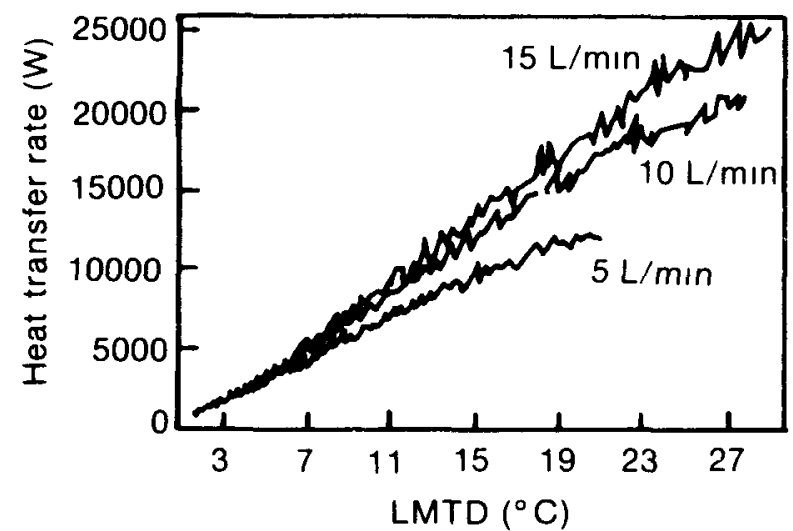

(c) $H X Q$ versus LMTD

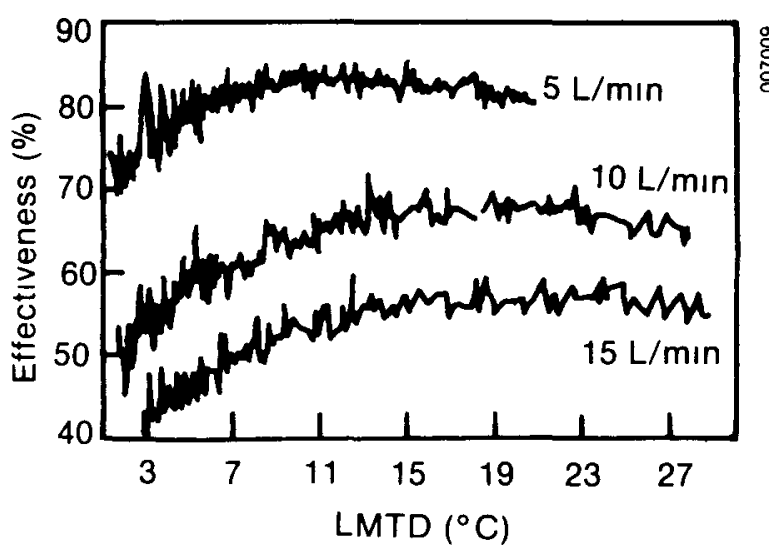

(b) HX effectiveness versus LMTD

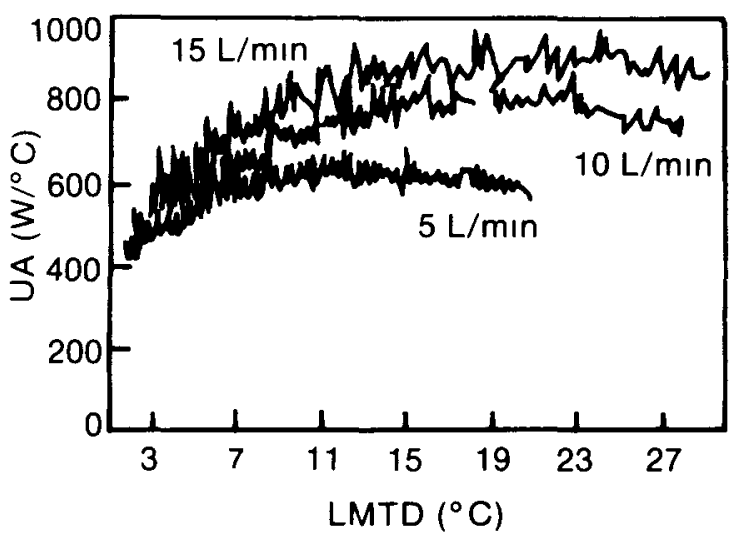

(d) HX UA versus LMTD

Figure 3-4. Smooth-Coil Heat Exchanger Test Results 
since the flow regime was either transitional or turbulent with Reynold numbers above 10,000. The finned tubing was also corrugated on the inside $(0.25 \mathrm{~mm}$ [0.010 in.] high and $2.5 \mathrm{~mm}$ [0.10 in. 1ong]) for the purpose of bending the tube. We used finned tubes to reduce the length of the heat exchanger.

We designed the heat exchanger for fluid to enter the top center of the tank, so that the hottest fluid would be at the center of the tank and develop a type of counterflow as explained for the smooth-coil heat exchanger.

Figure 3-6 shows finned-spiral heat exchanger effectiveness as a function of time during our testing. These results are typical for all of the heat exchangers we tested. The heat exchanger effectiveness changed gradually for low flow rates because the tank temperature changed gradually. At high flow rates the heat transfer rate, as shown in Figure 3-6b, was quite high and rapidly heated the tank so that the tank temperature rapidly approached the temperature of our heat source, causing the effectiveness to drop rapidly (Figure 3-6a).

The effectiveness and heat transfer rate of the finned-spiral heat exchanger as a function of the temperature difference and LMTD, respectively, are given in Figure 3-7. A significant drop in the effectiveness at low temperature differences is clearly evident in Figures $3-7 a$ and $b$. This heat exchanger did not perform as well as we expected. We observed a large number of bubbles between the fins of this heat exchanger after we began circulating hot water through it. This was probably caused by dissolved air coming out of solution. The solubility of air in water decreases significantly at higher temperatures. These bubbles undoubtedly reduced the heat transfer rate from the heat exchanger outside wall and fins to the tank water. If the tank were pressurized, the solubility of the air would increase slightly so there might

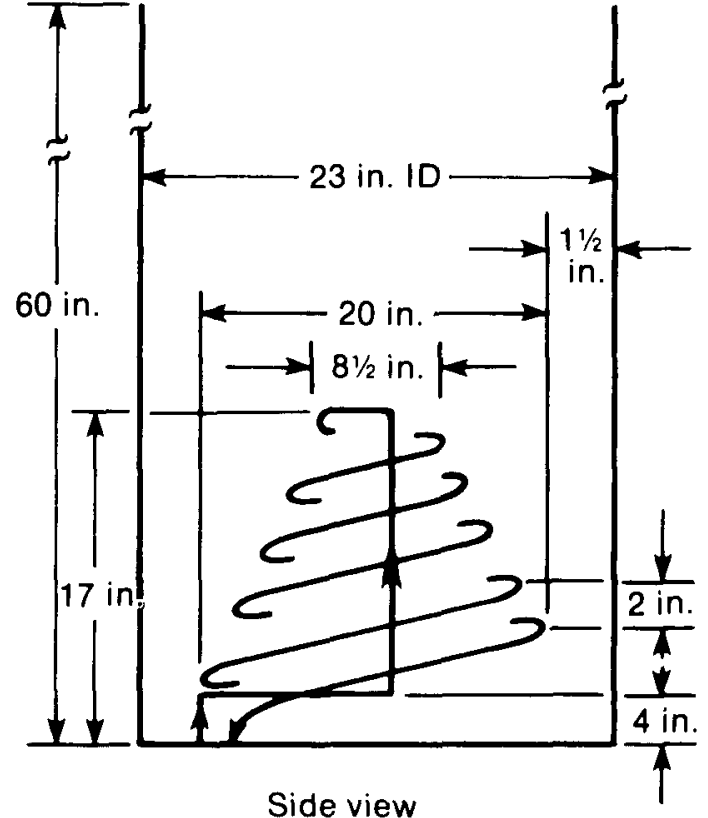

Side view

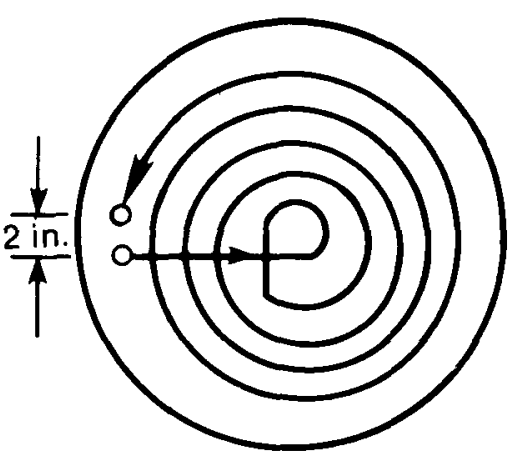

Top view

Figure 3-5. Finned-Spiral Heat Exchanger Geometry 


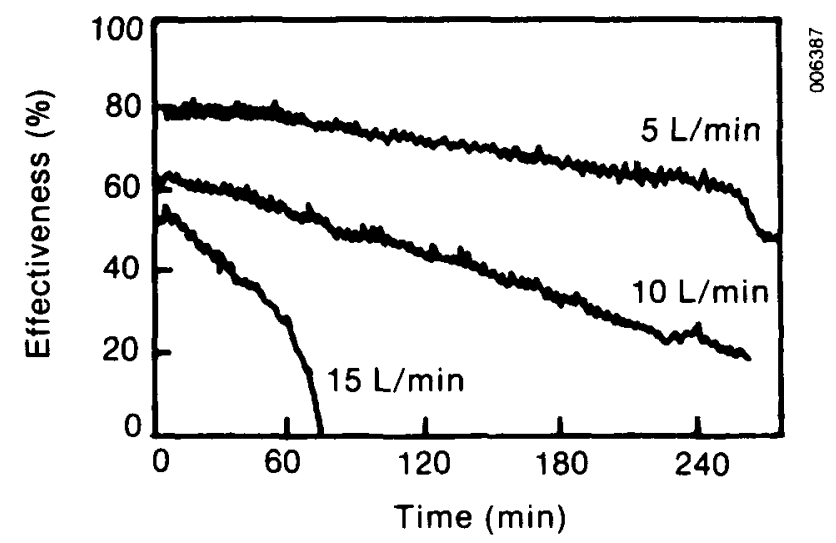

(a) $\mathrm{HX}$ effectiveness versus time

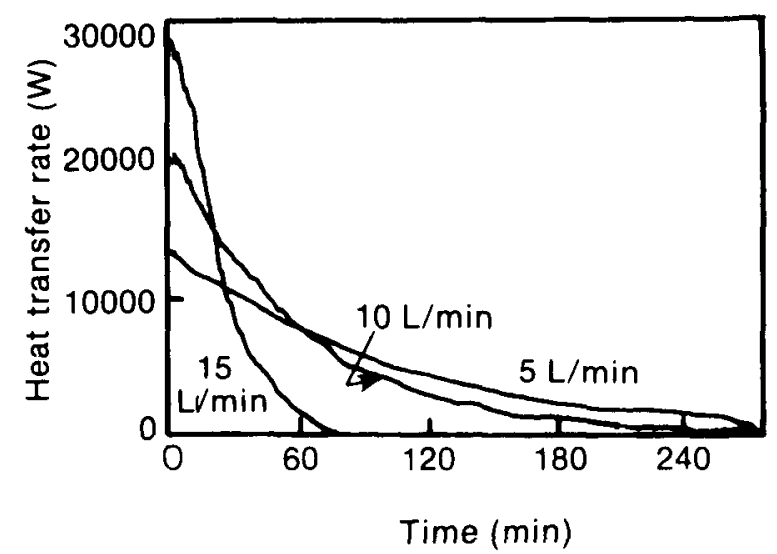

(b) $\mathrm{HX}$ heat transfer rate versus time

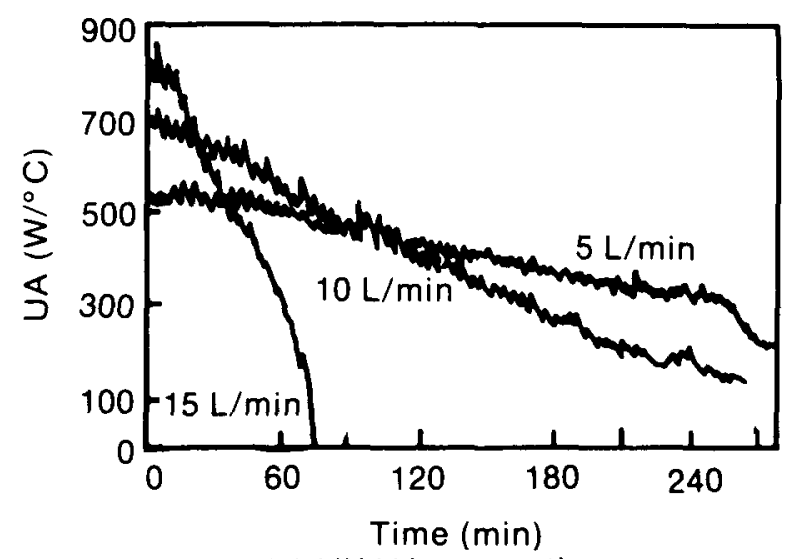

(c) HX UA versus time

Figure 3-6. Finned-Spiral Heat Exchanger Performance versus Time 


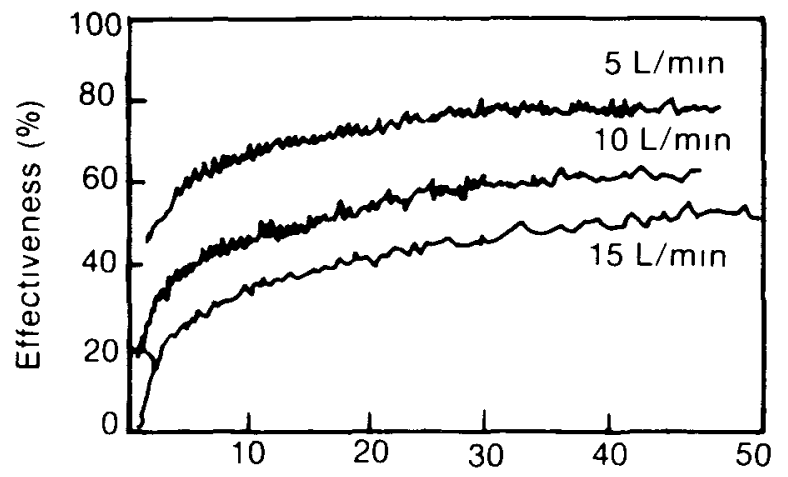

Temperature difference $\left({ }^{\circ} \mathrm{C}\right) \quad\left(T_{H \times 1}-T_{S}\right)$

(a) $\mathrm{HX}$ effectiveness versus $\Delta T$

$\stackrel{\leftarrow}{\infty}$

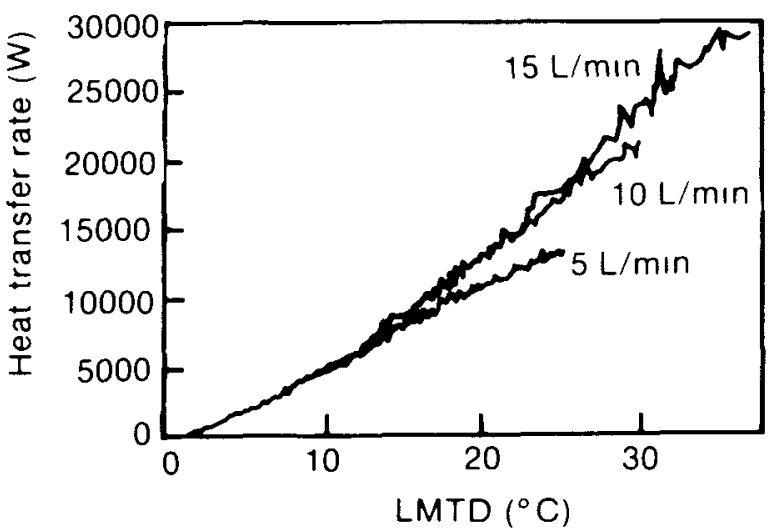

(c) HX heat transfer rate versus LMTD

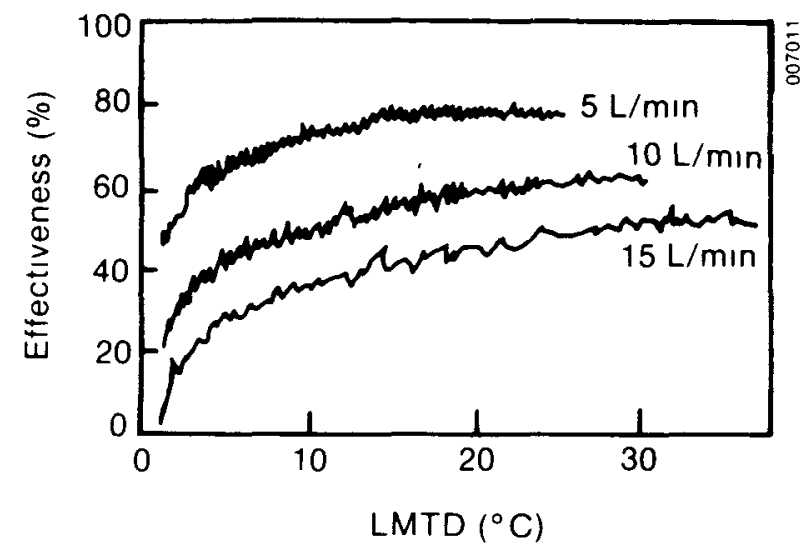

(b) $\mathrm{HX}$ effectiveness versus LMTD

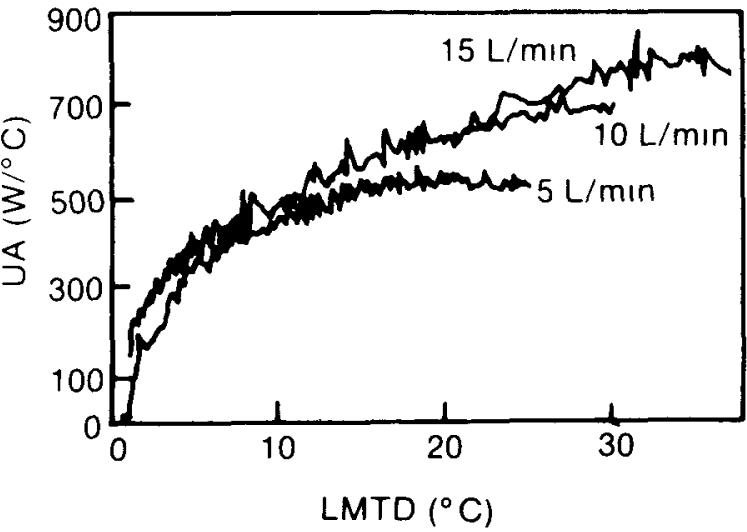

(d) HX UA versus LMTD 
be fewer bubbles. The increased pressure would also significantly decrease the size of the bubbles. If the tank were pressurized to $635 \mathrm{kPa}$ ( 80 psig) above atmospheric pressure, which would be almost a sixfold increase over the $99 \mathrm{kPa}(2.2 \mathrm{psig})$ from the $1.5 \mathrm{~m}(5 \mathrm{ft}$ ) of static head pressure, then the bubble volume might decrease by about sixfold based on the ideal gas law. The bubbles would be smaller and the performance of the spiral heat exchanger might improve. We did not observe significant accumulation of bubbles on any other heat exchanger.

The UA of this heat exchanger, shown in Figure 3-7d, varied more with the LMTD than the UA of the smooth-coil heat exchanger (Figure 3-4d). The dye injection tests showed results similar to the results from testing the coil heat exchanger. This was somewhat expected since the heat exchanger covered a large fraction of the bottom area of the tank.

\subsection{Single-Wall Bayonet Heat Exchanger}

This type of heat exchanger, shown in Figure 3-8, is quite common and offers several advantages although with severe performance penalties. The primary advantage of this type of heat exchanger is that it can be removed easily from a storage tank for inspection, maintenance, and replacement. It is inserted into an access hole near the bottom and through the side of a tank, and is secured with bolts and a gasket. It must be compact to fit through an access

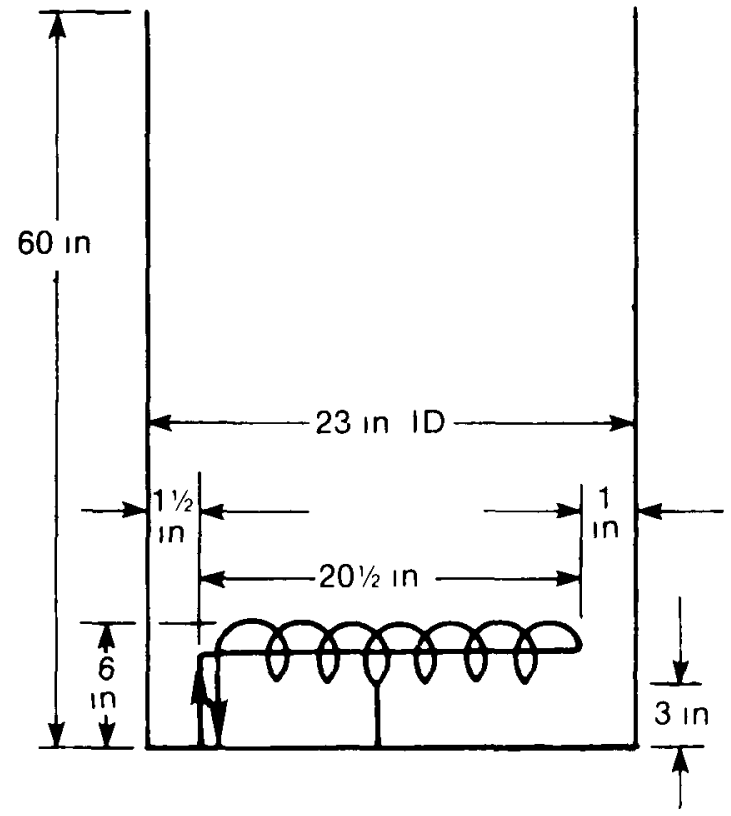

Side view

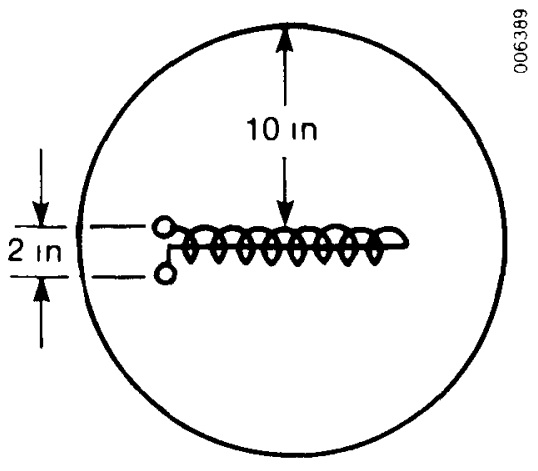

Top view

Figure 3-8. Single-Wall Bayonet Heat Exchanger Geometry 
hole. The compact nature of this heat exchanger causes lower performance since the natural convection flow is restricted as it passes around the tightly packed tubes. This heat exchanger came attached to a large steel flange for mounting to the tank and a metal support installed inside the heat exchanger coils. We removed them for our testing and mounted the heat exchanger as shown in Figure 3-8.

The results from testing the finned, single-wall (SW) bayonet heat exchanger are shown in Figure 3-9. Note the low effectiveness in Figures 3-9a and 3-9b at low temperature differences. At temperature differences of $3^{\circ}-5^{\circ} \mathrm{C}$ $\left(5^{\circ}-9^{\circ} \mathrm{F}\right)$, which are not uncommon in SDHW systems, the effectiveness ranged from 0.12 at $15 \mathrm{~L} / \mathrm{min}(4.0 \mathrm{gal} / \mathrm{min})$, which is a high flow rate for most applications, to 0.56 at $5 \mathrm{~L} / \mathrm{min}(1.3 \mathrm{gal} / \mathrm{min})$.

In Figure 3-9c, the heat exchanger $U A$ value is the slope of the curve since $q=U A(L M T D)$ (from Eq. 3-3). The UA values from this figure and from Figure $3-9 d$ were nearly independent of flow rate at low LMTDs. This was also true of the other heat exchangers tested, and this occurred because of the low driving force on the natural convection side across the entire heat exchanger. At large LMTDs, the higher flow rates maintained a greater temperature difference between the heat exchanger, causing a higher UA value because of greater convective heat transfer rate on the outside of the tube.

The SW bayonet heat exchanger did not have instructions or labels identifying the heat exchanger inlet and outlet. We plumbed it so that hot water flowed along the straight tube inside the coils and wound its way back to exit the heat exchanger. The straight tube was not symmetrically placed but was in contact with one side of the coils. We expected to see a convective cell with hot water rising above the coil and returning along each side of the coil. However, our dye injection showed a strong upward current along the half of the tank through which the straight tube ran and a downward current of cool water returning down the other side of the tank. The cold layer between the heat exchanger slowly oscillated between the two halves of the tank. The convective currents occasionally entrained water from the bottom part of the tank. Bubbles were evident along the heat exchanger inlet connection, but very few bubbles adhered to the returning coils.

\subsection{Double-Wa11 Bayonet Heat Exchanger}

A schematic diagram of the finned, double-wall (DW) bayonet heat exchanger we tested is shown in Figure 3-10. It was very similar to the $\mathrm{SW}$ bayonet heat exchanger except for the DW construction. This heat exchanger was plumbed in the same manner as the SW bayonet, with the heat exchanger inlet fluid flowing horizontally along the straight tube before spiraling back over itself.

The test results, shown in Figure 3-11, reveal that the DW bayonet design performed poorly. The heat exchanger effectiveness, which never exceeded 0.45 (Figures 3-11a and 3-11b), was low enough to critically affect system performance.

During the $15 \mathrm{~L} / \mathrm{min}(4.0 \mathrm{gal} / \mathrm{min})$ test we had a sudden, short loss of water pressure, which decreased the flow rate to $10 \mathrm{~L} / \mathrm{min}(2.6 \mathrm{gal} / \mathrm{min})$. The decreased flow rate lasted for about $2 \mathrm{~min}$ of the $120-\mathrm{min}$ test. We therefore 


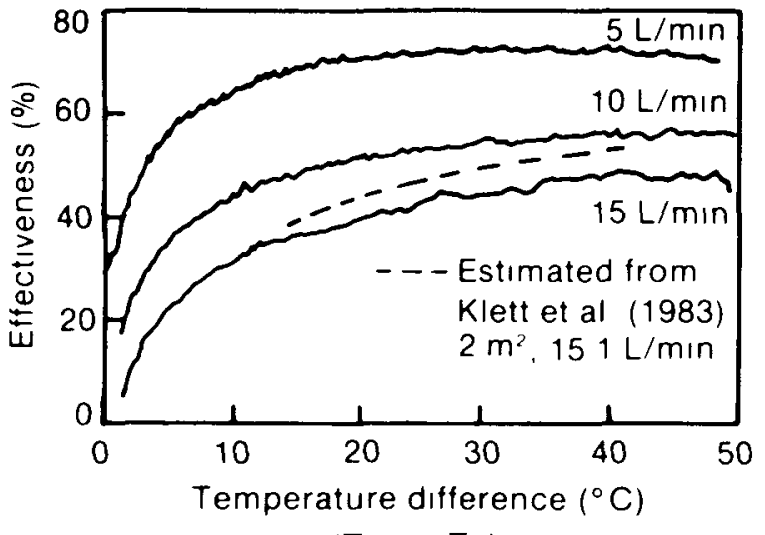

$\left(T_{H X},-T_{S}\right)$

(a) $H X$ effectiveness versus $\Delta T$

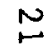

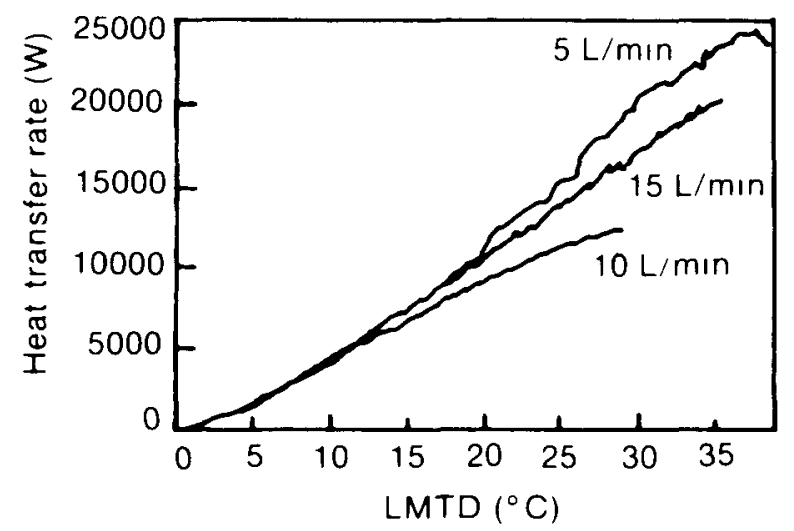

(c) $H X$ heat transfer rate versus LMTD

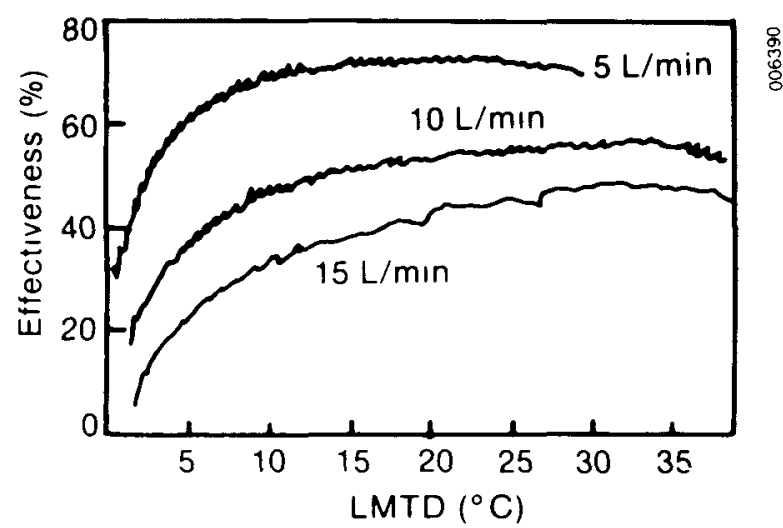

(b) HX effectiveness versus LMTD

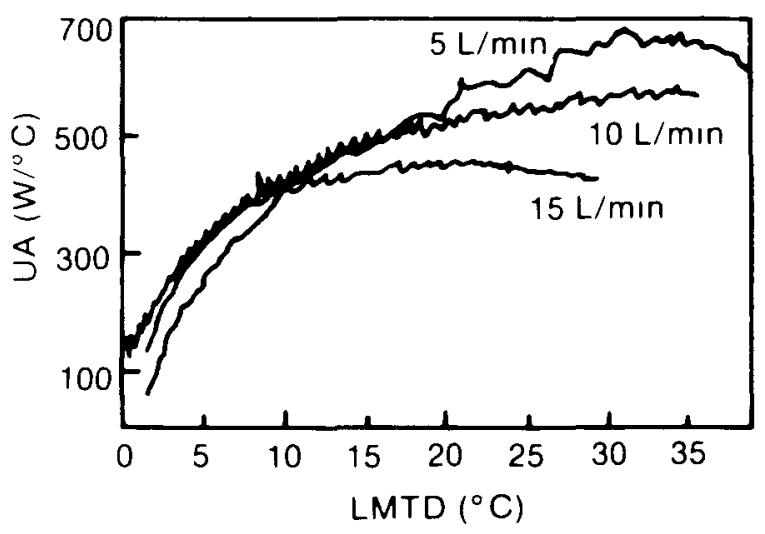

(d) HX UA versus LMTD

Figure 3-9. Single-Wa11 Bayonet Heat Exchanger Test Results 


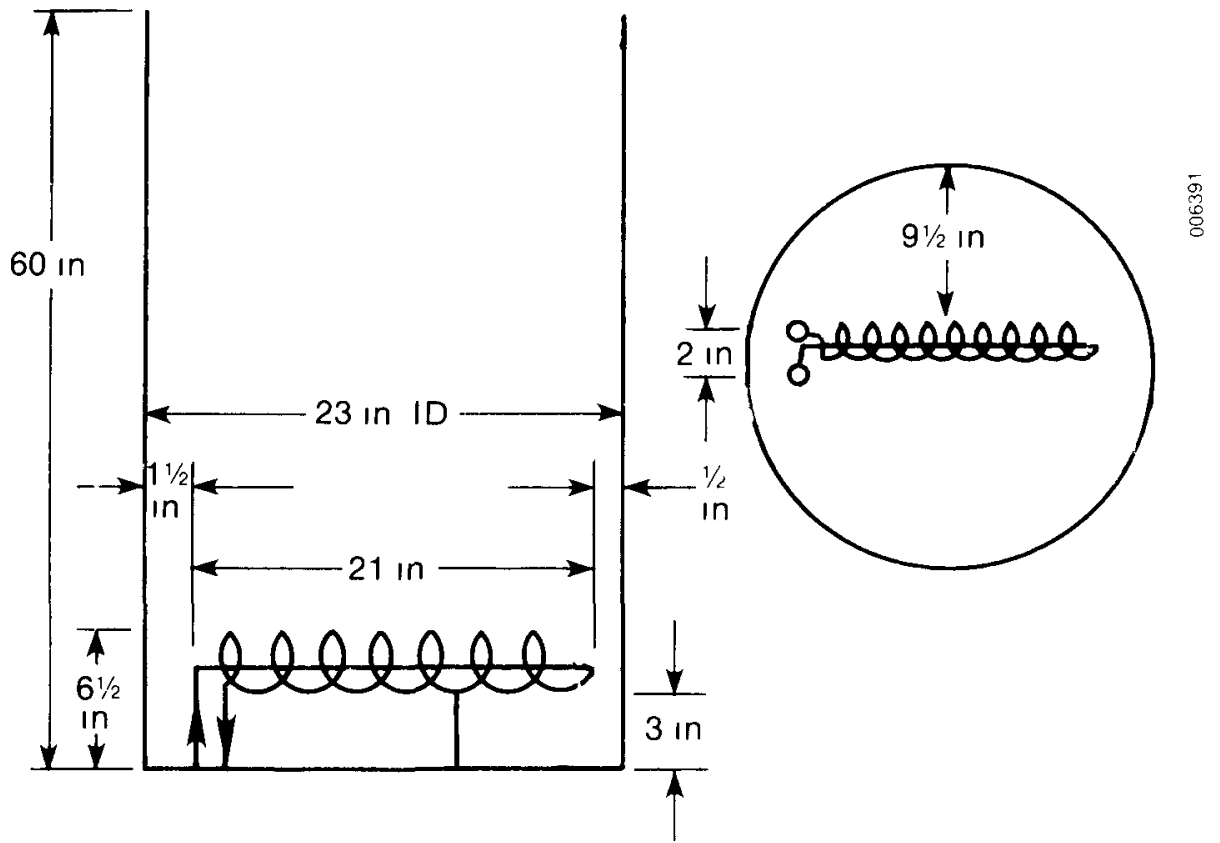

Side view

Top view

\section{Figure 3-10. Double-Wal1 Bayonet Heat Exchanger Geometry}

extrapolated the results at a temperature difference of $26^{\circ} \mathrm{C}\left(47^{\circ} \mathrm{F}\right)$ and an LMTD of $24^{\circ} \mathrm{C}\left(43^{\circ} \mathrm{F}\right)$.

The results from the dye injection test were very similar to those of the SW bayonet heat exchanger except that the rising hot flow was not as pronounced. This is probably because of the lower temperature of the outside wall of the heat exchanger caused by the larger thermal resistance of having two walls and contact space between them.

We also measured the effect of reversing the flow in this heat exchanger. Instead of flowing straight to the end of the heat exchanger and spiraling back, water flowed along the coils to the end and then returned along the straight section. The results are shown in Figure $3-12$ for $10 \mathrm{~L} / \mathrm{min}$ (2.6 gal/min). The initial flow direction showed a slightly higher effectiveness over most of the temperature difference range.

\subsection{Comparison of Results}

It is valuable to know not only how a particular heat exchanger performs under various conditions, but also how well it performs relative to other heat exchanger configurations. Figure 3-13a shows the performance of the four heat exchangers we tested at a flow rate of $5 \mathrm{~L} / \mathrm{min}(1.3 \mathrm{gal} / \mathrm{min})$. Included are the results of testing a $1.9-\mathrm{m}^{2}\left(20-\mathrm{ft}^{2}\right)$, finned-coil, DHW heat exchanger at $5 \mathrm{~L} / \mathrm{min}(1.3 \mathrm{gal} / \mathrm{min})$; these test results were used by Honeywell in the Packaged Systems Program (Farrington 1986). Even though the Honeywell heat exchanger had twice the heat exchanger area as the $0.9-\mathrm{m}^{2}\left(10-\mathrm{ft}^{2}\right)$ smooth-coil heat exchanger we built and tested, it performed only slightly better than our heat exchanger. The DW bayonet heat exchanger performed well below the other 


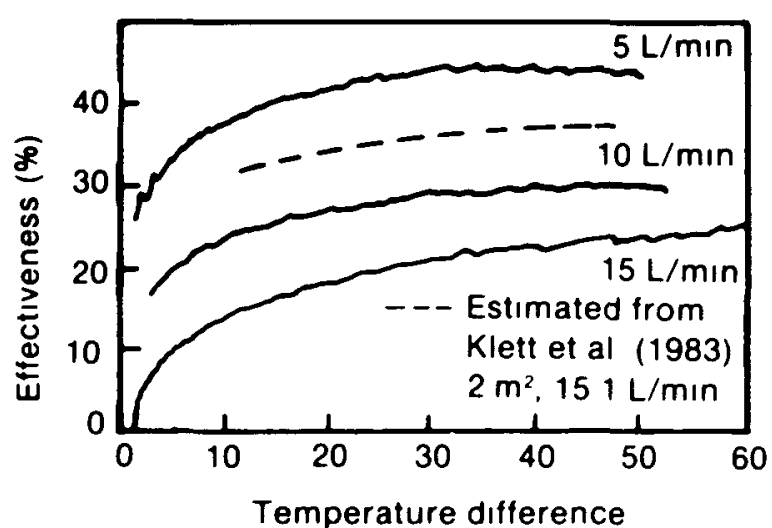

(a) $H X$ effectiveness versus $\Delta T$

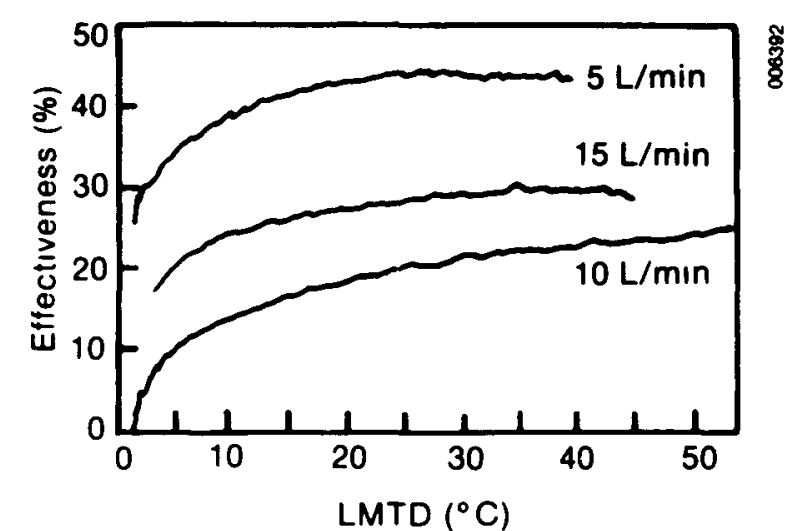

(b) $\mathrm{HX}$ effectiveness versus LMTD

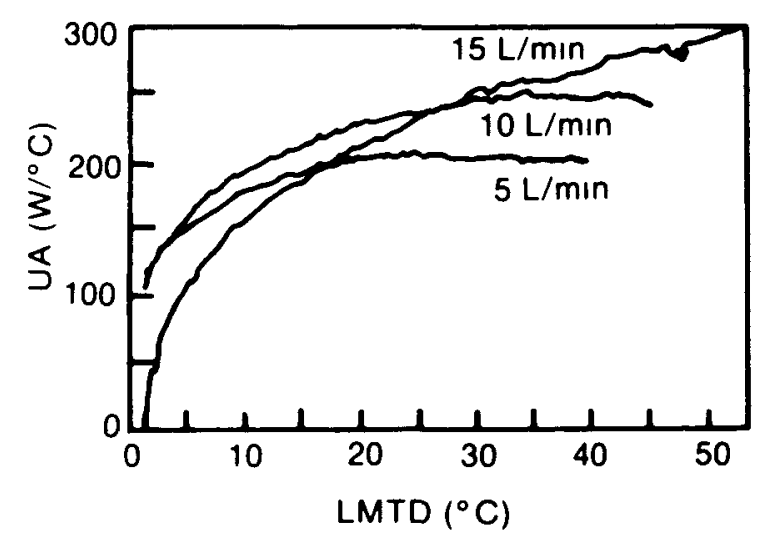

(d) HX UA versus LMTD

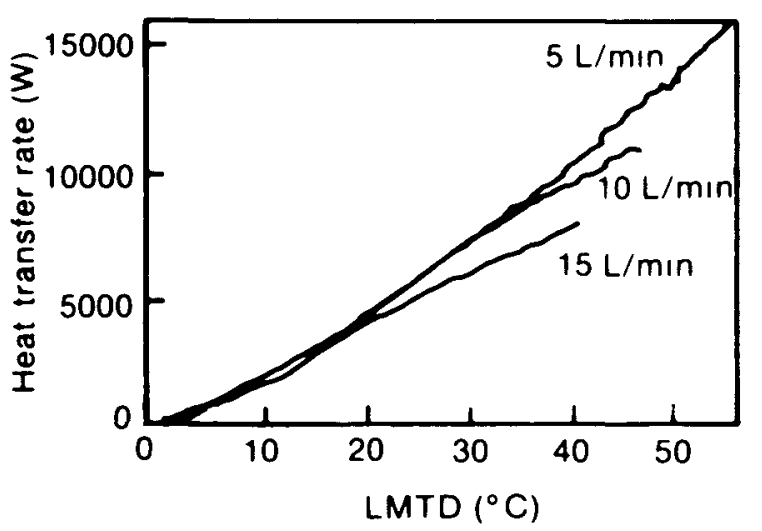

(c) $\mathrm{HX}$ heat transfer rate versus LMTD 


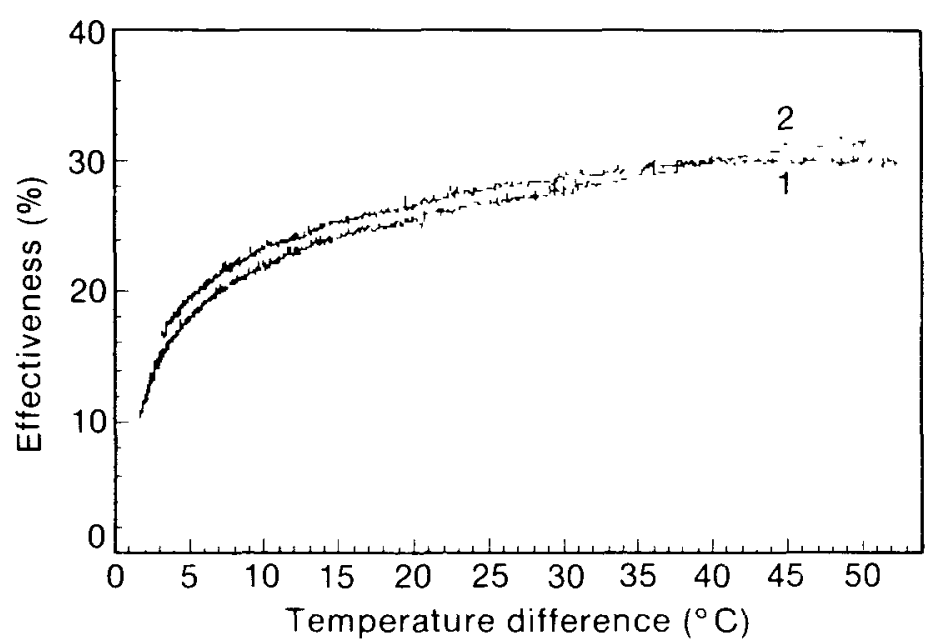

(a)

$\approx$

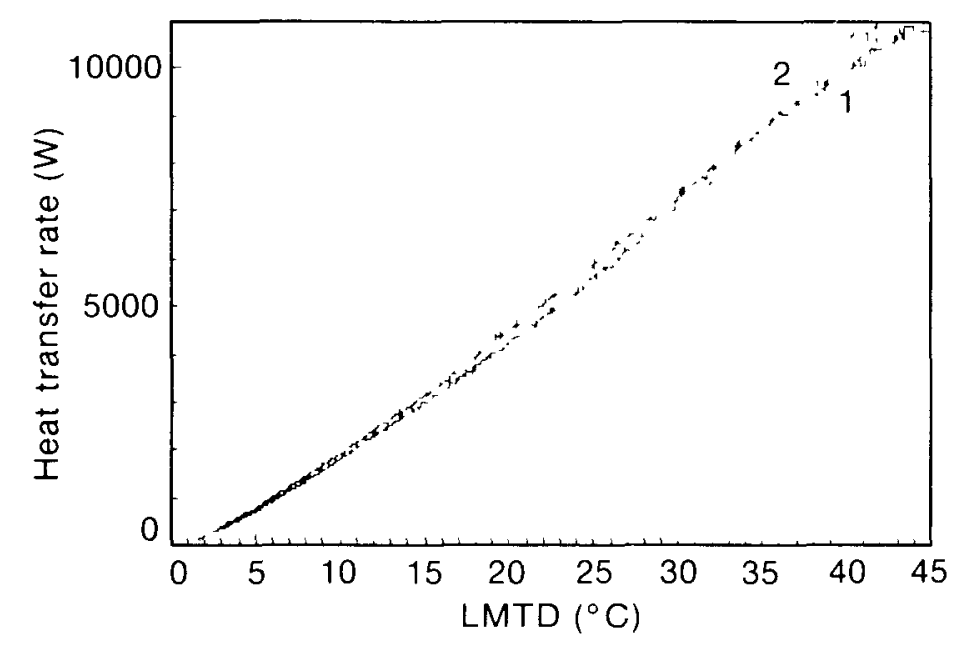

(c)

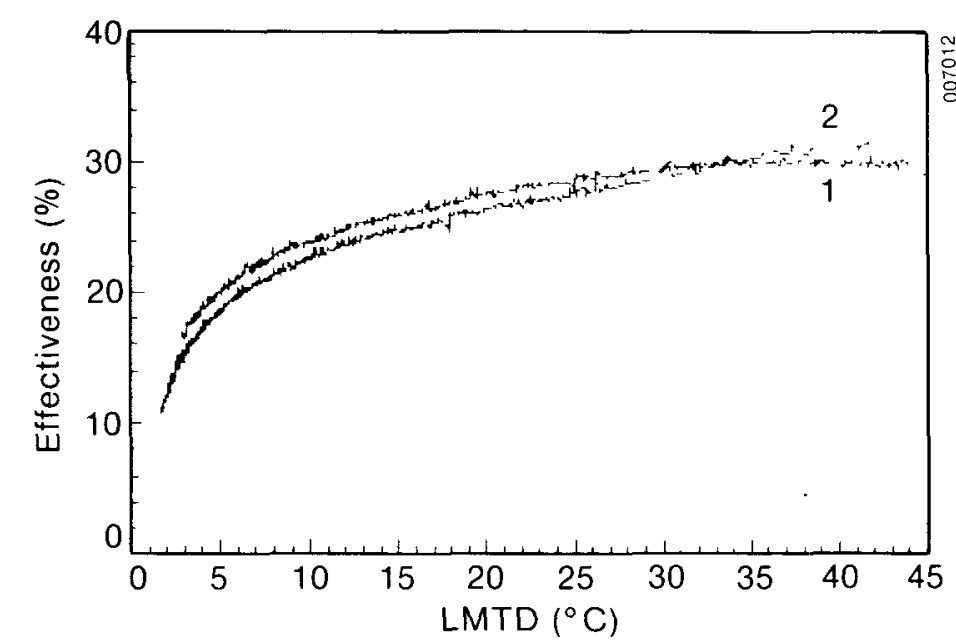

(b)

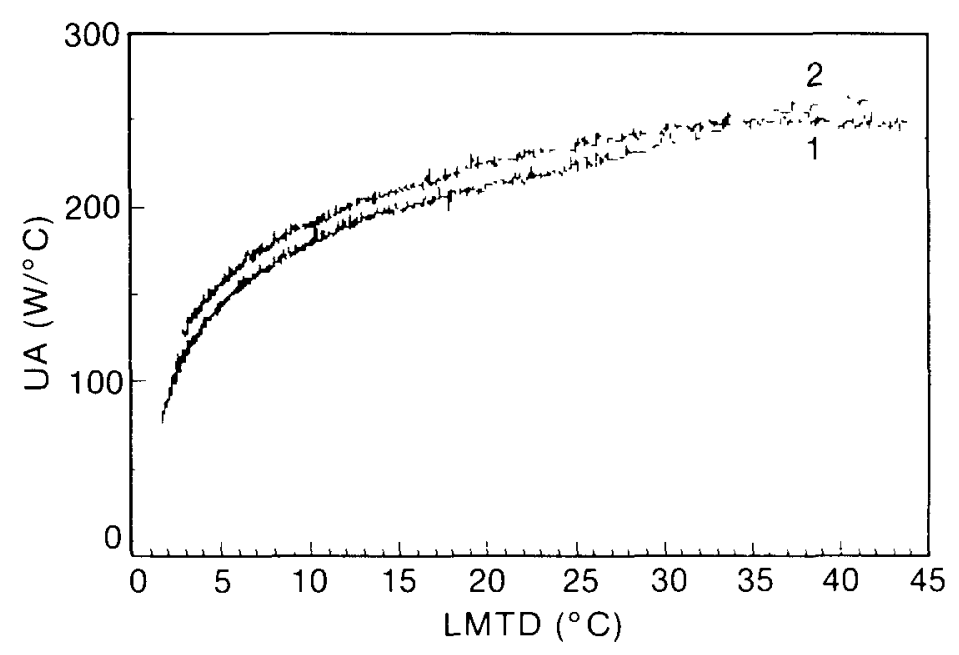

(d)

Figure 3-12. Comparison of Reverse Flow in Double-Wall Bayonet Heat Exchanger 


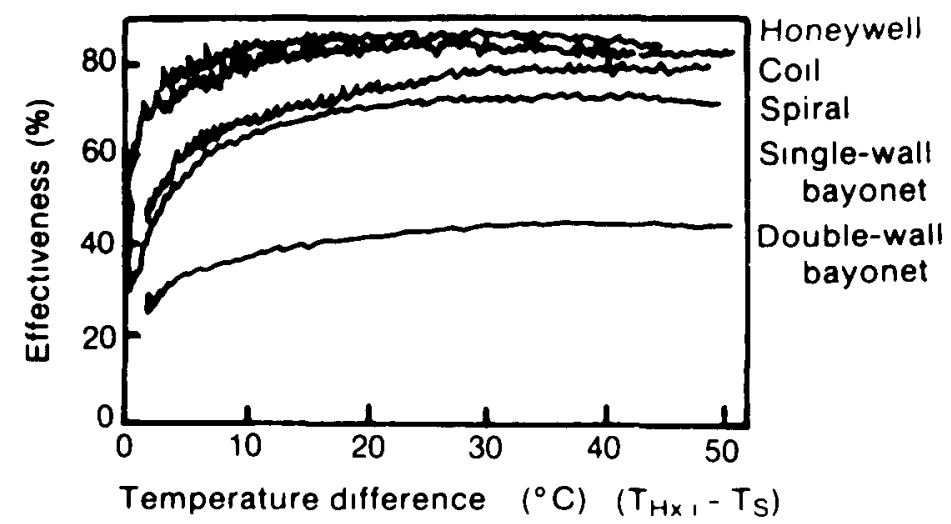

(a) $5 \mathrm{~L} / \mathrm{m} ı \mathrm{n}$

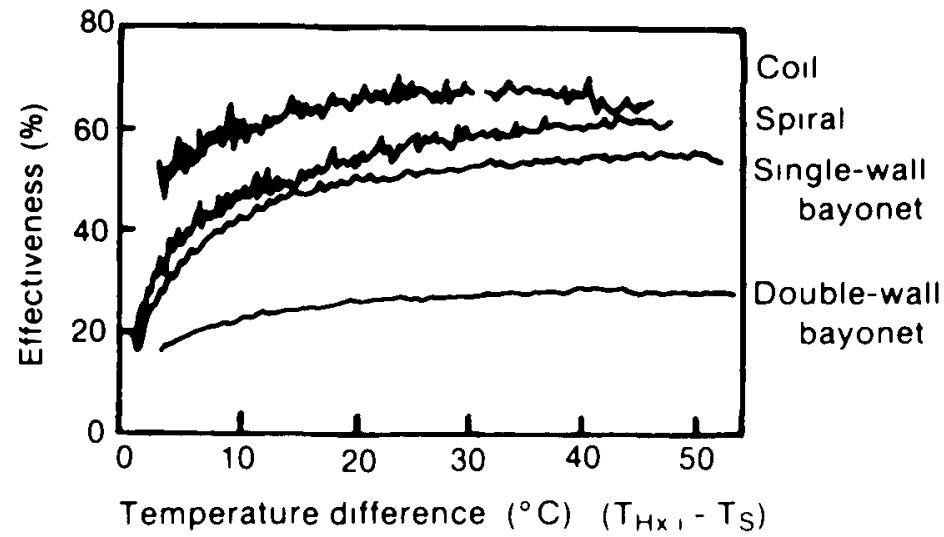

(b) $10 \mathrm{~L} / \mathrm{m}$ !n

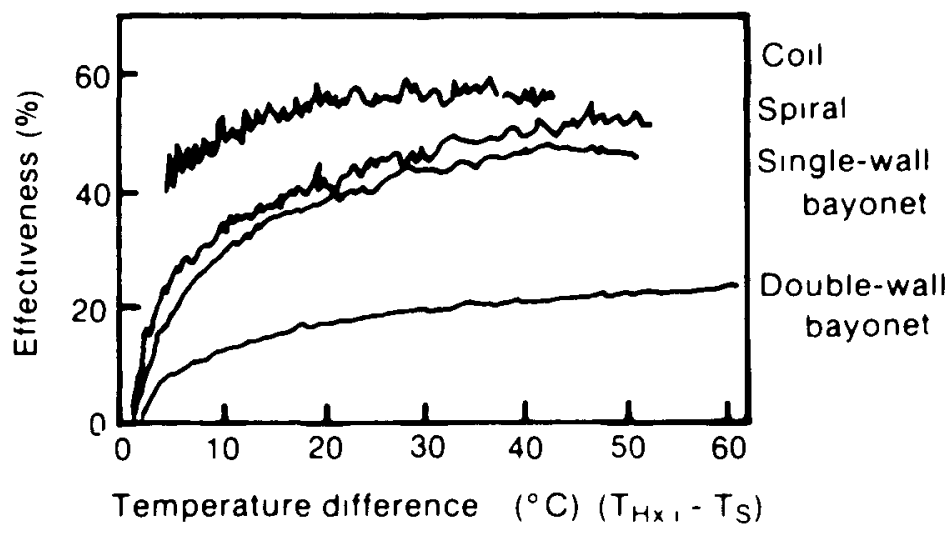

(c) $15 \mathrm{~L} / \mathrm{m}$ ।n

Figure 3-13. Comparison of All Heat Exchangers Tested (5, 10, and $15 \mathrm{~L} / \mathrm{min}$ ) 
heat exchanger designs, not only at $5 \mathrm{~L} / \mathrm{min}(1.3 \mathrm{gal} / \mathrm{min})$, but also at $10 \mathrm{~L} / \mathrm{min}(2.6 \mathrm{gal} / \mathrm{min}$ ) (see Figure $3-13 \mathrm{~b}$ ) and $15 \mathrm{~L} / \mathrm{min}(4.0 \mathrm{gal} / \mathrm{min}$ ) (see Figure $3-13 c)$.

We also correlated the Nusselt and Rayleigh numbers for each heat exchanger test. Figure 3-14 shows the results by heat exchanger type. Ideally, we should have measured the temperature along the outside of the heat exchanger surface instead of calculating it. However, even measuring it is not without difficulties. We corrected for the temperature drop using the Petukhov-Popov correlation (Petukhov 1970), which is

$$
\overline{\mathrm{Nu}}=\frac{(f / 8) \operatorname{RePr}}{K_{1}+K_{2}(f / 8)^{1 / 2}\left(\operatorname{Pr}^{2 / 3}-1\right)} \text {, }
$$

where

$$
\begin{aligned}
\mathrm{K}_{1} & =1+3.4 \mathrm{f} \\
\mathrm{K}_{2} & =11.7+1.8 /\left(\operatorname{Pr}^{1 / 3}\right) \\
\mathrm{f} & =\left(1.82 \log _{10} \mathrm{Re}-1.64\right)^{-2} .
\end{aligned}
$$

The inside Nusselt number was used to calculate $\bar{h}_{i}$ as

$$
\overline{\mathrm{h}}_{\mathrm{i}}=\frac{\mathrm{k} \overline{\mathrm{Nu}}}{\mathrm{id}} \text {, }
$$

which was then used to calculate the temperature drop from the heat exchanger fluid to the heat exchanger wall as

$$
\Delta \mathrm{T}_{\mathrm{f}, \mathrm{w}}=\mathrm{q} / \mathrm{A}_{\mathrm{i}} \overline{\mathrm{h}}_{\mathrm{i}}
$$

The LMTD was then modified to be

$$
(\text { LMTD })_{\text {revised }}=(\text { LMTD })_{\text {original }}-\left(\Delta \mathrm{T}_{f, \mathrm{w}}\right) \text {. }
$$

Only the Nusselt-Rayleigh correlations were changed by $\Delta T_{f, w}$ since they should be based on the heat exchanger wall temperature. The other test results $(\varepsilon, q$, UA) were correctly based on the actual LMTD.

We neglected the resistance of the copper wall for the SW heat exchangers. We did include the contact resistance between the two walls for the DW heat exchanger. For the contact resistance we used a value of $1.83 \times 10^{-3}{ }^{\circ} \mathrm{C} / \mathrm{W}$ based on testing by Feiereisen (1982).

The inside film coefficient is often considered insignificant if there is forced flow through the heat exchanger and natural convection on the outside. With smooth-coil heat exchangers, where there is no significant difference between the inside and outside surface areas, this is not a bad assumption. Figure 3-14a shows only a small shift in the Nusselt-Rayleigh curve caused by including the internal film resistance. Even so, the internal film resistance can cause up to $20 \%$ of the entire temperature difference at low flow rates and high temperature differences.*

*This is shown in Table 4-4 for the smooth coil where the fraction of the temperature drop caused by the inside film coefficient is $(1-F)$. 


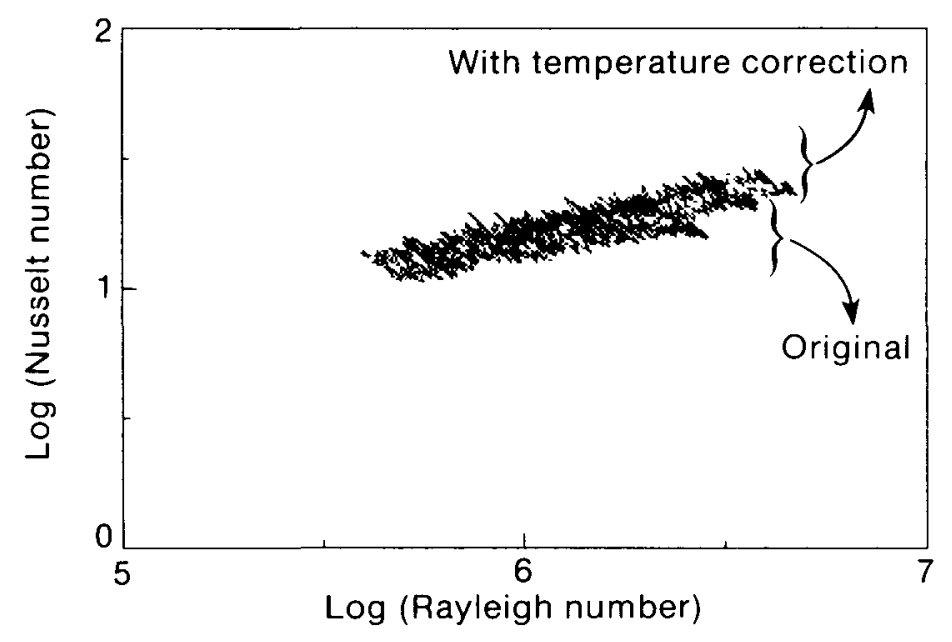

(a) Smooth coil

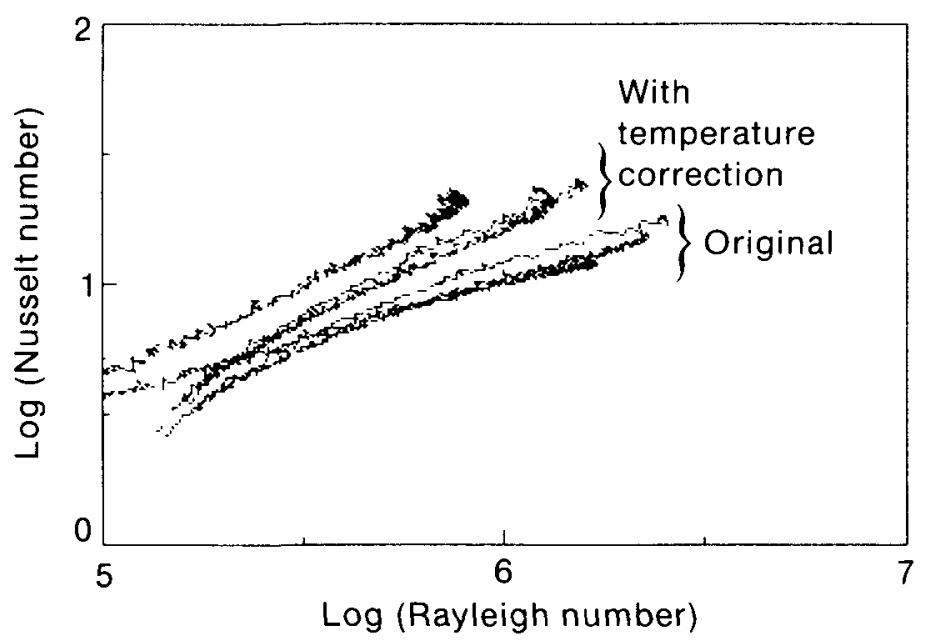

(c) Finned single-wall bayonet

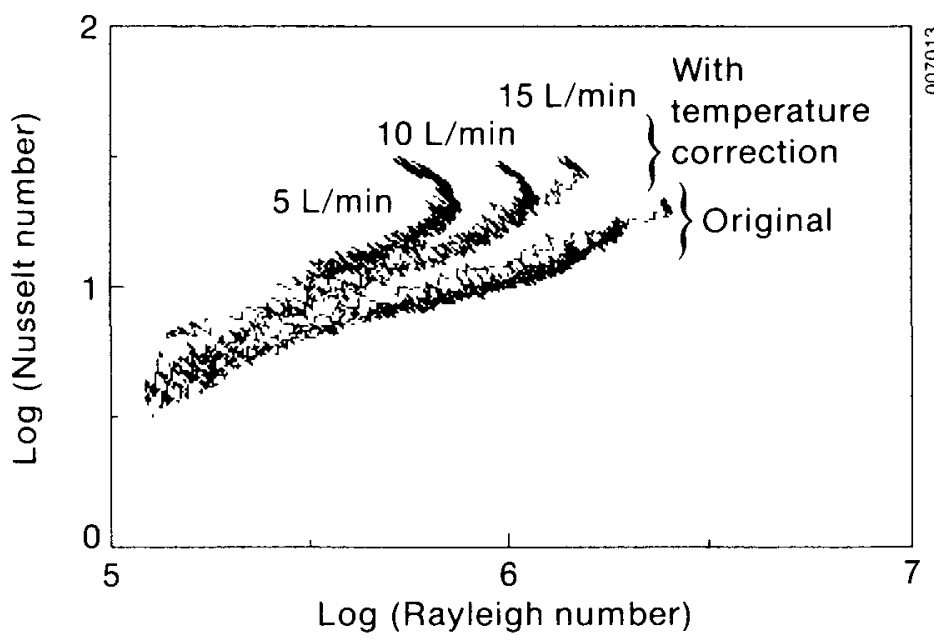

(b) Finned spiral

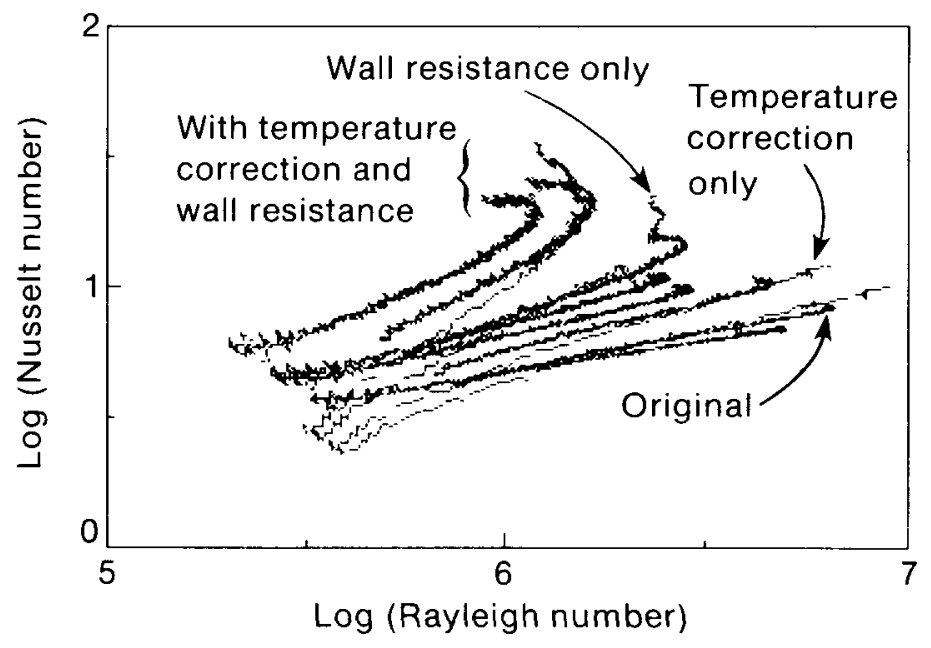

(d) Finned double-wall bayonet

Figure 3-14. Nusselt-Rayleigh Results by Heat Exchanger Type for All Flow Rates Tested 
However, for the finned heat exchangers, the temperature correction can be significant. This is caused by the large difference between the inside and outside heat transfer area. The ratio of the temperature drop from the heat exchanger fluid to the wall to the temperature drop from the wall to the storage tank is equal to $h_{0} A / h_{i} A_{i}$ in a steady-state situation. The ratio of the areas is very important. The smooth coil had a ratio of outside to inside surface area of 1.15, while the finned spiral and SW bayonet was 5.05 and the DW bayonet was 5.34. Since the same amount of energy is being transferred across both the inside and outside surfaces, the temperature difference (or driving force) must be larger for the smaller area if the convective heat transfer coefficients are similar. We modified the outside area of finned heat exchangers to account for the fin efficiency. Approximately $73 \%$ of the heat transfer area was because of the fins, which had an average efficiency of $80 \%$. The effective heat transfer area that we used for the finned heat exchangers was

$$
(0.27+0.73 \times 0.8) \mathrm{A}=0.854 \mathrm{~A} .
$$

However, our calculation did not account for fins being in contact with each other or for fins being in the center of a tightly packed bundle.

The temperature correction causes each curve to move slightly left (since a smaller LMTD leads to a smaller Rayleigh number) and also slightly upward (since a small LMTD leads to a higher heat transfer coefficient for a given heat transfer rate).

The temperature correction also caused an unexpected curve for the spiral (Figure 3-14b) as did the wall resistance correction for the DW bayonet heat exchanger (Figure 3-14d). Although we examined this effect, we do not know what caused the unexpected curves. It could be that we over-corrected for the temperature difference at high Rayleigh numbers for these heat exchangers. The correlation in the curved area is not physically meaningful.

Different flow rates appear to have little effect on the Nusselt-Rayleigh correlation until the temperature correction is applied. It is difficult to determine the impact of the heat exchanger design from the graphs. Table 3-3 shows the results from tabular data. Without correcting for inside film coefficient, there is little impact on the Nusselt number because of flow rate. With the temperature correction there is a more noticeable change at low Rayleigh numbers.

Figure 3-15 shows the Nusselt-Rayleigh correlations for all of the heat exchangers tested at all flow rates. Figure $3-15$ a includes the contact resistance for the DW bayonet heat exchanger but does not include any corrections for the inside film coefficient. Figure 3-15b includes a temperature correction for the inside film resistance for all of the heat exchangers and the contact resistance for the DW bayonet.

The Nusselt and Rayleigh numbers are related by a factor " $C$ " as shown in Eq. 3-11. Knowing this factor is necessary to determine the Nusselt number from the Rayleigh number if graphs are not used. Table 3-4 shows the values for $C$ with and without correcting for the inside film coefficient. The wide range of values for $C$ is consistent with the results of Feiereisen et al. 
Table 3-3. Nusselt Numbers at Selected Rayleigh Numbers

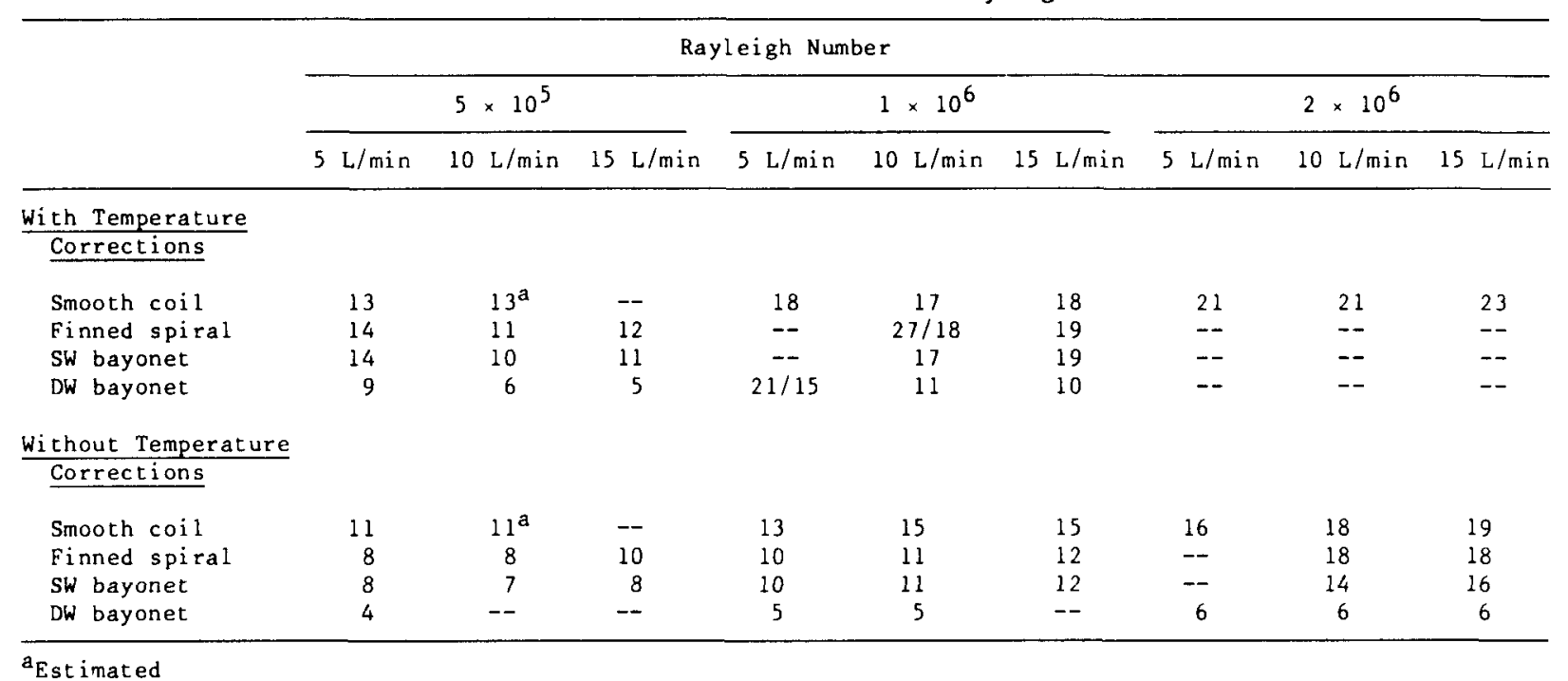

(1982); the maximum $C$ they obtained was approximately twice that of the minimum $C$. Our results may have a greater variation because of the larger range of temperature differences in our test, particularly at very low differences. Their results for a finned, DW bayonet heat exchanger with an outside surface area of $0.73 \mathrm{~m}^{3}\left(25.78 \mathrm{ft}^{3}\right)$ showed a value of 0.18 for $C$ for 30 observations at flow rates ranging from 4.5 to $7.5 \mathrm{~L} / \mathrm{min}(11.9$ to $19.9 \mathrm{gal} / \mathrm{min})$. Their worst-case conditions for $\mathrm{C}$ ranged from 0.12 to 0.24 . The range of $\mathrm{C}$ values from Feiereisen et al. (1982) results are very similar to our results without correcting for the wall resistance. Figure 3-16 shows how $C$ varies with LMTD for each heat exchanger type with and without temperature corrections. The temperature corrections led to large variations in the $\mathrm{C}$ factor.

In conclusion, the smooth-coil heat exchanger performed significantly better than the finned-spiral, the SW bayonet, and the DW bayonet heat exchangers at all flow rates and temperature differences tested. We did not expect the performance of the finned-spiral heat exchanger to be so low, and we suspect it may have been caused by air bubbles between the fins. In a pressurized tank, it might perform better.

Data from Klett et al. (1983) are shown in Figure 3-9a for their SW heat exchanger in a 450-L (119-gal) tank at a flow rate of $15.1 \mathrm{~L} / \mathrm{min}$ $(40 \mathrm{gal} / \mathrm{min})$. Although klett et al. did not include a diagram of the heat exchanger they tested, it appears from their description to be very similar to the SW bayonet heat exchanger we tested except that it had twice the heat transfer area. From Figure 3-9a it appears that the extra heat transfer area offers very little benefit for the SW bayonet heat exchanger. However, the extra heat transfer area substantially benefited the DW bayonet heat exchanger they tested, as shown in Figure 3-1la. 


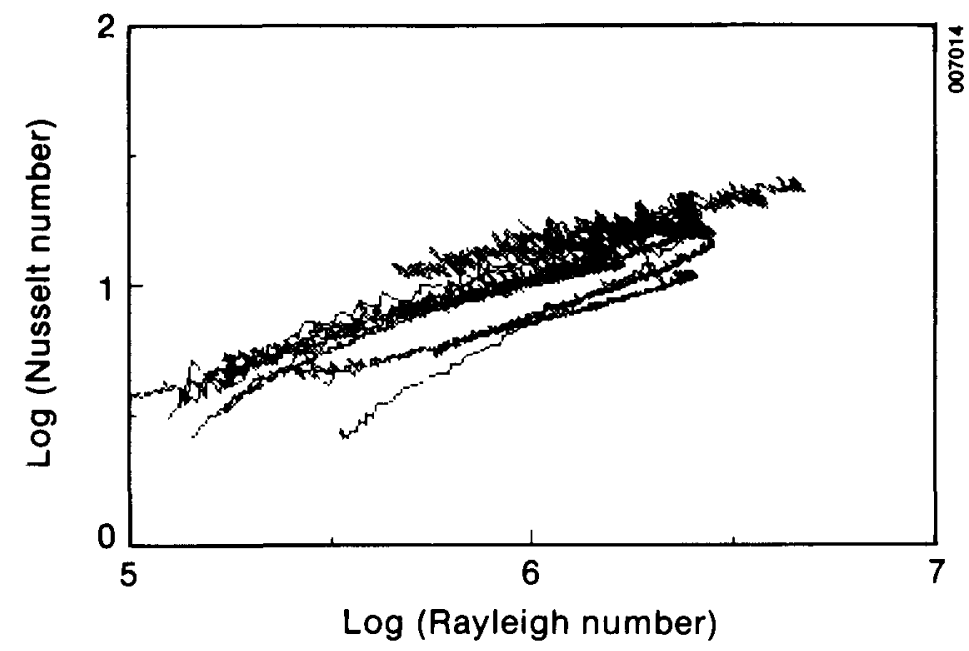

(a) Without temperature correction for inside film coefficient

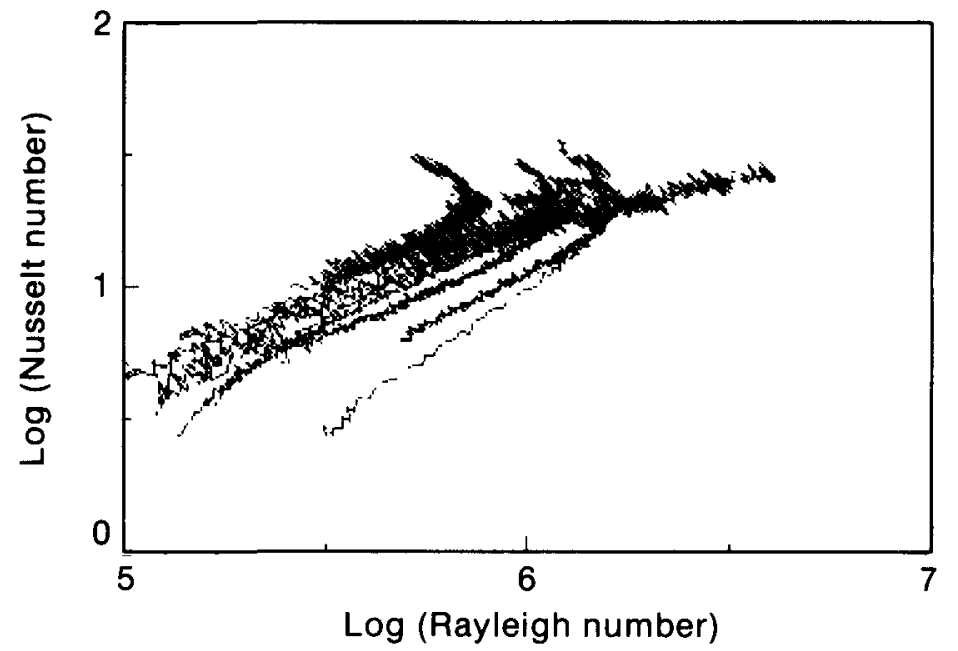

(b) With temperature corrections

Figure 3-15. Summary of Nusselt-Rayleigh Results for Al1 Heat Exchangers Tested 
Table 3-4. Sunmary of C Pactors

\begin{tabular}{|c|c|c|c|c|c|c|c|c|}
\hline \multirow{2}{*}{$\begin{array}{l}\text { Heat Exchanger } \\
\text { Type }\end{array}$} & \multirow{2}{*}{$\begin{array}{c}\text { Flow Rate } \\
\text { (L/min) }\end{array}$} & \multirow{2}{*}{$\begin{array}{l}\text { Number } \\
\text { of Data } \\
\text { Points }\end{array}$} & \multirow{2}{*}{$\begin{array}{c}\text { Without } \\
\begin{array}{c}\text { Mean } \\
\mathrm{C}\end{array}\end{array}$} & \multirow{2}{*}{ 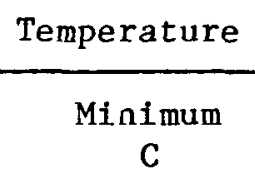 } & \multirow{2}{*}{$\frac{\text { Correction }}{\underset{\mathrm{C}}{\text { Maximum }}}$} & \multicolumn{2}{|c|}{ With Temperature } & \multirow{2}{*}{$\frac{\text { Correction }}{\underset{C}{\text { Maximum }}}$} \\
\hline & & & & & & $\begin{array}{l}\text { Mean } \\
\quad \mathrm{C}\end{array}$ & $\begin{array}{l}\text { Minimum } \\
\mathrm{C}\end{array}$ & \\
\hline Smooth coil & $\begin{array}{r}5 \\
10 \\
15\end{array}$ & $\begin{array}{l}459 \\
299 \\
198\end{array}$ & $\begin{array}{l}0.426 \\
0.474 \\
0.511\end{array}$ & $\begin{array}{l}0.375 \\
0.385 \\
0.446\end{array}$ & $\begin{array}{l}0.546 \\
0.560 \\
0.591\end{array}$ & $\begin{array}{l}0.538 \\
0.554 \\
0.580\end{array}$ & $\begin{array}{l}0.443 \\
0.422 \\
0.484\end{array}$ & $\begin{array}{l}0.706 \\
0.696 \\
0.688\end{array}$ \\
\hline Finned spiral & $\begin{array}{r}5 \\
10 \\
15\end{array}$ & $\begin{array}{l}569 \\
525 \\
141\end{array}$ & $\begin{array}{l}0.330 \\
0.328 \\
0.401\end{array}$ & $\begin{array}{l}0.242 \\
0.178 \\
0.165\end{array}$ & $\begin{array}{l}0.418 \\
0.503 \\
0.568\end{array}$ & $\begin{array}{l}0.642 \\
0.469 \\
0.562\end{array}$ & $\begin{array}{l}0.317 \\
0.196 \\
0.176\end{array}$ & $\begin{array}{l}1.18 \\
0.986 \\
0.984\end{array}$ \\
\hline SW bayonet & $\begin{array}{r}5 \\
10 \\
15\end{array}$ & $\begin{array}{l}615 \\
488 \\
139\end{array}$ & $\begin{array}{l}0.292 \\
0.296 \\
0.348\end{array}$ & $\begin{array}{l}0.197 \\
0.159 \\
0.132\end{array}$ & $\begin{array}{l}0.351 \\
0.408 \\
0.459\end{array}$ & $\begin{array}{l}0.513 \\
0.411 \\
0.473\end{array}$ & $\begin{array}{l}0.232 \\
0.174 \\
0.139\end{array}$ & $\begin{array}{l}0.790 \\
0.719 \\
0.720\end{array}$ \\
\hline $\begin{array}{l}\text { DW bayonet } \\
\text { w/o wall resis- } \\
\text { tance contact }\end{array}$ & $\begin{array}{r}5 \\
10 \\
15\end{array}$ & $\begin{array}{l}935 \\
665 \\
173\end{array}$ & $\begin{array}{l}0.148 \\
0.157 \\
0.160\end{array}$ & $\begin{array}{l}0.135 \\
0.139 \\
0.091\end{array}$ & $\begin{array}{l}0.162 \\
0.172 \\
0.193\end{array}$ & $\begin{array}{l}0.215 \\
0.200 \\
0.196\end{array}$ & $\begin{array}{l}0.167 \\
0.160 \\
0.097\end{array}$ & $\begin{array}{l}0.255 \\
0.244 \\
0.245\end{array}$ \\
\hline $\begin{array}{l}\text { DW bayonet } \\
\text { w/wa11 resis- } \\
\text { tance contact }\end{array}$ & $\begin{array}{r}5 \\
10 \\
15\end{array}$ & $\begin{array}{l}935 \\
665 \\
173\end{array}$ & $\begin{array}{l}0.239 \\
0.287 \\
0.338\end{array}$ & $\begin{array}{l}0.175 \\
0.193 \\
0.107\end{array}$ & $\begin{array}{l}0.292 \\
0.415 \\
0.569\end{array}$ & $\begin{array}{l}0.451 \\
0.444 \\
0.517\end{array}$ & $\begin{array}{l}0.227 \\
0.232 \\
0.115\end{array}$ & $\begin{array}{l}0.743 \\
0.823 \\
1.08\end{array}$ \\
\hline
\end{tabular}

${ }^{a}$ Correction for internal film coefficient. 


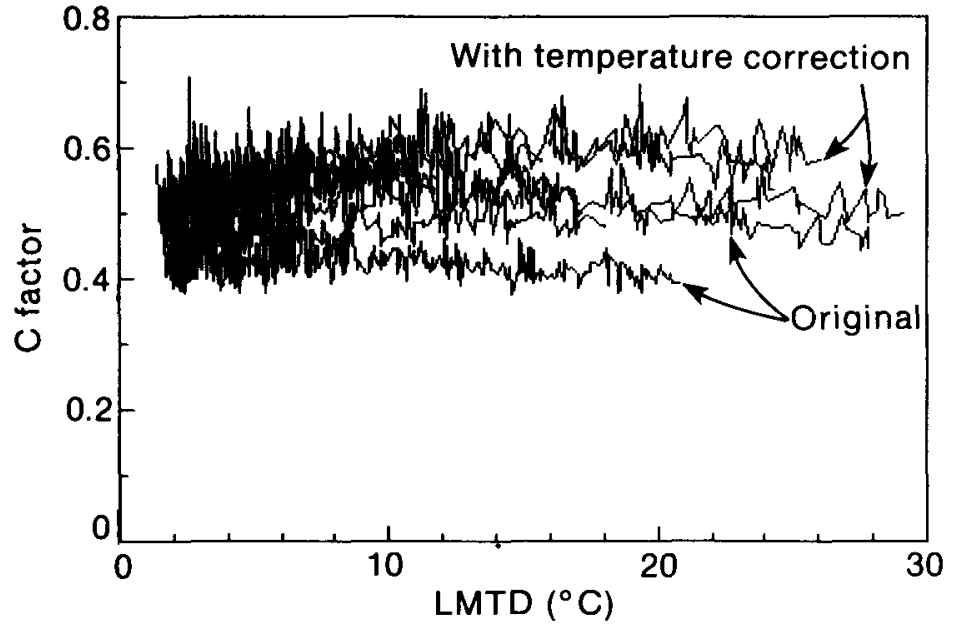

(a) Smooth coil

$\stackrel{w}{N}$

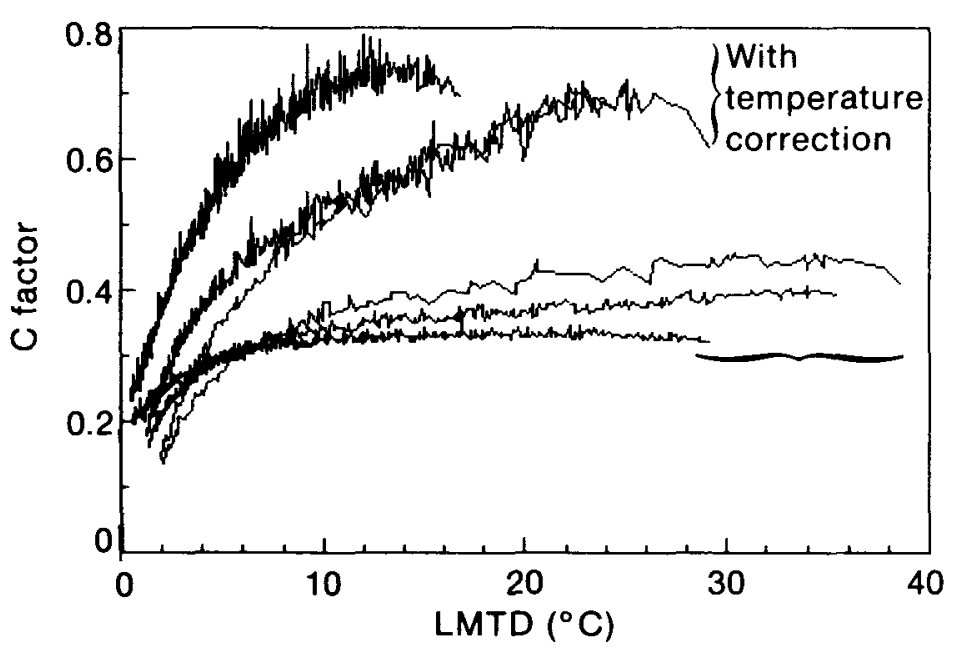

(c) Finned single-wall bayonet

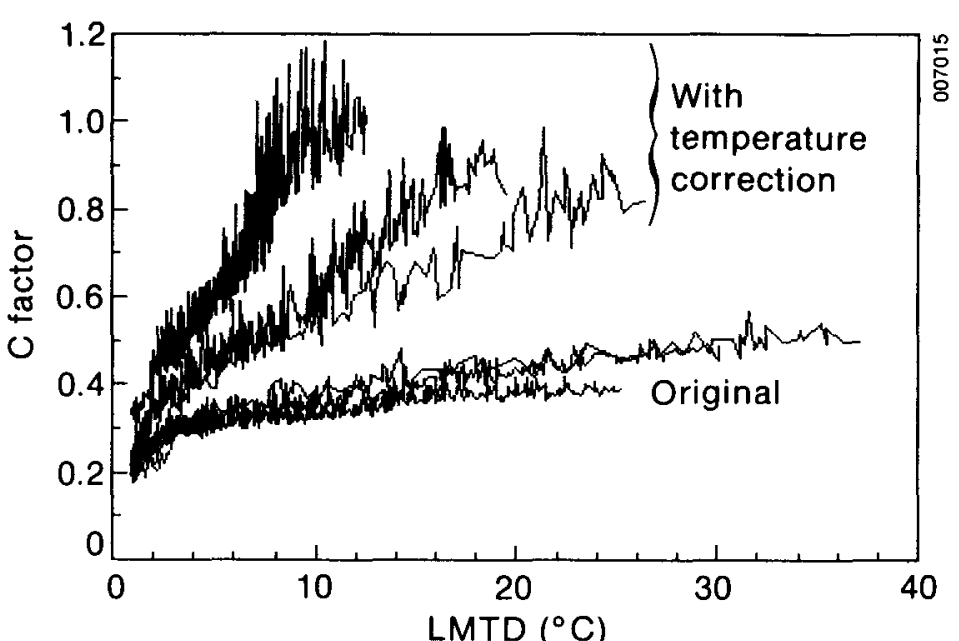

(b) Finned spiral

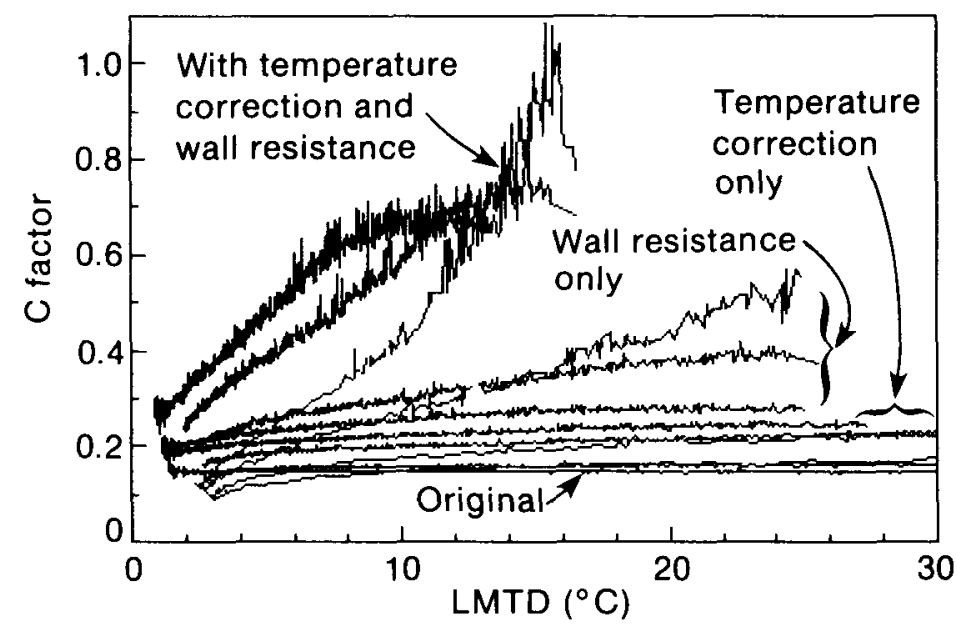

(d) Finned double-wall bayonet 


\subsection{ANALYTICAL MODELS}

Natural convective heat transfer is not easily modeled. The main difficulties arise from the coupled nature of the problem wherein both heat and momentum equations must be simultaneously solved in some form of the Navier-Stokes equation. Even simplifying assumptions, such as the Boussinesq approximation for nonconstant properties, lead to a nontrivial set of equations.

The coupled problem stems from the heat transfer from the tube to the liquid inducing a temperature $r$ ise in the nearby liquid and, therefore, a change in density. This change in density results in a buoyant force that leads to flow around the tube. Just as the flow past the tube is dependent on the heat transfer from the tube, the heat transfer coefficient from the tube is dependent on the fluid velocity past the tube. Hence, the coupled problem.

Design methods have frequent1y relied on the natural convective heat transfer coefficient from an infinite tube in an infinite medium to predict performance of immersed-coil heat exchangers. However, the heat transfer from an infinite tube in an infinite medium does not accurately represent the steady-state case of an immersed coil in an enclosure because it does not account for tube end effects, curvature of the tube coil, wall and floor effects, tube-to-tube effects, recirculation with the enclosure, and absence of good symmetry within the tank. These effects can cause large differences between the classical natural convection case and natural convection with an enclosure.

The presence of the walls, floor, and ceiling of the enclosure will lead to recirculation loops. These loops may result in the formation of stagnant pools that effectively reduce the available storage volume, resulting in a decrease of the temperature differential between the tube and the recirculating water. Drainback tanks with a free surface of water will have different recirculation loops because the plume will tend to dissipate at the free surface.

Plumes in a classical case will rise vertically. In an enclosure, the plume will be attracted by and follow nearby walls, which puts the hottest fluid next to the tank wall (increasing heat loss) and reduces mixing and heat transfer to the remaining storage volume. Likewise, plumes near enclosure floors, walls, and corners may not fully develop because of restricted fluid flow.

The heat exchanger geometry as well as the heat exchanger location within the tank is important. Closely spaced tubes will restrict natural convection around the tubes and limit the amount of effective heat exchanger area. For this reason, increasing heat exchanger area without regard to natural convective heat transfer may not bring the expected increased heat transfer. If tubes are placed above each other, the bottom tube experiences natural convection while the top tube transfers heat from both natural and forced convection. The forced convection comes from the fluid movement generated by the lower tube. While this fluid movement increases the heat transfer coefficient, it also decreases the available temperature difference to transfer heat since the water has been preheated by the lower tube. 
An analysis of the effects of heat exchanger geometry is complicated and must include the effects of the distance between the tube and the enclosure floor and sides, horizontal and vertical distance between tubes, and the skewedness of the tubes (the horizontal distance between the vertical centerline of the top and bottom tubes). Figure 4-1 shows various immersed heat exchanger geometries revealing the deviations from the classical case of an infinite tube in an infinite medium.

Other factors make this problem difficult to analyze: the problem is really three-dimensional, neither the heat exchanger nor the tank is isothermal, the heat source (solar) is nonuniform, and the load introduces transients that strongly affect a load-side exchanger since heat is generally withdrawn only over short time periods.

For these reasons, we developed three simple models (two analytical and one numerical) and varied the parameters to determine the degree to which a
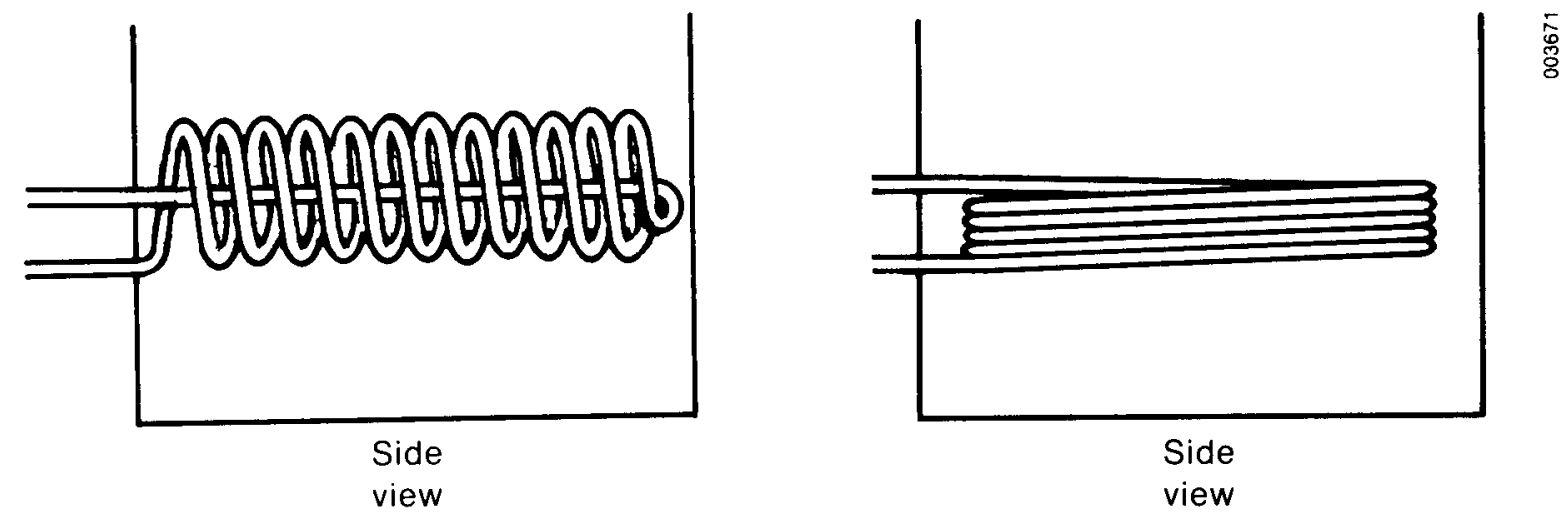

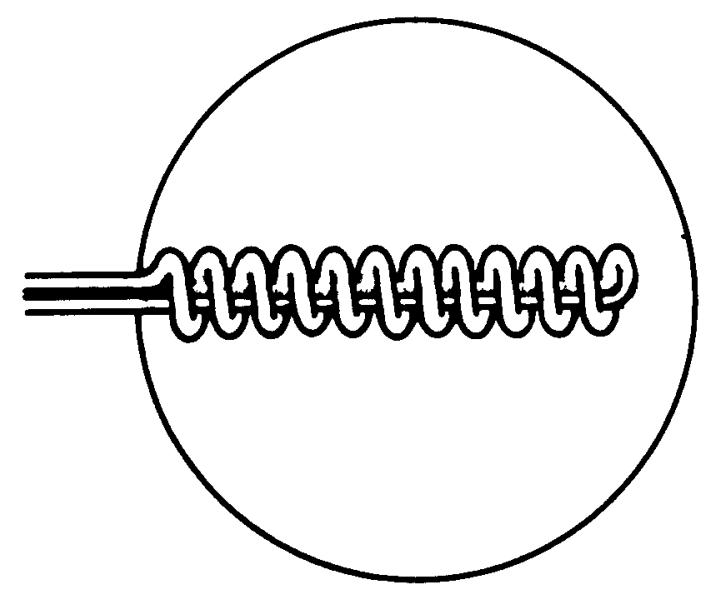

Top view

(a) Bayonet type

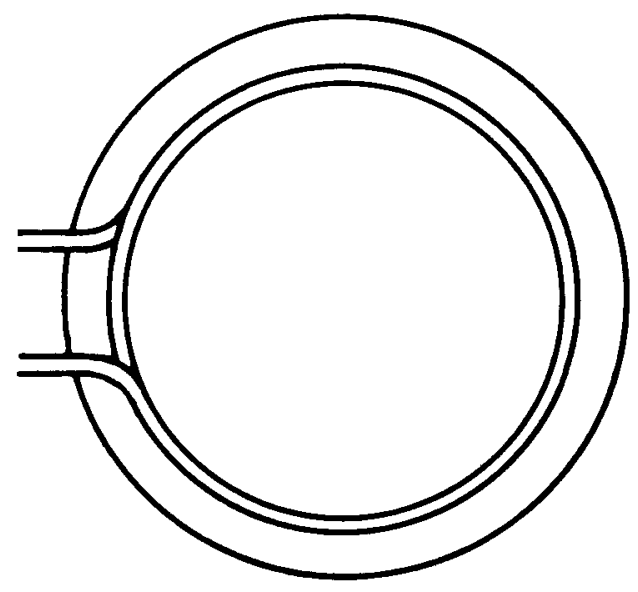

Top view

(b) Coil-in-tank type

Figure 4-1. Immersed-Coil Heat Exchanger Types 
particular parameter affects the heat exchanger effectiveness. These models simulate a collector-side heat exchanger since it is not as dependent on transients as is a load-side heat exchanger. Because of the previously discussed complications, this analysis addresses only a single horizontal tube.

In all three approaches, several basic relationships are used. The heat transfer by convection is given to be

$$
q(x)=h_{0} A \Delta T \text {, }
$$

where

$$
\mathrm{h}_{\mathrm{O}}=\mathrm{Nu} \frac{\mathrm{k}}{\mathrm{d}}
$$

and

$$
\mathrm{Nu}=\mathrm{C}(\mathrm{Ra})^{\mathrm{m}} \text {. }
$$

Therefore,

$$
q(x)=\frac{k A}{d} C(R a)^{m} \Delta T \text {. }
$$

Our final goal is to calculate the heat exchanger effectiveness $\varepsilon$ which is defined as

$$
\varepsilon=\frac{\left(\dot{\mathrm{m}} \mathrm{C}_{\mathrm{p}}\right)_{\mathrm{Hx}}\left(\mathrm{T}_{\mathrm{Hx}, \mathrm{i}}-\mathrm{T}_{\mathrm{Hx}, \mathrm{o}}\right)}{\left(\dot{\mathrm{m}} \mathrm{C}_{\mathrm{p}}\right)_{\min }\left(\mathrm{T}_{\mathrm{Hx}, \mathrm{i}}-\mathrm{T}_{\mathrm{S}}\right)},
$$

where the subscript $\mathrm{Hx}$ refers to the heat exchanger and the subscript min refers to the minimum capacitance. The tank is usually considered a much higher thermal capacitance, so

$$
\left.(\dot{\mathrm{m} C})_{\mathrm{p}}\right)_{\min }=\left(\dot{\mathrm{m} C} \mathrm{p}_{\mathrm{Hx}}\right.
$$

and

$$
\varepsilon=\frac{\left(\mathrm{T}_{\mathrm{Hx}, \mathrm{i}}-\mathrm{T}_{\mathrm{Hx}, \mathrm{o}}\right)}{\mathrm{T}_{\mathrm{Hx}, \mathrm{i}}-\mathrm{T}_{\mathrm{S}}} .
$$

\subsection{Mode1 I}

For the first model we assume that the heat transfer coefficient inside the tube is negligible, the tank is not stratified, the rate of temperature change within the tank is slow enough to consider it quasistatic, and the convective heat transfer coefficient along the tube can be represented by an average value.

An energy balance in differential form is

$$
\dot{m}_{p} \frac{d T(x)}{d x}=-h_{o} \pi d\left[T(x)-T_{S}\right]
$$

If

$$
\theta=T(x)-T_{S}
$$


and

$$
\mathrm{x}^{*}=\frac{\mathrm{x}}{\mathrm{L}}
$$

where $L$ is the heat exchanger length, then the energy balance becomes

Setting

$$
\frac{\partial \theta}{\partial \mathbf{x}^{*}}=-\left(\frac{\mathrm{h}_{\mathrm{o}} \mathrm{A}}{\dot{\mathrm{m}} \mathrm{C}_{\mathrm{p}}}\right) \theta \text {. }
$$

$$
R=\left(\frac{h_{0} A}{\dot{m} C_{p}}\right)^{-1}
$$

and assuming $h_{0}$ is constant along the tube $\left(h_{0}=\bar{h}_{0}\right)$ results in

$$
\theta=\theta_{0} e^{\left(\frac{-x^{*}}{R}\right)},
$$

where

$$
\theta_{\mathrm{o}}=\mathrm{T}_{\mathrm{Hx}, \mathrm{i}}-\mathrm{T}_{\mathrm{S}}
$$

As expected, these results show that the tube temperature decays exponentially along its length.

From the definition of $\theta$, at the heat exchanger outlet $(x=L),{ }_{L}$ is

$$
\theta_{\mathrm{L}}=\mathrm{T}_{\mathrm{Hx}, \mathrm{O}}-\mathrm{T}_{\mathrm{S}}
$$

or

$$
\mathrm{T}_{\mathrm{Hx}, \mathrm{O}}=\mathrm{T}_{\mathrm{S}}+{ }^{\theta} \mathrm{L} \cdot
$$

From the definition of $\varepsilon$,

$$
\varepsilon=\frac{T_{H x, i}-T_{H x, 0}}{T_{H x, i}-T_{S}}=\frac{T_{H x, i}-\left(T_{S}+\theta_{L}\right)}{\theta_{0}}
$$

or

$$
\varepsilon=\frac{\theta_{0}-\theta_{L}}{\theta_{0}}=1-\frac{\theta_{L}}{\theta_{0}} \text {, }
$$

where

$$
\theta_{L}=\left.\theta_{0} e^{-\frac{x^{*}}{R}}\right|_{x^{*}=1}=\theta_{0} e^{\frac{-1}{R}}
$$

Then the effectiveness becomes

$$
\varepsilon=1-e^{\left(\frac{-1}{R}\right)}
$$


or

$$
\varepsilon=1-e^{\left(\frac{-\bar{h}_{0} A}{\dot{m}_{\mathrm{p}}}\right)} .
$$

By properly integrating the heat transfer rate along the tube, it can be shown that

$$
\overline{\mathrm{Nu}}=\frac{\overline{\mathrm{h}}_{\mathrm{O}} \mathrm{L}}{\mathrm{k}} \mathrm{R}\left[1-\mathrm{e}^{\left(-\frac{1}{\mathrm{R}}\right)}\right] \text {. }
$$

In practice the heat transfer coefficient inside the tube is not negligible. This effect can be accounted for by using a correction factor in Eq. 4-7; the convective heat transfer coefficient $h_{0}$ is based on the pipe wall temperature $T_{W}$ and not a temperature of the fluid inside the pipe, $T(x)$. We define a temperature correction factor $F$, which is

$$
F=\frac{T_{w}(x)-T_{S}}{T(x)-T_{S}},
$$

the ratio of the temperature difference between the wall and the storage tank to the total temperature difference between the heat exchanger fluid and the storage tank. The effectiveness then becomes

$$
\varepsilon=1-e^{\left(\frac{-\bar{h}_{o} A F}{\dot{m}_{p}}\right)} \text {. }
$$

\subsection{Mode1 II}

Model II is similar to Model I except that it explicitly includes the dependence of the natural convective heat transfer coefficient on the difference between the local tube temperature and the bulk tank temperature. In Model I the natural convective heat transfer depends on the difference between the heat exchanger inlet temperature and the bulk storage tank temperature and does not account for the outside convective heat transfer coefficient varying along the tube.

As stated earlier, the local outside film coefficient has been found to fit the following equation:

$$
h_{0}=\frac{k}{d} C(R a)^{m} \text {. }
$$

For a given heat exchanger and specified water temperature, the Rayleigh number can be represented as

$$
\mathrm{Ra}=\mathrm{K}_{\mathrm{R}} \Delta \mathrm{T} \text {, }
$$

where $K_{R}$ encompasses the water properties, characteristic length, and constants:

$$
K_{R}=\frac{\rho^{2} \beta C_{p} g}{\mu k} d^{3},
$$


where the water properties are evaluated at the average tank temperature.

The convective heat transfer coefficient can be rewritten as

$$
\mathrm{h}_{\mathrm{o}}=\mathrm{K}(\Delta \mathrm{T})^{\mathrm{m}} \text {, }
$$

where

$$
\mathrm{K}=\mathrm{C} \frac{\mathrm{k}}{\mathrm{d}}\left(\mathrm{K}_{\mathrm{R}}\right)^{\mathrm{m}} \text {. }
$$

An energy balance along the tube results in

$$
-\dot{m} C_{p} \frac{d T(x)}{d x}=\pi d h_{o}\left[T(x)-T_{S}\right],
$$

or, substituting for $h_{0}$,

$$
-\dot{m} C_{p} \frac{d T(x)}{d x}=\pi d K\left[T(x)-T_{S}\right]^{m}\left[T(x)-T_{S}\right]
$$

Integrating with the boundary condition of $\mathrm{T}(\mathrm{x}=\mathrm{O})=\mathrm{T}_{\mathrm{Hx}, \mathrm{i}}$ results in

$$
\theta=\left(\theta_{0}-\mathrm{m}+\frac{\mathrm{mx} *}{\mathrm{R}^{*}}\right)^{\frac{-1}{\mathrm{~m}}},
$$

where

$$
\mathrm{x} *=\frac{\mathrm{x}}{\mathrm{L}}
$$

and

$$
R^{\prime}=\frac{\dot{m} C_{p}}{\pi d L} \cdot \frac{1}{K}
$$

Although this approach includes the temperature dependence of $h_{0}$, it assumes an infinite tube inside film coefficient, resulting in overpredicting the temperature drop down the tube and underpredicting $\theta$, the temperature difference between the tube and the tank. The additional resistance can be accounted for by incorporating the same correction factor for Model $I$ into Eq. 4-29. Therefore,

$$
\theta=F\left(\theta_{0}-\frac{F m x^{*}}{R^{\prime}}\right)^{\frac{-1}{m}} .
$$

The effectiveness can be determined from

$$
\varepsilon=1-\frac{{ }^{\theta} L}{\theta_{0}},
$$

which was derived earlier. In this case, 


$$
\varepsilon=1-\frac{\left(\theta_{0}-\mathrm{m}+\frac{F m}{R^{\top}}\right)^{\frac{-1}{m}}}{\theta_{0}} .
$$

\subsection{Model III--Finite Difference Model}

A simple, two-dimensional, steady-state finite difference model was developed that includes the inside film coefficient and the conductivity through the tube wall. Four radial nodes (centerline, inside tube wall, outside tube wall, and tank) and up to 50 axial nodes were used. Forward differencing equations for the nodes were solved iteratively. The tube wall was assumed adiabatic in the axial direction.

The effectiveness was calculated from the tank temperature and heat exchanger inlet and outlet temperatures using Eq. 4-6.

The overall Nusselt number based on the heat exchanger inlet temperature and storage tank temperature difference $\overline{\mathrm{Nu}}$ can be derived as

$$
\overline{\mathrm{Nu}}=\mathrm{R}^{\prime} \mathrm{C} \overline{\mathrm{Ra}} 1 / 4(1-\varepsilon),
$$

and is used to calculate the heat transfer as

$$
\mathrm{q}=\overline{\mathrm{Nu}} \frac{\mathrm{kA}}{\mathrm{D}} \theta_{\mathrm{O}} \text {. }
$$

We also began developing a more detailed model, which is discussed in Appendix C. The detailed model would allow us to determine the effect of heat exchanger geometry, such as varying tube spacing.

\subsection{Discussion of Models}

Parametric runs were made for Models I and III and variations of the base case. Table 4-1 gives the base case. Table 4-2 gives the ranges for each parameter and the resulting range of heat exchanger effectiveness. Figure 4-2 shows the parametric variations for Model III, the finite difference model, and Figure 4-3 shows the parametric variations for Model $I$.

The models were run, with various inputs, to compare them and to determine the effect of ignoring $h$ dependence on $x$ and assuming an infinite inside film coefficient. Table 4-3 shows the results of the comparisons. The effect of ignoring $h_{i}$ in Model III overpredicts the effectiveness by $16 \%$ from the base case, and ignoring the $x$ dependence of $h_{0}$ overpredicts it by only $8 \%$. The cumulative effect of ignoring both is overpredicting the effectiveness by $28 \%$.

Model I predicts the effectiveness of the heat exchanger within $1 \%$ of Model III if the inside convective heat transfer coefficient is set very high and the outside convective heat transfer coefficient does not vary along the tube. Model II, including the $x$ dependence of $h_{0}$ but ignoring $h_{i}$, predicts the effectiveness within $3 \%$ of the numerical model when $h_{i}$ is set very large in the latter. Model II can be used to predict the same performance as Model III by correctly choosing F. 
Table 4-1. Base Case

\begin{tabular}{lc}
\hline Parameter & Base-Case Value \\
\hline $\mathrm{L}$ & $9.1 \mathrm{~m}(30 \mathrm{ft})$ \\
$\mathrm{A}$ & $0.46 \mathrm{~m}^{2}\left(4.9 \mathrm{ft}^{2}\right)$ \\
$\mathrm{h}_{\mathrm{i}}$ & $2839 \mathrm{~W} / \mathrm{m}^{2}{ }^{\circ} \mathrm{C}\left(500 \mathrm{Btu} / \mathrm{h} \mathrm{ft}^{2} \mathrm{o} \mathrm{F}\right)$ \\
$\mathrm{T}_{\mathrm{Hx}, \mathrm{i}-\mathrm{T}_{\mathrm{S}}}$ & $11.1^{\circ} \mathrm{C}\left(20^{\circ} \mathrm{F}\right)$ \\
$\dot{\mathrm{m}}$ & $0.095 \mathrm{~kg} / \mathrm{s}(0.21 \mathrm{lb} / \mathrm{s})$ \\
Nodes & 30 \\
$\mathrm{~m}$ & 0.25 \\
$\mathrm{C}$ & 0.50 \\
\hline
\end{tabular}

Table 4-2. Parametric Variations ${ }^{a}$

\begin{tabular}{lcc}
\hline Parameter & Range & Effectiveness \\
\hline Base case & $0-61 \mathrm{~m}(0-200 \mathrm{ft})$ & 0.435 \\
$\mathrm{~L}$ & $0-3.04 \mathrm{~m}^{2}\left(0-32.7 \mathrm{ft}^{2}\right)$ & $0.0-0.951$ \\
$\mathrm{~A}$ & $0-5.678 \mathrm{E} 10 \mathrm{~W} / \mathrm{m}^{2}{ }^{\circ} \mathrm{C}$ & $0.0-0.951$ \\
$\mathrm{~h}_{\mathrm{i}}$ & $\left(0-1 \mathrm{E} 10 \mathrm{Btu} /{\mathrm{h}{ }^{\circ} \mathrm{F} \mathrm{tt}}^{2}\right)$ & $0.0-0.506$ \\
& $0^{\circ}-55.6^{\circ} \mathrm{C}\left(0^{\circ}-100^{\circ} \mathrm{F}\right)$ & $0.0-0.531$ \\
$\mathrm{~T}_{\mathrm{Hx}, \mathrm{i}-\mathrm{T}_{\mathrm{S}}}$ & $0-0.25 \mathrm{~kg} / \mathrm{s}(0-0.69 \mathrm{lb} / \mathrm{s})$ & $1-0.163$ \\
$\dot{\mathrm{m}}$ & $2-49$ & $0.598-0.435$ \\
Number of & $0.20-0.30$ & $0.282-0.592$ \\
nodes & $0.00-1.00$ & $0.0-0.595$ \\
$\mathrm{~m}$ & $\mathrm{C}$ &
\end{tabular}

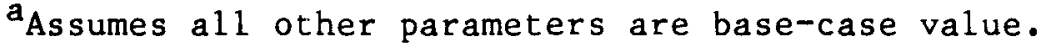




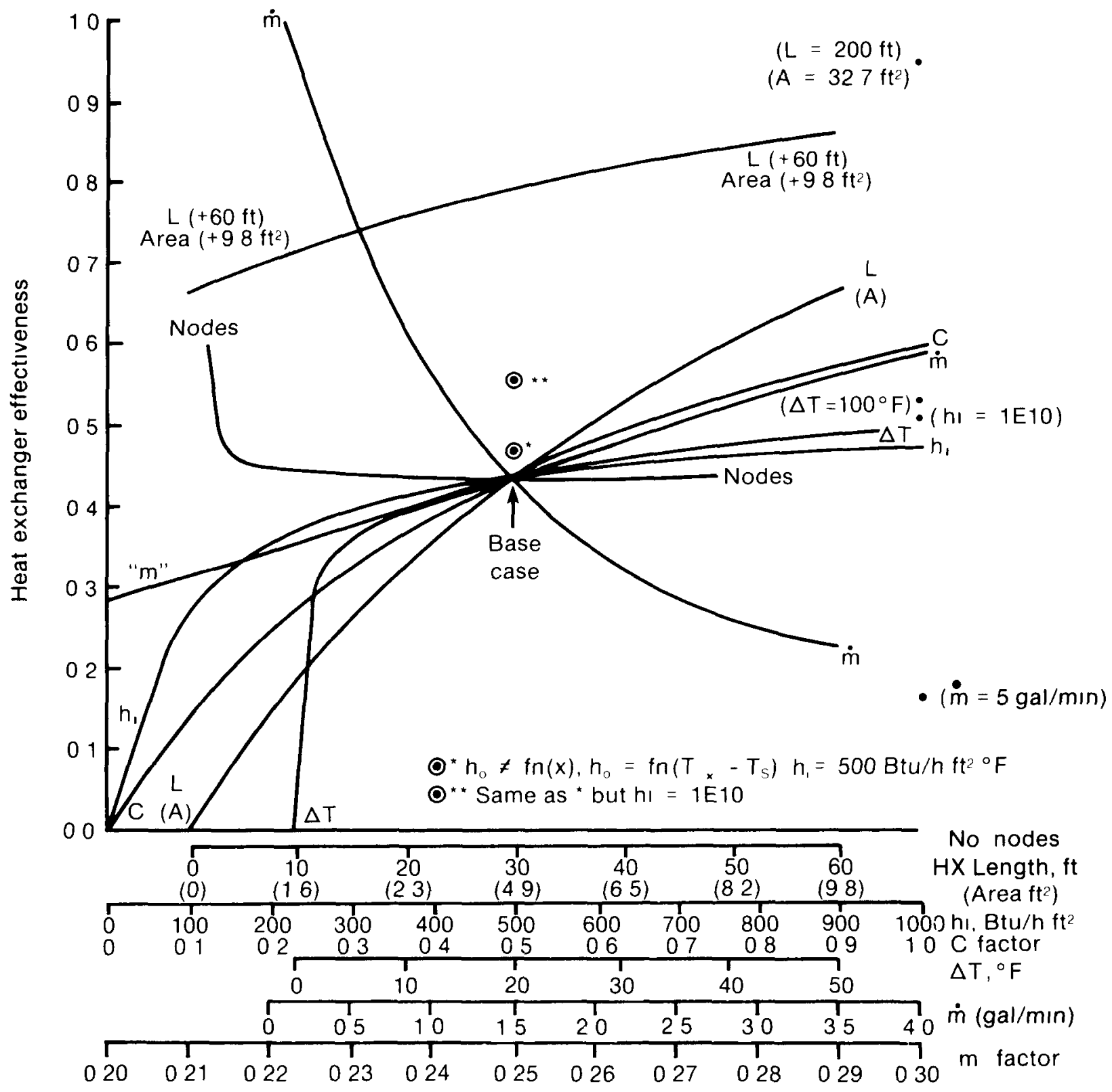

Figure 4-2. Finite Difference Model Parametric Variation for Immersed-Coil Heat Exchanger 


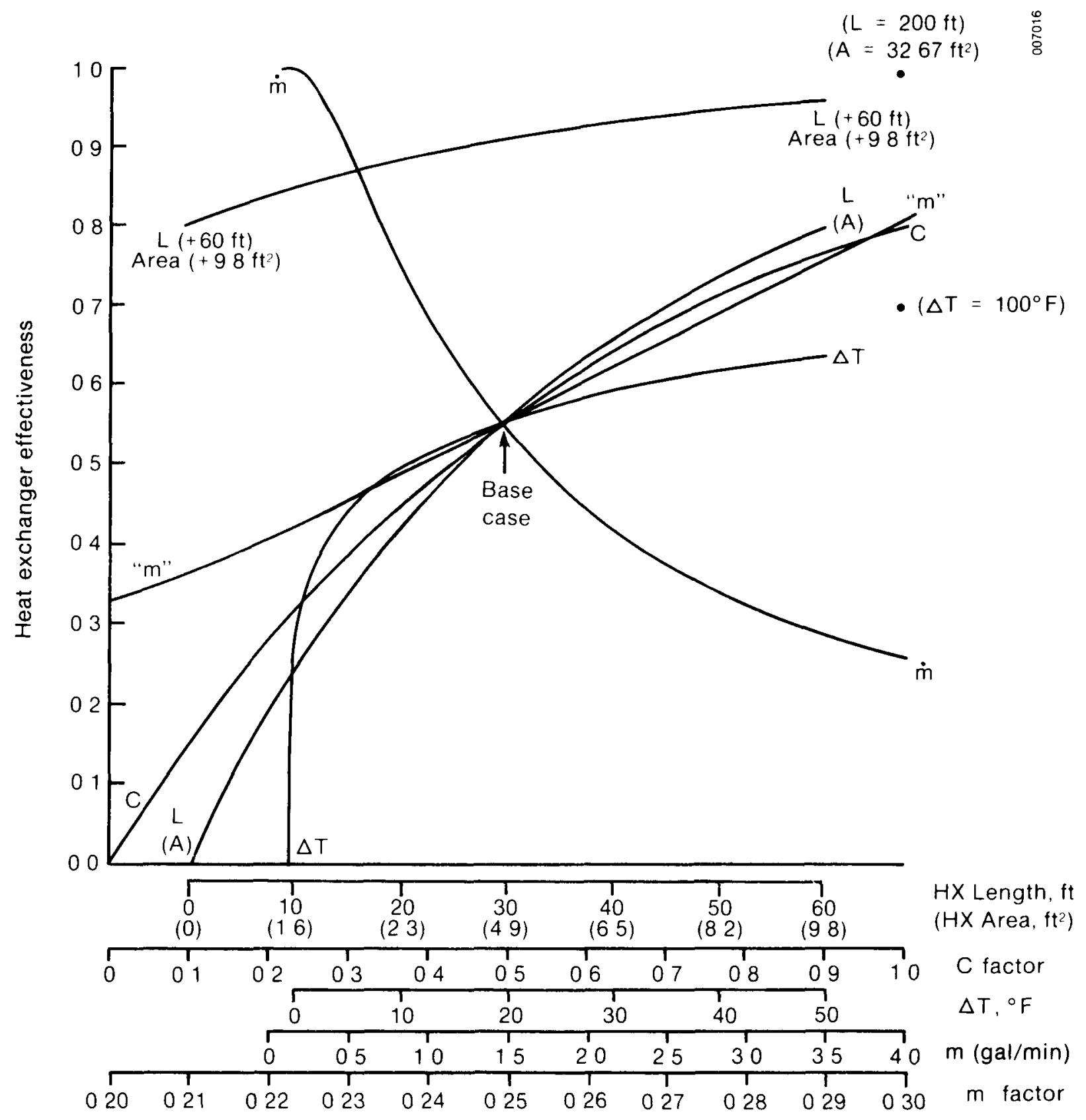

Figure 4-3. Parametric Variations for Immersed-Coil Heat Exchanger,

$$
\varepsilon=1-e^{-\left(\frac{\bar{h}_{o} A}{\operatorname{mC} C_{p}}\right)} \text {, using 1.2-cm }(1 / 2-i n .) \text { tube }
$$


Table 4-3. Comparisons of Models I, II, and III

\begin{tabular}{llc}
\hline \multicolumn{1}{c}{ Mode1 } & Effectiveness \\
\hline I & Base case, $h_{i}=\infty, h_{0} \neq f n(x)$ & 0.552 \\
II & Base case, $F=1.0,\left(h_{i}=\infty\right), h_{0}=f n(x)$ & 0.519 \\
& Base case, $F=1.15, h_{0}=f n(x)$ & 0.447 \\
III & Base case & 0.435 \\
& Base case, $h_{0} \neq f n(x)$ & 0.469 \\
& Base case, $h_{i}=\infty$ & 0.506 \\
& Base case, $h_{i}=\infty, h_{0} \neq f n(x)$ & 0.557
\end{tabular}

These models can be useful to predict the performance of immersed-coil heat exchangers if their assumptions are clearly understood and if the inputs are wel1-known. Most of the input parameters are well-known, with the exception of $C$ and $L$. The effective heat exchanger area (determined from $L$ ) is not easily determined because of complicated heat exchanger designs. Perhaps the most difficult input is $C$, which can range from 0.15 to 0.70 . This factor is used in the Nusselt-Rayleigh relationship:

$$
\mathrm{Nu}=\mathrm{C}(\mathrm{Ra})^{\mathrm{m}} \text {. }
$$

This equation empirically relates the heat transfer ( $\mathrm{Nu}$ ) and momentum ( $\mathrm{Ra}$ ) effects. Factors $\mathrm{C}$ and $\mathrm{m}$ are determined empirically, and factor $\mathrm{C}$ can vary greatly among heat exchanger geometries. For example, previous work at the University of Wisconsin (Feiereisen et a1. 1982) showed a range for the factor $C$ of 0.18 to 0.65 for various types of heat exchanger designs.

These models show the same general trends as our test results for flow rate and temperature difference variations. With these models, low temperature differences cause the effectiveness to drop more rapidly than our actual results.

\subsection{Comparison of Models with Experimental Results}

The critical aspect of any model is how well it compares with measured results. Our first comparison is with the smooth-coil heat exchanger since it did not have any extended surfaces ( $f$ ins) that complicate the heat transfer analysis. The comparisons are shown for a wide range of conditions in Table 4-4.

We used experimental results for the inputs where appropriate. In Model I we used the measured flow rate and an overall $\bar{h}_{0}$ based on the LMTD corrected for the temperature drop from the heat exchanger fluid to the heat exchanger wall. The temperature drop was calculated using the Petukhov-Popov correlation (Petukhov 1970). In Model II we used the measured flow rate, temperatures, and the $\mathrm{C}$ factor determined from the experimental results. In Model III, we used the measured flow rate, heat exchanger inlet temperature, storage 
tank temperature, and the $C$ factor calculated from the results as well as the same inside heat transfer convective coefficient used to calculate $\bar{h}_{0}$ from the experimental results.

Model III (the finite difference model) only slightly underpredicted the effectiveness while both Models I and II significantly overpredicted the performance if the pipe internal convective coefficient was neglected. However, when the proper temperature difference was used, the analytical results only slightly overpredicted the measured effectiveness. The results for the finite difference model, and for Models $I$ and II when $F$ was included, were all within the measurement uncertainty of the effectiveness (see Appendix A). For these results, we calculated $F$ to be the temperature drop from the heat exchanger fluid to the wall (using the Petukhov-Popov correlation) divided by the LMTD. Calculating $F$ without any experimental data would require detailed iterative computations.

We also compared Models I and II with the results of the SW bayonet heat exchanger. The particular test data chosen were the same as the data used for the uncertainty analysis in Appendix A. We did not compare these results to the finite difference model since that model did not incorporate heat transfer from extended surfaces. In this comparison we included the fin efficiency of the heat exchanger. Approximately $73 \%$ of the heat exchanger area was from the fins, which had an average efficiency of $80 \%$. This led to an effective heat transfer area that was $85.4 \%$ of the total heat exchanger area. The effects of correcting for the temperature drop between the heat exchanger fluid and the pipe wall and for the fin efficiency are shown in Table 4-5. Model I closely predicted the heat exchanger effectiveness while Model II overpredicted the effectiveness. 
Table 4-4. Comparison of Analytical Results to Measured Performance of Smooth-Coil Heat Exchanger

\begin{tabular}{|c|c|c|c|c|c|c|c|c|}
\hline \multirow[b]{2}{*}{$\begin{array}{l}\text { Flow Rate } \\
(\mathrm{L} / \mathrm{min})\end{array}$} & \multirow[b]{2}{*}{$\begin{array}{c}\mathrm{T}_{\mathrm{Hx}, \mathbf{i}}-\mathrm{T}_{\mathrm{S}} \\
\left({ }^{\mathrm{o}} \mathrm{C}\right)\end{array}$} & \multicolumn{4}{|c|}{ Effectiveness } & \multicolumn{3}{|c|}{ Effectiveness with $F$} \\
\hline & & Measured & Model I & Mode1 II & Mode1 III & $\mathrm{F}$ & Mode1 I & Mode 1 II \\
\hline 5 & 34.47 & 0.8494 & 0.9096 & 0.8977 & 0.8467 & 0.7997 & 0.8538 & 0.8528 \\
\hline 5 & 3.56 & 0.7232 & 0.7785 & 0.7686 & 0.7129 & 0.8690 & 0.7302 & 0.7274 \\
\hline 10 & 33.49 & 0.6920 & 0.7497 & 0.7443 & 0.6904 & 0.8603 & 0.6962 & 0.6985 \\
\hline 10 & 3.00 & 0.4983 & 0.5349 & 0.5313 & 0.4882 & 0.9201 & 0.5056 & 0.5046 \\
\hline 15 & 36.07 & 0.5850 & 0.6325 & 0.6298 & 0.5842 & 0.8895 & 0.5895 & 0.5915 \\
\hline 15 & 5.22 & 0.4229 & 0.4521 & 0.4487 & 0.4120 & 0.9320 & 0.4292 & 0.4275 \\
\hline
\end{tabular}

Table 4-5. Comparison of Measured and Predicted Effectiveness for Finned, Single-Wall Bayonet Heat Exchanger at $10 \mathrm{~L} / \mathrm{min}$

\begin{tabular}{ccccccc}
\hline $\begin{array}{c}\mathrm{T}_{\mathrm{Hx}, \mathrm{i}}-\mathrm{T}_{\mathrm{S}} \\
\left({ }^{\circ} \mathrm{C}\right)\end{array}$ & Measured & Model & $\begin{array}{c}\text { No } \\
\text { Corrections }\end{array}$ & $\begin{array}{c}\text { Temperature } \\
\text { Corrections Only }\end{array}$ & $\begin{array}{c}\text { Fin Efficiency } \\
\text { Corrections }\end{array}$ & $\begin{array}{c}\text { Both } \\
\text { Only }\end{array}$ \\
Corrections
\end{tabular}




\subsection{CONCLUSIONS AND RECOMMENDATIONS}

We have tested the performance of four different immersed heat exchangers over a wide range of conditions and have developed two analytical models and one simple numerical model.

We experimentally determined heat exchanger performance over a wide range of temperature differences at flow rates of 5,10 , and $15 \mathrm{~L} / \mathrm{min}(1.3,2.6$, and $4.0 \mathrm{gal} / \mathrm{min})$. The DW bayonet heat exchanger was the only heat exchanger we tested that had a consistently low effectiveness. The effectiveness of all of the heat exchangers we tested dropped rapidly at low temperature differences between the heat exchanger inlet and tank. This is a significant result since previous studies have shown the effectiveness to be relatively constant. The smooth-coil heat exchanger we built performed very well, nearly as well as a commercially available heat exchanger with twice the heat transfer area. The finned-spiral heat exchanger we built did not perform as well as we expected, probably because of the bubbles (from air coming out of the solution) that were trapped between the fins.

Low heat exchanger effectiveness can lead to inefficient and uneconomical operation. By equating the operating cost with the value of the collected energy, a simple expression for the minimum turn-off differential $\Delta T_{\text {off }}$ can be derived as

$$
\Delta T_{\text {off }}=Q_{p} C_{E^{N}}{ }_{A} / C_{A} \varepsilon \dot{m} C_{p},
$$

for a typical example, with

$$
\begin{aligned}
\mathrm{Q}_{\mathrm{p}} & =100 \mathrm{~W}, \text { pump power } \\
\mathrm{N}_{\mathrm{A}} & =80 \%, \text { auxiliary fuel efficiency } \\
\mathrm{C}_{\mathrm{E}} / \mathrm{C}_{\mathrm{A}} & =3 \text {, ratio of electric to natural gas costs } \\
\dot{\mathrm{m}} & =5 \mathrm{~L} / \mathrm{min}, \text { collector flow rate } \\
\mathrm{C}_{\mathrm{P}} & =3.4 \mathrm{~J} / \mathrm{g}{ }^{\circ} \mathrm{C}, \text { collector fluid specific heat } \\
\varepsilon & =0.2 \text {, heat exchanger effectiveness. }
\end{aligned}
$$

The minimum turn-off differential is $4.2^{\circ} \mathrm{C}\left(7.6^{\circ} \mathrm{F}\right)$, higher than specifications for the turn-off differential of many controllers. Operating below this point would be uneconomical since the value of the collected energy would be less than the cost to collect it. Systems with larger pumps would have higher turn-off differentials.

To accurately predict system performance, the actual flow rate and range of temperature differences must be known. The performance of the immersed heat exchangers is strongly dependent on flow and temperature differences at low temperature differences.

We developed two analytical models, a simple finite difference model and a detailed numerical model. There was good agreement between the methods as well as with experimental data if the internal film coefficient and fin efficiencies were properly included. 
Very important work remains to be done. It is important to know how performance of immersed heat exchangers is affected by scale deposits and what the long-term effectiveness is likely to be. We need to examine the possibility of stratifying tanks using low flow rates in collectors. Using flow rates as low as a tenth of those typically used, as suggested by the University of Wisconsin Solar Energy Laboratory and the National Bureau of Standards for direct systems, offers not only improved system performance but also the possibility of very simple control systems.

If designers need an average effectiveness, then we need to determine typical temperature differences for various system configurations and load patterns and the effect of using an average effectiveness. An hourly computer model should be run to determine the effect of varying effectiveness on system performance.

We have tested and modeled only supply-side immersed heat exchangers and need to examine load-side immersed heat exchangers. The effectiveness in a loadside heat exchanger is even more critical since it is a once-through heat exchanger. 


\subsection{REFERENCES}

Balcomb, D., 1982, "Stratification in Hot Water Tanks," LA-UR-82-423, Los Alamos, NM: Los Alamos National Laboratory.

Bergles, A., and R. Webb, Aug. 1985, "A Guide to the Literature on Convective Heat Transfer Augmentation," Advances in Enhanced Heat Transfer - 1985, ASME, HTD-Vol . 43 .

Chaffin, D. J., D. H. Vine, G. L. Askew, and F. C. Wessling, Sept. 1982, "Results of TVA Monitoring of Residential Solar Water Heaters," Proceedings of the Solar Hot Water Field Test Technical Review Meeting, July 14-15, Atlanta, GA: Energy Systems Group, Inc., p. 219.

Farouk, B., and S. I. Guceri, 1983, "Natural and Mixed Convection from Horizontal Cylinders in Interacting Flow Fields," Int. J. Heat Mass Transfer, Vo1. 26, No. 22, pp. 231-243.

Farrington, R. B., 1986, Test Results of Immersed-Coil Heat Exchangers and Liquid Storage Tanks Used in the Packaged Systems Program, SERI/TR-254-2841, Golden, CO: Solar Energy Research Institute.

Feiereisen, T., 1982, "An Experimental Study of Immersed Coil Heat Exchangers," Master's thesis, Madison, WI: University of Wisconsin.

Feiereisen, T., S. Klein, J. Duffie, and W. Beckman, 1982, "Heat Transfer from Immersed Coils," ASME 82-WA/So1-18, Madison, WI: University of Wisconsin.

Klett, D., D. Goswami, and M. Saad, Apr. 1983, "Thermal Performance of Submerged Coil Heat Exchangers Used in Solar Energy Storage Tanks," presented at ASME technical conference on commercial building heating and cooling applications, held $19 \mathrm{Apr}$. in Orlando, FL.

Kreith, F., 1973, Principles of Heat Transfer, NY: Intext Press, Inc.

McAdams, W., 1954, Heat Transmission, NY: McGraw-Hil1 Book Company, Inc.

Mumma, S. A., L. P. Milnarist, and J. M. Rodriguez-Anza, Dec. 1978, "Innovative Double Walled Heat Exchanger for Use in Solar Water Heating," presented at ASME conference on thermal storage and heat transfer in solar energy systems, held 10 Dec. in San Francisco, CA.

Petukhov, B. S., 1970, "Heat Transfer and Friction in Turbulent Pipe Flow with Variable Physical Properties," Advances in Heat Transfer, Vo1. 6, p. 503. 


\subsection{BIBLIOGRAPHY}

Al-Arabi, M., and M. Khamis, 1982, "Natural Convection Heat Transfer from Inclined Cylinders," Int. J. Heat Mass Transfer, Vol. 25, No. 1, pp. 3-15.

Buel1, J. C., and I. Catten, May 1983, "The Effect of Wall Conduction on the Stability of a Fluid in a Right Circular Cylinder Heated from Below," J. Heat Transfer, Vol. 105, pp. 255-260.

Chan, A., P. Smereka, and D. Giusti, Aug. 1983, "A Numerical Study of Transient Mixed Convection Flows in a Thermal Storage Tank," J. Solar Energy Engineering, Vol. 105, pp. 246-253.

Churchill, S., and H. Chu, 1975, "Correlating Equations for Laminar and Turbulent Free Convection from a Horizontal Cylinder," Int. J. Heat Mass Transfer, Vol. 18, pp. 1049-1053.

Cole, R., K. Nield, R. Rohde, and R. Wolosewicz, Jan. 1980, Design and Installation Manual for Thermal Energy Storage, 2nd edition, Argonne National Laboratory, ANL-79-15, Pp. 199-216.

DeSoto, L., 1983, "Laminar Free Convection around Horizontal Circular Cylinders," Int. J. Heat Mass Transfer, Vol. 26, 1977, pp. 1669-1677.

Fand, R. M., E. W. Morris, and M. Lum, 1977, "Natural Convection Heat Transfer from Horizontal Cylinders to Air, Water and Silicone Oils for Rayleigh Numbers between $3 \times 10^{2}$ and $2 \times 10^{7}, "$ Int. J. Heat Mass Transfer, Vo1. 20, pp. 1173-1184.

Farouk, B., and S. Guceri, 1982, "Natural and Mixed Convection Heat Transfer around a Horizontal Cylinder within Confining Walls," Numerical Heat Transfer, Vol. 5, 1983, pp. 329-341.

Farouk, B., and S. I. Guceri, 1983, "Natural Convection from Horizontal Cylinders in Interacting Flow Fields," Int. J. Heat Mass Transfer, Vol. 26, No. 2, pp. 231-243.

Federico, I., and F. Foraboschi, 1966, "A Contribution to the Study of Free Convection in a Fluid Layer Heated from Below," Int. J. Heat Mass Transfer, Vol. 9, pp. 1351-1360.

Feiereisen, T., S. Klein, J. Duffie, and W. Beckman, 1982, "Heat Transfer from Immersed Coils," ASME 82-WA/So1-18, Madison, WI: University of Wisconsin.

Forstom, R. J., and M. Spanow, 1967, "Experiments on the Buoyant Plume above a Heated Horizontal Wire," Int. J. Heat Mass Transfer, Vol. 10, pp. 321-331.

Fuji, T., 1963, "Theory of the Steady Laminar Natural Convection above a Horizontal Line Heat Source and a Point Heat Source," Int. J. Heat Mass Transfer, Vol. 6, pp. 597-606. 
Fuji, T., M. Fujii, and T. Matsunaga, 1979, "A Numerical Analysis of Laminar Free Convection around an Isothermal Horizontal Circular Cylinder," Numerical Heat Transfer, Vol. 2, pp. 329-344.

Gebhart, B., L. Pera, and A. W. Schorr, 1970, "Steady Laminar Natural Convection Plumes above a Horizontal Line Heat Source," Int. J. Heat Mass Transfer, Vol. 13, pp. 161-171.

Goswami, D., and D. Klett, 1983, "On Thermal Performance Testing of Compact Heat Exchangers for Low Temperature Solar Energy Systems," Greensboro, NC: North Carolina A\&T State University.

Gray, D., and A. Giorgini, 1976, "The Validity of the Boussinesq Approximation for Liquids and Gases," Int. J. Heat Mass Transfer, Vol. 19, pp. 545-551.

Heat Exchanger Design Handbook, Vol. 2, 1983, NY: Hemisphere Publishing Corp., PP. 2.5.7-20 to 2.5.7-23.

Holman, J., Heat Transfer, 4th edition, NY: McGraw-Hi11, Pp. 235-272.

Incropera, F., and M. Yaghoubi, Nov. 1979, "Free Convection Heat Transfer from Heated Cylinders Immersed in a Shallow Water Layer," J. Heat Transfer, 161.101 , pp. 743-745.

Jaluria, Y., Natural Convection Heat and Mass Transfer, NY: Pergamon Press.

Kamotani, Y., L. Wang, and S. Ostrach, "Natural Convection Heat Transfer in a Water Layer with Localized Heating from Below," Natural Convection in Enclosures, ASME, HTD-Vo1. 26, pp. 43-48.

Kays, W., and A. London, 1964, Compact Heat Exchangers, 2nd edition, NY: McGraw-Hi11.

Kern, D., 1950, Process Heat Transfer, NY: McGraw-Hil1, pp. 214-219.

Kuehn, T., and R. Goldstein, 1980, "Numerical Solution to the Navier-Stokes Equations for Laminar Natural Convection about a Horizontal Isothermal Circular Cylinder," Int. J. Heat Mass Transfer, Vo1. 23, pp. 971-979.

Kuiken, H. K., 1968, "Axisymmetric Free Convection Boundary-Layer Flow Past Slender Bodies," Int. J. Heat Mass Transfer, Vo1. 11, pp. 1141-1153.

Lauer, B., "How to Evaluate Film Coefficients for Heat Transfer Calculations," reprinted from The Oil and Gas Journal.

Lieberman, J., and B. Gebhart, 1969, "Interactions in Natural Convection from an Array of Heated Elements, Experimental," Int. J. Heat Mass Transfer, Vol. 12 , pp. 1385-1396.

Lin, Y.-S., and R. G. Akins, 1983, "An Experimental Study of Flow Patterns and Heat Transfer by Natural Convection inside Cubical Enclosures," Natural Convection in Enclosures - 1983, ASME, HTD-Vo1. 26, pp. 35-42. 
Marsters, G. F., 1972, "Arrays of Heated Horizontal Cylinders in Natural Convection," Int. J. Heat Mass Transfer, Vo1. 15, pp. 921-933.

McAdams, W., Heat Transmission, 3rd edition, NY: McGraw-Hil1, pp. 165-183, 272 .

Ostrach, S., 1982, "Natural Convection Heat Transfer in Cavities and Cells," Heat Transfer 1982, Proceedings of the 7th International Heat Transfer Conference, Vol. 1, NY: McGraw-Hi11, pp. 365-379.

Patankar, S., 1980, Numerical Heat Transfer and Fluid Flow, NY: Hemisphere.

Somerscales, E., and D. Dropkin, 1966, "Experimental Investigation of the Temperature Distribution in a Horizontal Layer of Fluid Heated from Below," Int. J. Heat Mass Transfer, Vol. 9, pp. 1189-1204.

Sparrow, E. M., and D. S. Boessneck, May 1983, "Effect of Transverse Misalignment on Natural Convection from a Pair of Parallel, Vertically Stacked, Horizontal Cylinders," J. Heat Transfer, Vol. 105, pp. 241-247.

Sparrow, E., D. Cook, and G. Chrysler, Feb. 1982, "Heat Transfer by Natural Convection from an Array of Short, Wall-Attached Horizontal Cylinders," J. Heat Transfer, Vol. 104, pp. 125-131.

Sparrow, E. M., and J. E. Niethammer, Nov. 1981, "Effect of Vertical Separation Distance and Cylinder-to-Cylinder Temperature Imbalance on Natural Convection for a Pair of Horizontal Cylinders," J. Heat Transfer, Vol. 103, pp. 638-644.

Sparrow, E., and C. Prakash, May 1980, "Enhancement of Natural Convection Heat Transfer by a Staggered Array of Discrete Vertical Plates," J. Heat Transfer, Vo1. 102, pp. 215-220.

Todd, J., and H. Ellis, Applied Heat Transfer, NY: Harper and Row, pp. 122139.

Vrentas, J., R. Narayanan, and S. Agrawa1, 1981, "Free Surface Convection in a Bounded Cylindrical Geometry," Int. J. Heat Mass Transfer, Vol. 24, pp. 1513-1529.

Warrington, R. O., Jr., and G. Crupper, Jr., Feb. 1981, "Natural Convection Heat Transfer between Cylindrical Tube Bundles and a Cubical Enclosure," J. Heat Transfer, Vol. 103, pp. 103-107. 


\section{APPENDIX A}

\section{MEASUREMENT UNCERTAINTY ANALYSIS}

\section{A.1 Sources of Heat Exchanger Test Measurement Error}

In a recent conference paper, Farrington (1986) discusses the procedure used for this measurement uncertainty analysis. Table A-1 lists sources of elemental error for measuring the effectiveness of an immersed heat exchanger. Within each category, the error sources are classified as to their nature, whether they cause scatter in the data (random or precision errors), or whether they cause fixed offsets in the data (systematic or bias errors).

The elemental errors were derived from various sources. When possible they were measured or derived from manufacturers' specifications. When this was not possible they were calculated or estimated using the best information available.

First, the sources of error in the calibration process were considered. These errors originated from the standards used to establish the known temperatures, the circulating liquid calibration baths in which the temperature sensors were calibrated, the instrumentation to measure the sensors during the calibration, self-heating errors in the sensors during calibration, etc. The errors that resulted from the curve-fitting process used with the calibration data to establish the polynomial expressions (used in the data acquisition computer to calculate temperatures from measuring the resistance of the sensors) are included in the data reduction category of errors.

Four-wire RTDs were used where possible to eliminate the effect of lead resistance. The RTD leads were short-circuited near the sensor to ensure that a proper four-wire measurement was being made.

The heat exchanger RTDs were about $1 \mathrm{~m}$ from the actual inlet and outlet of the heat exchanger. Although the sensor and pipe outlets were well-insulated, an energy balance showed that the temperature of the fluid dropped about $0.010 \mathrm{~K}$ at a flow rate of $5 \mathrm{~L} / \mathrm{min}$ and dropped about $0.003 \mathrm{~K}$ at $15 \mathrm{~L} / \mathrm{min}$. This was a systematic error that was always negative. Since these errors were in the same direction, they canceled for calculation of the heat transfer from the heat exchanger and in the numerator of the effectiveness calculation. Stainless-steel, sheathed RTDs $30 \mathrm{~cm}$ long and $0.3 \mathrm{~cm}$ in diameter were immersed directly into the center of and parallel to the fluid stream using tees. They were well-insulated to minimize conduction losses along the sheath and to the supporting structure.

Very small thermistors with a very short time constant (measured as $18 \mathrm{~ms}$ using the plunge into water technique) to avoid disturbing the convective flow and allowing detection of very rapid changes in the convective currents were used to measure the tank temperature.

The thermistors were provided with $2-\mathrm{m}$ leads calibrated by the manufacturer. The tank temperature thermistor had a $2-\mathrm{m}$ lead resistance of $46.79 \Omega$ and a 
Table A-1. Elemental Errors (mK)

\begin{tabular}{|c|c|c|c|}
\hline Error Sources & Systematic & Random & $\begin{array}{l}\text { Degrees of } \\
\text { Freedom }\end{array}$ \\
\hline \multicolumn{4}{|l|}{ Calibration } \\
\hline Triple point of water & \pm 0.2 & & \\
\hline $\begin{array}{l}\text { Reproducibility in } \\
\text { DQT calibration }\end{array}$ & $-0,+1.0$ & & \\
\hline $\begin{array}{l}\text { DQT calibration } \\
\text { resolution }\end{array}$ & \pm 0.5 & & \\
\hline DQT stability & \pm 10.0 & & \\
\hline $\begin{array}{l}\text { DQT linearity and } \\
\text { hysteresis }\end{array}$ & \pm 16.0 & & \\
\hline Bath stability & \pm 3.0 & & \\
\hline Bath gradients & \pm 3.0 & & \\
\hline $\begin{array}{l}\text { RTD resistance } \\
\text { measurement }\end{array}$ & \pm 12.5 & \pm 3.8 & $>30$ \\
\hline RTD stem conductance & \pm 5.0 & & \\
\hline RTD self-heating & \pm 0.1 & & \\
\hline DVM $^{* *}$ thermal EMFs & \pm 2.5 & & \\
\hline $\begin{array}{l}\text { Thermistor, factory } \\
\text { calibration }\end{array}$ & \pm 100.0 & & \\
\hline Thermocouple, $\mathrm{T}_{\mathrm{a}}$ & \pm 100.0 & & \\
\hline Flowmeter calibration & $\pm 0.05 \%$ & & \\
\hline \multicolumn{4}{|l|}{ Acquisition } \\
\hline \multicolumn{4}{|l|}{ RTD: } \\
\hline $\begin{array}{l}\text { DVM, 4-wire ohms } \\
\text { Self-heating } \\
\text { Stability }\end{array}$ & $\begin{aligned} & \pm 3.2 \\
& \pm 0.1 \\
& \pm 125.0\end{aligned}$ & \pm 0.9 & $>30$ \\
\hline Repeatability & & \pm 5.0 & $>30$ \\
\hline Installation & -10.0 & & \\
\hline \multicolumn{4}{|l|}{ Thermistors: } \\
\hline $\begin{array}{l}\text { DVM, 2-wire ohms } \\
\text { Self-heating } \\
\text { stability }\end{array}$ & $\begin{array}{c} \pm 7.0 \\
-0, \quad+170.0 \\
\pm 25.0\end{array}$ & \pm 0.1 & $>30$ \\
\hline Repeatability & & \pm 5.0 & $>30$ \\
\hline $\begin{array}{l}\text { Temp. effects of } \\
\text { lead resistance }\end{array}$ & \pm 0.1 & & \\
\hline Thermocouple, $\mathrm{T}_{\mathrm{a}}$ & \pm 100.0 & \pm 1.0 & \\
\hline \multicolumn{4}{|l|}{ Flowmeter: } \\
\hline Stability & $\pm 0.5 \%$ & & \\
\hline Repeatability & & $\pm 0.20 \%$ & $>30$ \\
\hline $\begin{array}{l}\text { Temperature effects } \\
\text { Frequency measurement }\end{array}$ & $\begin{array}{l}\text { negligible } \\
\pm 0.1 \%\end{array}$ & $\pm 0.1 \%$ & $>30$ \\
\hline
\end{tabular}


Table A-1. Elemental Errors (mK) (Concluded)

\begin{tabular}{lccc}
\hline Error Sources & Systematic & Random & $\begin{array}{c}\text { Degrees of } \\
\text { Freedom }\end{array}$ \\
\hline $\begin{array}{l}\text { Reduction } \\
\text { RT curve fitting to } \\
\text { calibration data } \\
\quad \text { (worst residual) }\end{array}$ & \pm 2.1 & \\
$\begin{array}{l}\text { Computation of } \\
\text { temperature } \\
\text { from polynomial }\end{array}$ & & \\
$\begin{array}{l}\text { Curve fitting Ta } \\
\text { Curve fitting flow rate }\end{array}$ & \pm 50.0 & & \\
\hline
\end{tabular}

*DQT, HP 2804A digital quartz thermometer.

*DVM, HP 3056A digital voltmeter.

resistance from additional leads of $3.40 \Omega$. The lead resistance was accounted for in the data acquisition program. The change in resistance of the leads, because of varying temperature of the environment, was less than $1 \mathrm{mK}$.

\section{A.2 Uncertainty Calculations and Results}

Theoretically, only three sensors are required to determine the effectiveness of an immersed heat exchanger: sensors measuring the temperature of the fluid entering the heat exchanger, the temperature of the fluid leaving the heat exchanger, and the temperature of the tank.

The effectiveness for an immersed heat exchanger is

$$
\begin{aligned}
\varepsilon & =\frac{\text { actual heat transfer }}{\text { theoretical max. heat transfer }} \\
& =\frac{\left(\dot{\mathrm{m}} \mathrm{C}_{\mathrm{p}}\right)_{\mathrm{Hx}}\left(\mathrm{T}_{\mathrm{Hx}, \mathrm{i}}-\mathrm{T}_{\mathrm{Hx}, \mathrm{o}}\right)}{\left(\dot{\mathrm{m}} \mathrm{C}_{\mathrm{p}}\right)_{\min }\left(\mathrm{T}_{\mathrm{Hx}, \mathrm{i}}-\mathrm{T}_{\mathrm{S}}\right)} .
\end{aligned}
$$

The minimum heat capacitance $\left(\dot{\mathrm{m}} \mathrm{C}_{\mathrm{p}}\right)_{\min }$ is on the heat exchanger side and, hence, equal to $\left(\dot{m} c_{p}\right)_{H x}$ since the storage tank has a very large thermal capacitance. $\quad \mathrm{T}_{\mathrm{Hx}}, \mathrm{i}$ is the temperature of the fluid entering the heat exchanger, $\mathrm{T}_{\mathrm{Hx}, \mathrm{O}}$ is the temperature of the fluid leaving the heat exchanger, and $\mathrm{T}_{\mathrm{S}}$ is the tank temperature. The fluid in the tank was well-mixed throughout the tests since it was heated from the bottom. Therefore, Eq. A-2 is written as

$$
\varepsilon=\frac{T_{H x, i}-T_{H x, o}}{T_{H x, i}-T_{S}} .
$$

The total systematic error is 


$$
\mathrm{B}_{\varepsilon}=\left[\left(\frac{\partial \varepsilon}{\partial \mathrm{T}_{\mathrm{Hx}, 0}} \mathrm{~B}_{\mathrm{Hx}, \mathrm{o}}\right)^{2}+\left(\frac{\partial \varepsilon}{\partial \mathrm{T}_{\mathrm{Hx}, \mathrm{i}}} \mathrm{B}_{\mathrm{Hx}, \mathrm{i}}\right)^{2}+\left(\frac{\partial \varepsilon}{\partial \mathrm{T}_{\mathrm{S}}} \mathrm{B}_{\mathrm{S}}\right)^{2}\right]^{1 / 2}, \quad(\mathrm{~A}-3)
$$

which equals

$$
\begin{aligned}
\mathrm{B}_{\varepsilon}= & \left\{\left(\frac{1}{\mathrm{~T}_{\mathrm{Hx}, \mathrm{i}}-\mathrm{T}_{\mathrm{S}}}\right)^{2} \mathrm{~B}_{\mathrm{T}_{\mathrm{Hx}, \mathrm{o}}}^{2}+\left[\frac{\mathrm{T}_{\mathrm{Hx}, \mathrm{o}}-\mathrm{T}_{\mathrm{S}}}{\left(\mathrm{T}_{\mathrm{Hx}, \mathrm{i}}-\mathrm{T}_{\mathrm{S}}\right)^{2}}\right]{ }^{2} \mathrm{~B}_{\mathrm{T}_{\mathrm{Hx}, \mathrm{i}}}\right. \\
& +\left[\frac{\mathrm{T}_{\mathrm{Hx}, \mathrm{i}}-\mathrm{T}_{\mathrm{Hx}, \mathrm{o}}}{\left(\mathrm{T}_{\mathrm{Hx}, \mathrm{i}}-\mathrm{T}_{\mathrm{S}}\right)^{2}}\right]{ }_{\mathrm{B}_{\mathrm{S}}}^{2} \mathrm{~T}^{2},
\end{aligned}
$$

where the Bs are the total systematic errors for that measurement. The same equation is used to calculate the total random error for the heat exchanger effectiveness except that the individual random measurement errors $R_{J}$ are used instead of $B_{J}$.

Properly combining the uncertainties (including using methods of combining large and small errors) from each elemental source of error leads to the results shown in Table $A-2$.

The uncertainties need to be calculated for the total positive systematic error and the total negative systematic error (since these are some asymmetrical systematic errors) as well as the total random error. After that the two types of errors are combined. For a high temperature difference between the SW bayonet heat exchanger inlet and tank, the following conditions existed during the test:

$$
\begin{aligned}
\dot{\mathrm{m}} & =0.164 \mathrm{~kg} / \mathrm{s}(9.85 \mathrm{~L} / \mathrm{min}) \\
\mathrm{T}_{\mathrm{S}} & =30.80^{\circ} \mathrm{C} \\
\mathrm{T}_{\mathrm{Hx}, \mathrm{i}} & =69.68^{\circ} \mathrm{C} \\
\mathrm{T}_{\mathrm{Hx}, 0} & =48.43^{\circ} \mathrm{C}
\end{aligned}
$$

Table A-2. Total Sensor Measurement Uncertainty (mK)

\begin{tabular}{lcc}
\hline \multicolumn{1}{c}{ Measurement } & Bias Limit & $\begin{array}{c}\text { Random } \\
\text { Uncertainty }\end{array}$ \\
\hline $\begin{array}{l}\text { Heat Exchanger } \\
\text { inlet temperature }\end{array}$ & \pm 173.7 & \pm 8.1 \\
Heat Exchanger & & \\
$\quad$ out let temperature & \pm 173.7 & \pm 8.1 \\
Tank temperature & $+295.1,-125.2$ & \pm 5.0 \\
Ambient temperature & \pm 150 & \pm 1.0 \\
Flow rate & $\pm 0.59 \%$ & $\pm 0.22 \%$ \\
\hline
\end{tabular}




$$
\begin{aligned}
\mathrm{UA}_{\mathrm{Hx}} & =543.7 \mathrm{~W} /{ }^{\circ} \mathrm{C} \\
\mathrm{q} & =14,610 \mathrm{~W} \\
\varepsilon & =54.65 \% .
\end{aligned}
$$

These values are put into $\mathrm{Eq} . \mathrm{A}-4$, which results in

$$
\mathrm{B}_{\varepsilon}=\left(0.000662 \mathrm{~B}_{\mathrm{T}_{\mathrm{Hx}, 0}^{2}}^{2}+0.000136 \mathrm{~B}_{\mathrm{T}_{\mathrm{Hx}, \mathrm{i}}^{2}}^{2}+0.000198 \mathrm{~B}_{\mathrm{T}_{\mathrm{S}}}^{2}\right)^{1 / 2} . \quad(\mathrm{A}-5)
$$

It is clear that at these conditions the accuracy of $T_{H x, o}$ is more important than the other two temperatures and would be the first one to improve if higher accuracies were required. This basic equation is used to calculate both systematic errors (positive and negative) and the random error. The sensor uncertainties from Table A-2 are used in Eq. A-5 to give

$$
\begin{aligned}
\mathrm{B}_{\varepsilon}^{+} & =\left[\left(19.97 \times 10^{-6}\right)+\left(4.10 \times 10^{-6}\right)+\left(17.24 \times 10^{-6}\right)\right]^{1 / 2} \\
& =0.0064 .
\end{aligned}
$$

It is quite clear that the uncertainties associated with $\mathrm{T}_{\mathrm{Hx}}, \mathrm{o}$ and $\mathrm{T}_{\mathrm{S}}$ are the greatest contributors to the overall uncertainty for the total positive systematic error.

The same procedure is followed for the total negative systematic error, which leads to

$$
\mathrm{B}_{\varepsilon}^{-}=0.0052 \text {, }
$$

and for the total random error, which leads to

$$
\mathrm{R}_{\varepsilon}= \pm 0.0002 \text {. }
$$

The largest contributor to both $\mathrm{B}_{\varepsilon}^{-}$and $\mathrm{R}_{\varepsilon}$ is $\mathrm{T}_{\mathrm{Hx}}, 0^{\circ}$. It is important to realize that the systematic errors are much larger than the random errors.

At this point the different types of errors are combined to get

$$
\begin{aligned}
& U_{95}^{+}=\left[(0.0064)^{2}+\frac{(1.96)(0.0002)^{2}}{1}\right]^{1 / 2}=+0.0064 \\
& U_{95}^{+}=\left[(-0.0052)^{2}+\frac{(1.96)(0.0002)^{2}}{1}\right]^{1 / 2}=-0.0052
\end{aligned}
$$

for $\mathrm{U}_{95}$ and

$$
\begin{aligned}
& U_{99}^{+}=0.0064+\frac{(1.96)(0.0002)}{1}=+0.0068 \\
& {U_{99}^{-}}^{-}=-0.0052-\frac{(1.96)(0.0002)}{1}=-0.0056
\end{aligned}
$$

for $\mathrm{U}_{99}$. For this example the overall uncertainty using $\mathrm{U}_{95}$ is

$$
\varepsilon=0.5465+0.0064,-0.0052,
$$


or an error range from $-1.0 \%$ to $+1.2 \%$. The error range using $U_{99}$ is also $-1.0 \%$ to $+1.2 \%$.

Higher errors would be expected at smaller temperature differences. For a low temperature difference between the SW bayonet heat exchanger inlet and tank, the following conditions existed during the testing:

$$
\begin{aligned}
\dot{\mathrm{m}} & =0.165 \mathrm{~kg} / \mathrm{s}(9.89 \mathrm{~L} / \mathrm{min}) \\
\mathrm{T}_{\mathrm{S}} & =55.40^{\circ} \mathrm{C} \\
\mathrm{T}_{\mathrm{Hx}, \mathrm{i}} & =60.37^{\circ} \mathrm{C} \\
\mathrm{T}_{\mathrm{Hx}, \mathrm{o}} & =58.67^{\circ} \mathrm{C} \\
\mathrm{UA}_{\mathrm{Hx}} & =290.2 \mathrm{~W} /{ }^{\circ} \mathrm{C} \\
\mathrm{q} & =1176 \mathrm{~W} \\
\varepsilon & =34.33 \% .
\end{aligned}
$$

When these values are put into Eq. A-4, the result is

$$
\mathrm{B}_{\varepsilon}=\left(0.04048 \mathrm{~B}_{\mathrm{T}_{\mathrm{Hx}, \mathrm{O}}}^{2}+0.01753 \mathrm{~B}_{\mathrm{T}_{\mathrm{Hx}, \mathrm{i}}^{2}}^{2}+0.00474 \mathrm{~B}_{\mathrm{T}_{\mathrm{S}}}^{2}\right)^{1 / 2} . \quad(\mathrm{A}-14)
$$

At the low temperature differences, the accuracy of $\mathrm{T}_{\mathrm{Hx}}, \mathrm{O}$ is the most important contributor for both the systematic and random errors. Following the same procedures as before, the results are

$$
\begin{aligned}
B_{\varepsilon}^{+} & =+0.0465 \\
B_{\varepsilon}^{-} & =-0.0427 \\
R & = \pm 0.0020
\end{aligned}
$$

and

$$
\begin{aligned}
& U_{95}=+0.0466,-0.0428 \\
& U_{99}=+0.0504,-0.0466 .
\end{aligned}
$$

This leads to the result that the overall uncertainty using $U_{95}$ ranges from $-12.5 \%$ to $+13.6 \%$ of the measured effectiveness. The uncertainty range increases using $U_{99}$, ranging from $-13.6 \%$ to $+14.7 \%$ of the measured effectiveness. This higher uncertainty is expected at the lower temperature difference since the sensor error is a larger fraction of the temperature differences.

However, for back-to-back tests and comparisons the systematic error cancels and the uncertainty is $t_{95} R$, which is equal to \pm 0.0004 or $\pm 0.1 \%$ for the first example and \pm 0.004 or $\pm 1.2 \%$ for the second example.

The heat transfer was calculated from

$$
\mathrm{q}=\left(\dot{\mathrm{mC}} \mathrm{p}_{\mathrm{Hx}}\left(\mathrm{T}_{\mathrm{Hx}, \mathrm{i}}-\mathrm{T}_{\mathrm{Hx}, \mathrm{o}}\right)\right.
$$


The total systematic error of the calculated heat transfer is

$$
\mathrm{B}_{\mathrm{q}}=\dot{\mathrm{m}} \mathrm{C}_{\mathrm{p}}\left\{\left[\frac{\left(\mathrm{T}_{\mathrm{Hx}, \mathrm{i}}-\mathrm{T}_{\mathrm{Hx}, \mathrm{o}}\right)}{\dot{\mathrm{m}}}\right]_{\mathrm{m}}{ }_{\mathrm{m}}^{2}+\mathrm{B}_{\mathrm{T}_{\mathrm{Hxi}}}^{2}+\mathrm{B}_{\mathrm{T}_{\mathrm{Hx}, \mathrm{o}}}^{2}\right\}^{1 / 2},
$$

which assumes negligible error in calculating the heat capacity of water, as was done for the other calculations.

The heat exchanger UA was calculated from

$$
(\mathrm{UA})_{\mathrm{Hx}}=\left(\dot{\mathrm{mC}}_{\mathrm{p}}\right)_{\mathrm{Hx}} \ln \left(\frac{\mathrm{T}_{\mathrm{Hx}, \mathrm{i}}-\mathrm{T}_{\mathrm{S}}}{\mathrm{T}_{\mathrm{Hx}, \mathrm{o}}-\mathrm{T}_{\mathrm{S}}}\right) \text {. }
$$

The total systematic error of the heat exchanger UA is

$$
\begin{aligned}
& \mathrm{B}(\mathrm{UA})_{\mathrm{Hx}}=\dot{\mathrm{m} C} \mathrm{p}\left\{\left[\frac{1}{\dot{m}} \ln \left(\frac{\mathrm{T}_{\mathrm{Hx}, \mathrm{i}}-\mathrm{T}_{\mathrm{S}}}{\mathrm{T}_{\mathrm{Hx}, \mathrm{o}}-\mathrm{T}_{\mathrm{S}}^{\mathrm{r}}}\right) \mathrm{B}_{\dot{\mathrm{m}}}\right] 2+\left(\frac{-1}{\mathrm{~T}_{\mathrm{Hx}, \mathrm{i}}-\mathrm{T}_{\mathrm{S}}} \mathrm{B}_{\mathrm{Hx}, \mathrm{i}}\right)^{2}\right. \\
& \left.+\left(\frac{1}{\mathrm{~T}_{\mathrm{Hx}, \mathrm{O}}-\mathrm{T}_{\mathrm{S}}} \mathrm{B}_{\mathrm{T}}, \mathrm{o}\right)^{2}+\left(\frac{1}{\mathrm{~T}_{\mathrm{Hx}, \mathrm{i}}-\mathrm{T}_{\mathrm{S}}}-\frac{1}{\mathrm{~T}_{\mathrm{Hx}, \mathrm{O}}-\mathrm{T}_{\mathrm{S}}}\right)^{2} \mathrm{~B}_{\mathrm{T}}^{2}\right\}^{1 / 2} \text {. }
\end{aligned}
$$

A summary of the bias limits (or systematic error) and random errors is given in Table A-3 for the effectiveness, heat transfer, and UA for both the high and low temperature difference cases. A summary of the total measurement error for both cases is given in Table A-4 for each calculated quantity.

Since our final systematic errors were asymmetrical, we calculated positive and negative uncertainties. These results state that the actual effectiveness should rarely be beyond these uncertainty limits. It also shows to what extent the heat exchanger effectiveness can be measured confidently. Changes in heat exchanger effectiveness of $0.1 \%$ to $1 \%$, which is the random uncertainty component of the result, can be measured if the instrumentation is not altered

\begin{tabular}{|c|c|c|c|c|}
\hline \multirow{2}{*}{ Quantity } & \multicolumn{2}{|c|}{ High $\Delta \mathrm{T}$} & \multicolumn{2}{|c|}{ Low $\Delta \mathrm{T}$} \\
\hline & Bias Limit & Random Error & Bias Limit & Random Error \\
\hline$\varepsilon$ & $-0.0052,+0.0064$ & \pm 0.0002 & $-0.0427,+0.0465$ & \pm 0.0020 \\
\hline$q(w)$ & \pm 189.33 & \pm 33.04 & \pm 10.52 & \pm 8.32 \\
\hline $\mathrm{UA}_{\mathrm{Hx}}\left(\mathrm{w} /{ }^{\circ} \mathrm{C}\right)$ & $-8.52,+10.24$ & \pm 1.2 & $-44.87,+48.85$ & \pm 2.2 \\
\hline
\end{tabular}
(sensors untouched, digital voltmeter [DVM] left on, same environmental conditions, etc.).

Table A-3. Summary of Bias Limits and Random Errors 
Table A-4. Measurement Uncertalaty Sumary

\begin{tabular}{|c|c|c|c|c|c|c|}
\hline \multirow{2}{*}{ Quant1ty } & \multicolumn{3}{|c|}{$\mathrm{H} 1 \mathrm{gh} \Delta \mathrm{T}$} & \multicolumn{3}{|c|}{ Low $\Delta \mathrm{T}$} \\
\hline & Value & $\mathrm{U}_{95}$ & $\mathrm{U}_{99}$ & Value & $\mathrm{U}_{95}$ & $\mathrm{U}_{99}$ \\
\hline$\varepsilon$ & 0.5465 & $\begin{array}{c}-0.0052,+0.0064 \\
-1.0 \% \text { to }+1.2 \%\end{array}$ & $\begin{array}{c}-0.0056,+0.0068 \\
-1 \% \text { to }+1.2 \%\end{array}$ & 0.3433 & $\begin{array}{l}-0.0428,+0.0466 \\
-12.5 \% \text { to }+13.6 \%\end{array}$ & $\begin{array}{l}-0.0466,+0.0504 \\
-13.6 \% \text { to }+14.7 \%\end{array}$ \\
\hline$q(W)$ & 14,610 & $\begin{array}{l} \pm 200.1 \\
\pm 1.4 \%\end{array}$ & $\begin{array}{l} \pm 254.1 \\
\pm 1.7 \%\end{array}$ & 1,176 & $\begin{array}{l} \pm 19.4 \\
\pm 1.7 \%\end{array}$ & $\begin{array}{l} \pm 26.8 \\
\pm 2.3 \%\end{array}$ \\
\hline$(\mathrm{UA})_{\mathrm{Hx}}\left(\mathrm{W} /{ }^{\circ} \mathrm{C}\right)$ & 543.7 & $\begin{array}{c}-9.1,+10.7 \\
-1.7 \% \text { to }+2.0 \%\end{array}$ & $\begin{array}{c}-11.0,+12.7 \\
-2.0 \% \text { to }+2.3 \%\end{array}$ & 290.2 & $\begin{array}{c}-45.1,+49.0 \\
-15.5 \% \text { to }+16.9 \%\end{array}$ & $\begin{array}{c}-49.13,+53.11 \\
-16.9 \% \text { to }+18.3 \%\end{array}$ \\
\hline
\end{tabular}


An end-to-end analysis of the measurement system was conducted using two digital quartz thermometer probes as reference temperatures in a stirred icebath. The results were checked against systematic errors determined in the pretest analysis. The measurement system showed the response of $\mathrm{T}_{\mathrm{Hx}} \mathrm{i}$ to be $0.023 \mathrm{~K}$ below and $\mathrm{T}_{\mathrm{Hx}, \mathrm{O}}$ to be equal to the digital quartz thermometers near the ice point of water. Each sensor had 100 consecutive readings taken to determine the random error of the measurement system for that sensor. The random error was $2.3 \mathrm{mK}$ for the heat exchange inlet RTD, $2.2 \mathrm{mK}$ for the heat exchanger outlet RTD, and $0.7 \mathrm{mK}$ for the tank thermistor. These results show that the errors are well within the expected range of errors. However, the end-to-end check includes some built-in systematic errors in the standards that could not be determined. The results of the end-to-end check are well within the detailed calculations and are a necessary and useful check to show that there were not any gross errors in the experiment or uncertainty analysis.

Sensor failure, including severe degradation or catastrophic failure, will cause the result to exceed the uncertainty limits. In addition, the measurements must be in the proper location.

This uncertainty analysis was useful in detecting unsteady sensors and channels, increasing confidence in the results, and permitting others to make meaningful decisions by knowing the range of possible errors in the data.

\section{A.3 References}

Farrington, R. B., Apr. 1986, A Thorough Approach to Measurement Uncertainty Analysis Applied to Immersed Heat Exchanger Testing, SERI/TP-253-2862, Golden, Co: Solar Energy Research Institute. 


\section{APPENDIX B}

\section{SYSTEM PARAMETERS FOR FIGURE 3-3}

The system was modeled using F-CHART Version $5.6 . *$ All the parameters were the same except for the collector area storage tank volume and tank UA, which are given in Figure 3-3.

The inputs were:

1. Number of collector panels.......... 2, 3, or 4

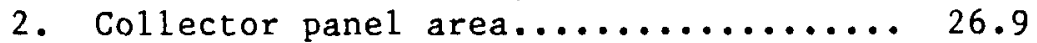

3. FR*UL (test slope).................. 1

4. FR*TAU*ALPHA (test intercept)....... 0.8

5. Collector slope................. 45

6. Collector aximuth $($ south $=0) \ldots \ldots \ldots 0$

7. Incidence angle mod type $(8-10) \ldots \ldots \ldots 8$

8. Number of glazings............... 1

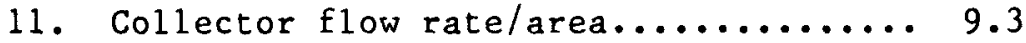

12. Collector fluid specific heat......... 1

13. Modify test values $(1=\mathrm{Y}, 2=\mathrm{N}) \ldots \ldots \ldots \ldots 2$

1. City call number................. 59

2. Average daily energy use.............. 0.0465

3. Average daily load flow............. 664

4. Load heat exchanger effectiveness...... 1

5. Minimum useful temperature........... 120

6. Liquid storage tank volume.......... 80 or 120

7. Tank liquid specific heat............ 1

8. Tank liquid density................ 62.4

9. UA of solar storage tank.............. 1.5 or 2

10. Tank environment temperature......... 68

11. Fuel $(1=\mathrm{EL}, 2=\mathrm{NG}, 3=0 \mathrm{i} 1,4=0$ ther $) \ldots \ldots 1$

12. Efficiency of fuel usage........... $100 \%$

13. Pi pe heat loss $(1=\mathrm{Y}, 2=\mathrm{N}) \ldots \ldots \ldots \ldots \ldots \ldots \ldots$

14. Inlet pipe UA.................. 0.75

15. Outlet pipe UA................ 0.75

16. Collector-storage $\mathrm{HX}(1=\mathrm{Y}, 2=\mathrm{N}) \ldots \ldots \ldots 1$

17. Tank side flow rate/area........... 9.3

18. Heat exchanger effectiveness........ 1

$\mathrm{ft} \mathrm{t}^{2}$ $\mathrm{Btu} / \mathrm{h} \mathrm{ft}^{2} \mathrm{O}_{\mathrm{F}}$

deg

deg

$1 \mathrm{~b} / \mathrm{h} \mathrm{ft} \mathrm{t}^{2}$

$\mathrm{Btu} / 1 \mathrm{~b}{ }^{\circ} \mathrm{F}$

Denver, Co

MMBtu/day

$1 \mathrm{~b} /$ day

${ }^{\circ} \mathrm{F}$

gal

$\mathrm{Btu} / 1 \mathrm{~b}{ }^{\circ} \mathrm{F}$

$\mathrm{lb} / \mathrm{ft}^{3}$

$\mathrm{Btu} / \mathrm{h}{ }^{\mathrm{O}} \mathrm{F}$

${ }^{\mathrm{O}} \mathrm{F}$

$\%$

$\mathrm{Btu} / \mathrm{h}{ }^{\mathrm{O}} \mathrm{F}$

Btu/h ${ }^{\circ} \mathrm{F}$

$1 \mathrm{~b} / \mathrm{h} f \mathrm{t}^{2}$

*F-CHART, IBM PC Version 5.6, copyright October 15, 1985, by S. A. Klein and W. A. Beckman, Madison, Wisc. 


\section{APPENDIX C \\ DETAILED NUMERICAL MODEL}

As identified in Section 1.0, there is a large discrepancy between the predicted performance and measured performance of the heat exchanger. This discrepancy is not unexpected when one looks at existing correlations used for the heat transfer predictions for the heat exchangers. Generally the predictions are based on horizontal tubes in an infinite medium. The actual geometry, a helical coil confined in a cylindrical tank, is far removed from the hypothesized geometry.

As an illustration of the thermal-hydraulic phenomenon that occurs in a realistic coil heat exchanger, consider what happens when the heated fluid enters the bottommost heat exchanger coil. The hot fluid in this coil loop produces a buoyant flow resulting in a plume that rises and interacts with the next tube above it. This second tube now experiences both free and forced convection with the tank surroundings because of the induced flow field from the bottom tube. Likewise all tubes above the lowest tube experience both free and forced, mixed convection. The flow field surrounding the subsequent tubes and the accompanying heat transfer is not necessarily the same as that experienced by the first two coils.

There are basically two effects that arise, one due to the flow generated by the hotter tube and the other due to the temperature field in this wake. The induced flow causes an increased velocity in the surrounding field and hence an increase in the forced convection between the tube and its surroundings. However, for an isothermal tube element located vertically above another and thus in its wake, the Nusselt number decreases because of the increase in the temperature of the fluid in its vicinity. Also, the driving temperature difference between the coil element and the bulk tank fluid at this location has decreased and thus the heat transfer from this tube element has also decreased.

Whether or not the tube-to-tank fluid heat transfer increases or decreases depends on a number of variables, principally: tube vertical center-to-center spacing, transverse offset between subsequent tube coils, horizontal spacing between tank wall and tube centerline, and the flow field (laminar or turbulent). It cannot be said with certainty whether the tube vertical separation or transverse offset will increase or decrease the heat transfer. A number of investigators have demonstrated both analytically and experimentally that the heat transfer can be enhanced or retarded above that of a single tube depending on the selection of the above-mentioned parameters.

The objective of this portion of the study is to evaluate the relative merits of various coil-type heat exchanger configurations by using numerical techniques. As a way to reach this goal, a finite difference numerical model of an existing coil heat exchanger being used in this study as a test article was developed for this analysis. 


\section{C.1 Existing Correlations}

Recently, results from a number of studies involving convection from horizontal cylinders in interacting flow fields have been made available. The first, by Farouk and Guceri (1983), is a detailed analytical study in which solutions are obtained to the Navier-Stokes and energy equations for steadystate, two-dimensional, laminar and turbulent natural convection in interacting flow fields. Effects of varying tube spacings are considered. Results are given in the form of a mean Nusselt number as a function of the Rayleigh number for single and double rows of cylinders. The Rayleigh number $\left(10^{3}-10^{9}\right)$ covers both laminar and turbulent regimes.

Sparrow and Niethammer (1981) experimentally investigated convection from a pair of parallel, vertically stacked, horizontal cylinders. This study, performed in air, considered Rayleigh numbers that varied from $2 \times 10^{4}$ to $2 \times 10^{5}$. The vertical tube separation distance varied from one to nine tube diameters. It was found that the heat transfer enhancement or degradation was a strong function of separation distance. Heat transfer degradation for the parallel, vertically stacked, horizontal cylinders was more apparent at small separation distances than it was for single vertical tubes, and enhancement prevailed at larger separations. The maximum enhancement occurs in the separation range of seven to nine tube diameters. The results are reported as Nusselt number versus normalized separation distance with Rayleigh number as a parameter.

Sparrow and Boessneck (1983) experimentally investigated the effect of transverse offset in the vertically stacked, horizontal-tube arrangement. This study (also performed in air) covered the same Rayleigh number range from $2 \times 10^{4}$ to $2 \times 10^{5}$. At small vertical separation, transverse offsetting caused an increase in the upper cylinder Nusselt number above the increase in a no-offset case. However, at larger vertical separations, the offsetaffected Nusselt number was less than the Nusselt number having no offset. The results are reported as Nusselt number versus normalized vertical separation distance with Rayleigh number as a parameter for three transverse misalignment values.

\section{C.2 Methodology}

For this analysis, we developed a finite difference numerical model of an existing coil heat exchanger used in this study as a test article. The model uses the MITAS (Conner et al. 1971) thermal analyzer computer program. MITAS is a general-purpose program designed primarily to solve lumped parameter (i.e., resistor-capacitor $[\mathrm{R}-\mathrm{C}])$, network representations of thermal systems. It has the capability to solve large thermal networks (up to 8,200 nodes and 12,000 unique conductors). Users can interact with the network solution by providing their own logic to direct the program execution. This is done through a user input language very similar to FORTRAN but allows the user access to all the program variables during execution.

The finite difference MITAS model developed has 54 nodes to represent the tank, tank fluid, heat exchanger tube, and tube fluid. Boundary conditions for the model are the inlet fluid temperature, heat exchanger flow rate, and tank ambient surrounding temperature. The coil heat exchanger is modeled as vertically stacked, horizontal-tube/fluid nodes surrounded by tank fluid volume nodes. MITAS user interaction allows us to calculate and incorporate 
the tube wall to the surrounding fluid convection coefficients taken from the correlations discussed above. Also, heat transfer coefficient correlations for fluid flow in a pipe are used to evaluate heat transfer between the heat exchanger fluid in the tube and tube wall as well as the tank fluid and tank side wal1. Fluid thermophysical properties (density, viscosity, and coefficient of thermal expansion) are evaluated as a function of temperature for every time step.

Because of the complexities associated with calculating the tank fluid volume flow field and because of the comparative nature of the study, the model solves a simplified one-dimensional momentum equation for the tank fluid velocity. The equation is based on a driving temperature difference between the first two fluid layers along with the volumetric coefficient of expansion and the tube-to-tube separation distance to arrive at a fluid velocity. The velocity is multiplied by the cross-sectional area of the tank and appropriate density to give the tank mass flow rate. This procedure calculates typical flow rates corresponding from 0.5 to $1 \mathrm{ft} / \mathrm{s}$ up the tank side wall. This flow rate is also consistent with dye injections used to observe tank flow patterns on the test article.

The model was developed primarily for transient cool-down and heat-up analysis from an initial steady-state tank temperature. However, transient analysis capability for time-varying tank loads simulating profiles of hot water use is also incorporated in the model.

The parameters for the tank/heat exchanger base-case model are given in Table C-1. This represents the smooth-coil configuration used in the laboratory tests discussed in Section 3.1. A nodal schematic of the tank/heat exchanger model is shown in Eigure $\mathrm{C}-1$. The smooth-coil heat exchanger is simulated using 13 horizontal tube wall nodes. There is one node for each coil loop. This tube wall node has two corresponding fluid nodes: one for the heat exchanger fluid and another for the surrounding tank fluid. Five subsequent nodes above the heat exchanger are used to model the remaining tank fluid volume. This allows for the calculation of the tank stratification. There are six tank internal side wall nodes: one in the corresponding heat exchanger vicinity and the other five corresponding to the tank side wall for each of the fluid volumes above the heat exchanger. Six external tank wall nodes are used to represent the tank insulation blanket and the external skin. One boundary node represents the heat exchanger inlet temperature and another boundary node represents the room ambient temperature.

Table C-1. Base Case

\begin{tabular}{lc}
\hline \multicolumn{1}{c}{ Parameter } & Base-Case Value \\
\hline Tube length & $18.63 \mathrm{~m}(61.1 \mathrm{ft})$ \\
Tube area & $0.929 \mathrm{~m}^{2}(10.0 \mathrm{ft})$ \\
Tank diameter & $0.586 \mathrm{~m}(1.92 \mathrm{ft})$ \\
Tank height & $1.52 \mathrm{~m}(5.0 \mathrm{ft})$ \\
Heat exchanger flow rate & $0.095 \mathrm{~L} / \mathrm{s}(1.5 \mathrm{gal} / \mathrm{min})$ \\
Tank material & $1 / 2-i n$. plexiglass \\
Tube material & $1 / 2-i n$. copper tubing \\
\hline
\end{tabular}




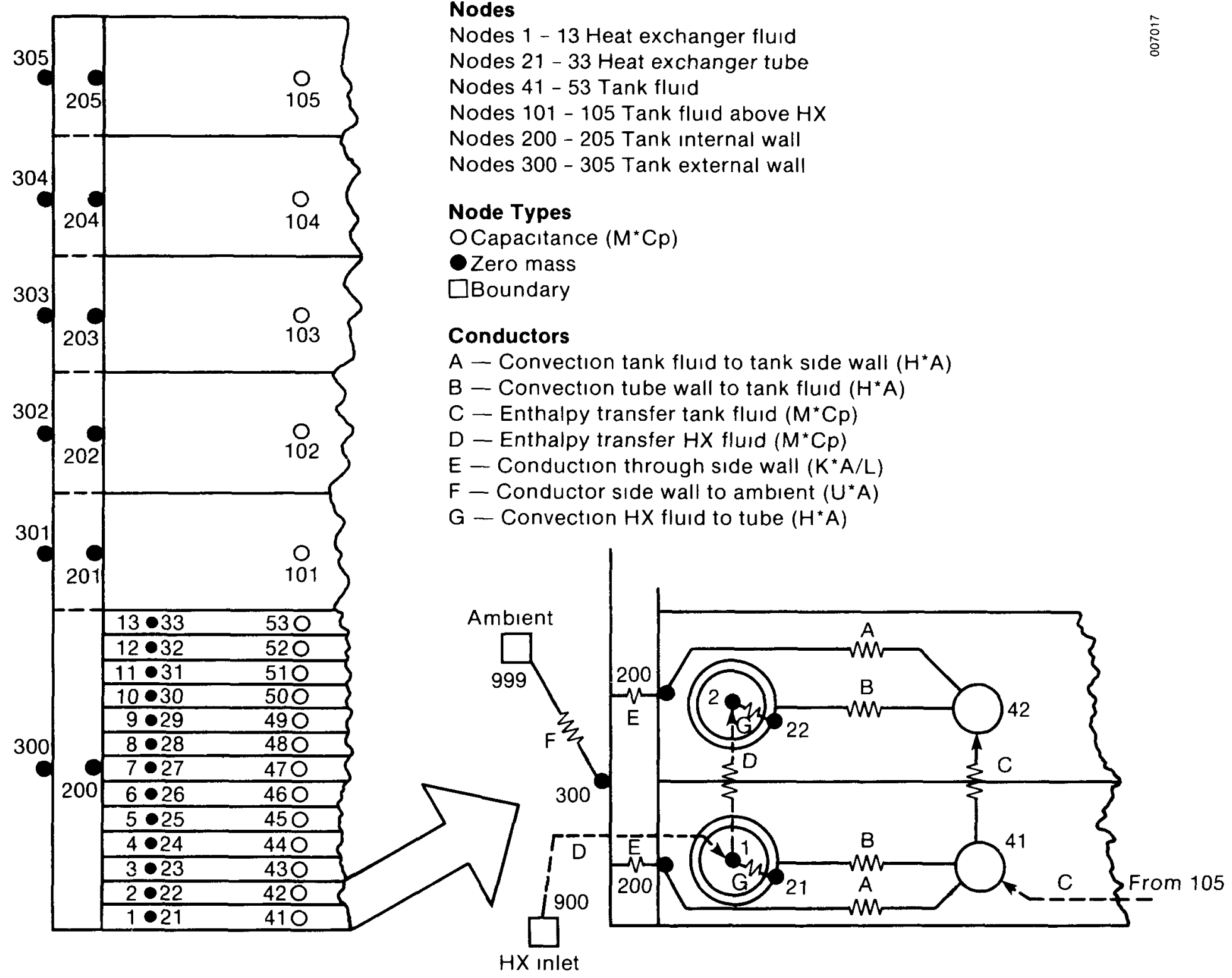

Figure C-1. Thermal Model of Nodal Schematic DHW Tank/Heat Exchanger 
The heat exchanger tube wall is coupled to the internal and external fluid by convection couplings. The internal tube heat transfer coefficient is based on the Dittus-Boelter equation (Dittus and Boelter 1930). The external tube heat transfer coefficient as a function of tube spacing was taken from Sparrow and Niethammer (1981). The results are reported as a Nusselt number ratio versus separation distance (normalized by the diameter, S/D) with Rayleigh number as a parameter. The Nusselt ratio is the upper tube Nusselt number divided by a single-cylinder, undisturbed stream Nusselt number. Because the Sparrow and Niethammer results were for only two cylinders, the Nusselt number for coil tubes above the second were calculated based on the below-tube Nusselt number multiplied by the Nusselt number ratio for the first pair of tubes.

\section{C.3 Parametric Evaluation Results}

After the initial model was constructed to configure the test article, it was exercised to establish the base-case performance. The base case has 1.6-cm (5/8-in.) outer diameter (OD) tubes with a $0.3-\mathrm{cm}(1 / 8-\mathrm{in}$.$) gap between$ tubes. This gives a tube spacing/tube diameter (S/D) ratio of 1.20, which corresponds to a Nusselt number ratio (i.e., the upper tube Nusselt number divided by a single-cylinder, undisturbed stream Nusselt number) of 0.78 . This factor was applied to the Nusselt number for the subsequent tubes. For comparison, an S/D of 3 , which corresponds to a Nusselt number ratio of 1 , was chosen. This results in a tube separation distance of $4.76 \mathrm{~cm}$ ( 1.875 in.) compared to the $0.3-\mathrm{cm}(1 / 8-\mathrm{in}$.$) separation in the test article. A11 other$ parameters for the comparison remained the same.

The results of the comparison for the $5-\mathrm{L} / \mathrm{min}$ heat exchanger flow rate case are given in Figures $\mathrm{C}-2$ through $\mathrm{C}-7$. Figure $\mathrm{C}-2$ gives the average tank temperature versus time for the two different tube spacing cases and the test data. Although the S/D of 1.2 should better represent the test article temperature results, the S/D ratio of 3 matched the measured temperatures more closely. This may be due to the way that the Nusselt number for coil tubes above the second were calculated as explained in the conclusion below. Figure $\mathrm{C}-3$ gives the heat exchanger outlet temperature versus time for the two different tube spacing cases and the test data. Again the $S / D=3$ case seems to better represent the actual test data.

In practice it is customary to use the logarithmic mean temperature difference (LMTD) as an indicator of the heat exchanger performance. The LMTD relates the heat exchanger temperature difference to the tank temperature difference as defined by Eq. 3-4. Figures $\mathrm{C}-4$ through $\mathrm{C}-6$ show the heat exchanger thermal performance as a function of the LMTD. Figure C-4 shows the total heat transfer (Eq. 3-2) obtainable from the two different configurations. Figure C-5 shows the overall heat transfer area coefficient (UA, defined by Eq. 3-3) for the two configurations. Figure $\mathrm{C}-6$ shows how changing the S/D spacing influences the overall heat exchanger effectiveness ( $\varepsilon$, defined by Eq. 3-1). Figure $\mathrm{C}-7$ plots the same effectiveness versus the heat exchanger inlet minus the average tank temperature for the two different cases. 


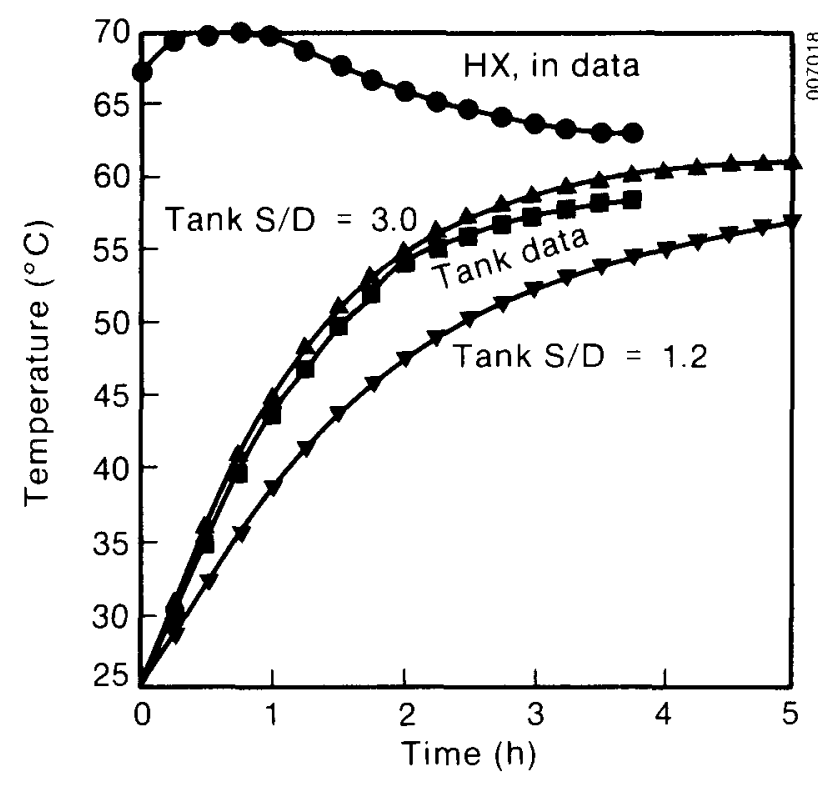

Figure C-2. System Temperature versus Time $(5 \mathrm{~L} / \mathrm{min})$

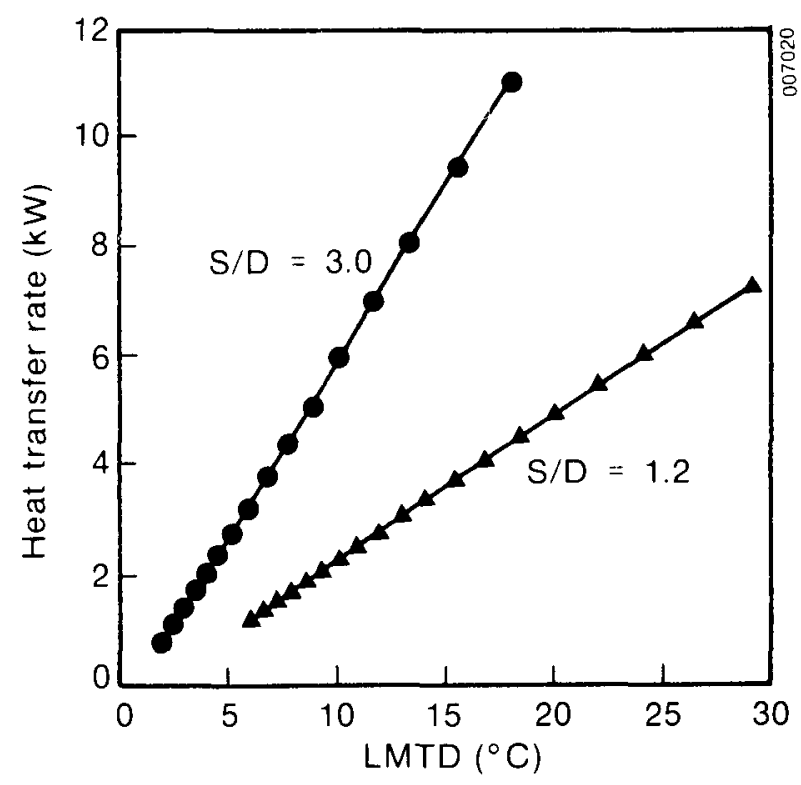

Figure C-4. Heat Exchanger Heat Transfer versus LMTD ( $5 \mathrm{~L} / \mathrm{min}$ )

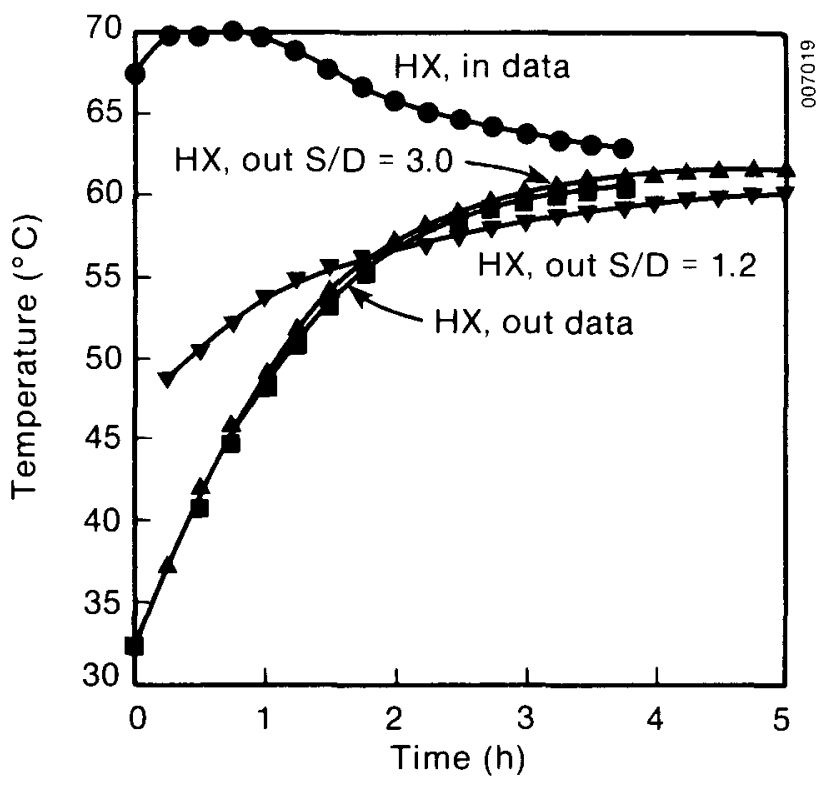

Figure C-3, Heat Exchanger Temperature versus Time ( $5 \mathrm{~L} / \mathrm{min}$ )

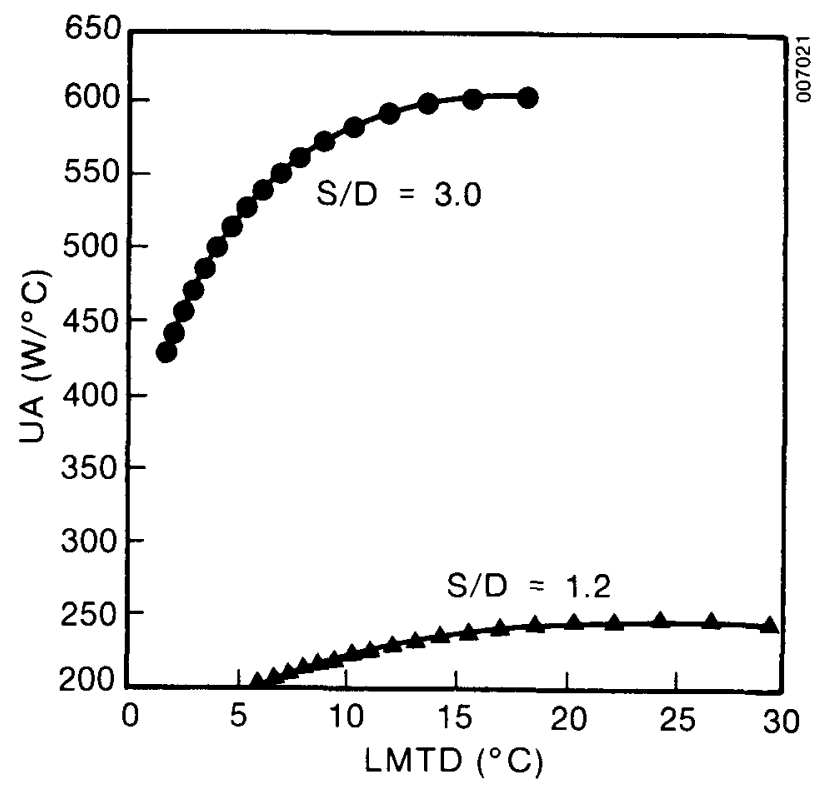

Figure C-5. Heat Exchanger UA versus LMTD ( $5 \mathrm{~L} / \mathrm{min})$ 


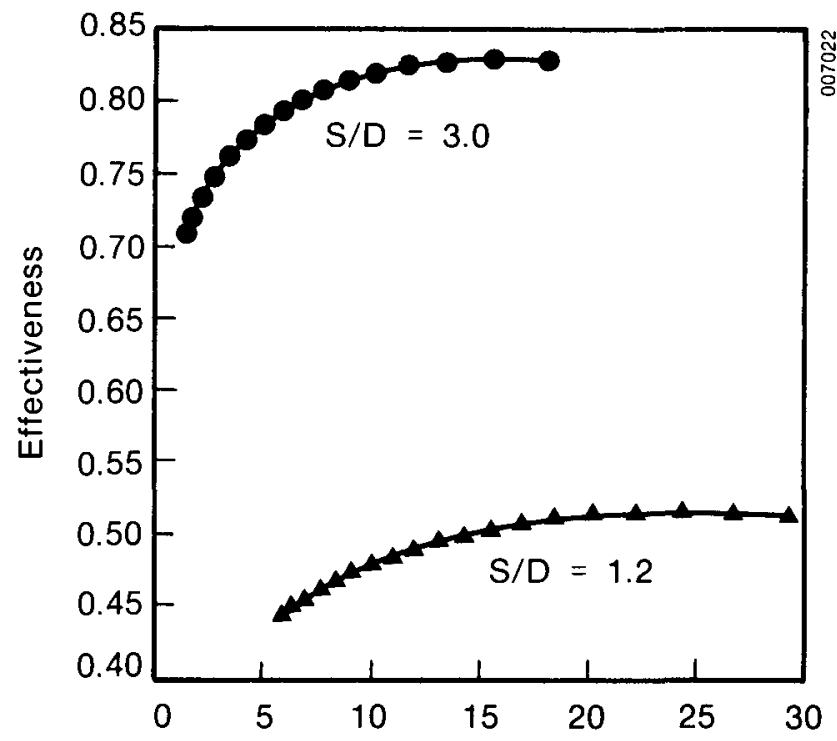

Figure C-6. Heat Exchanger

Effectiveness versus

LMTD ( $5 \mathrm{~L} / \mathrm{min})$

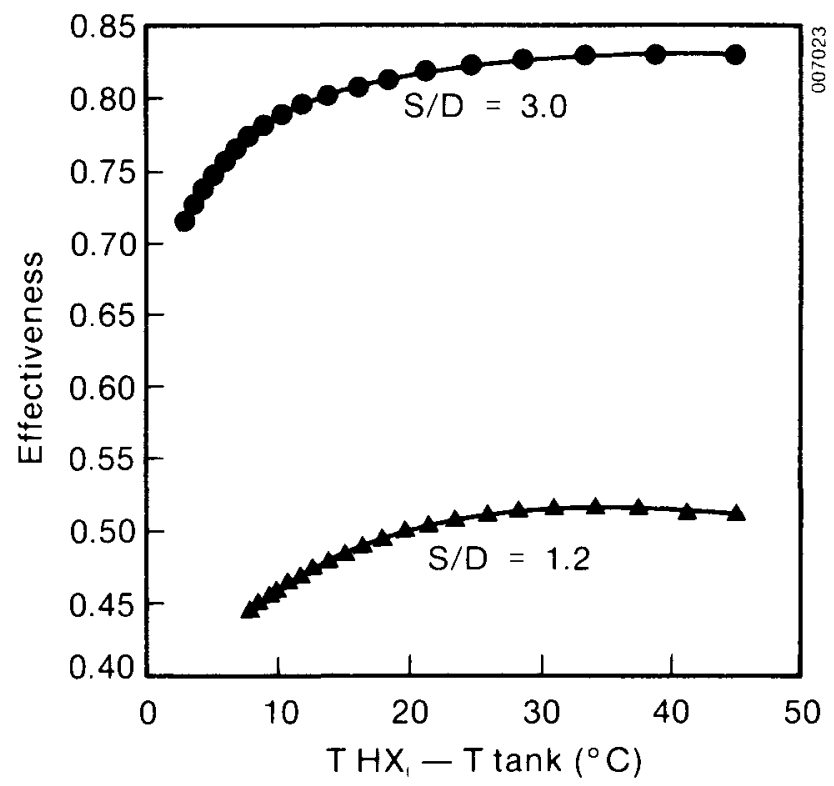

Figure C-7. Heat Exchanger Effectiveness versus Temperature Difference ( $5 \mathrm{~L} / \mathrm{min})$

\section{C.4 Conclusions and Recommendations}

Heat exchanger configuration, and in particular tube-to-tube spacing in coiltype heat exchangers, has been shown to be a critical parameter in the overall thermal performance of heat exchangers. The numerical model has shown that the thermal performance can be almost doubled just by increasing the separation distance between tube coils. Many simplifications and assumptions were made, even in this somewhat detailed model, which may affect the results. However, the trend of improved heat transfer with proper selection of configuration parameters seems to be consistent with the numerical model and with the analytical and experimental investigations of Farouk and Guceri (1983), Sparrow and Niethammer (1981), Sparrow and Boessneck (1983), and Conner et al. (1971).

One of the main assumptions made in the model is the manner in which the Nusselt numbers for the heat exchanger tube wall to the tank fluid are calculated and applied to the tubes above the first pair. Because the Sparrow and Niethammer results were for only two cylinders, the Nusselt number for coil tubes above the second coil tube were calculated based on the below-tube Nusselt number multiplied by the Nusselt number ratio for the first pair of tubes. Implicit in this procedure is that the heat transfer effect on subsequent tubes above the first pair is the same as the heat transfer effect for the first pair of tubes. This is probably not the real situation because the second tube also produces a buoyant flow resulting in a plume that rises and interacts with the next tube above it. This plume would be different than the plume from the first tube. However, because of the comparative nature of the 
study and the lack of any other reliable data, this procedure was incorporated into the model and was felt to be adequate to indicate the effect of tube spacing. In the future better data, taking into account multiple tube effects, need to be gathered to better represent the real phenomena.

Another simplification employed in the model is the way in which the tank flow field is calculated. The model solves a simplified one-dimensional momentum equation for the tank fluid velocity. A detailed analytical solution of the coupled energy and momentum equations in the interacting flow field was not warranted for the present study. If further investigation into heat exchanger performance is made, then a more appropriate flow field solution should be performed.

\section{C.5 References}

Conner, R. J., et al., June 1981, Martin Interactive Thermal Analysis System (MITAS), MOS-SPLPD-71-FD238, Denver, CO: Martin Marietta Corp.

Dittus, F. W., and L. K. M. Boelter, 1930, "University of California Publication in Engineering," Vol. 2, pp. 443.

Farouk, B., and S. I. Guceri, 1983, "Natural and Mixed Convection from Horizontal Cylinders in Interacting Flow Fields," Int. J. Heat Mass Transfer, Vol. 26, No. 22, pp. 231-243.

Sparrow, E. M., and D. S. Boessneck, May 1983, "Effect of Transverse Misalignment on Natural Convection from a Pair of Parallel, Vertically Stacked, Horizontal Cylinders," J. Heat Transfer, Vo1. 105, pp. 241-247.

Sparrow, E. M., and J. E. Niethammer, Nov. 1981, "Effect of Vertical Separation Distance and Cylinder-to-Cylinder Temperature Imbalance on Natural Convection for a Pair of Horizontal Cylinders," J. Heat Transfer, Vo1. 103, pp. 638-644. 
SELECTED DISTRIBUTION LIST

Alabama Solar Energy Center University of Alabama Huntsville, AL 35899

Attn: Dr. Gerry Guinn

ALTEN

2581 Leghorn Street Mountain View, CA 94043

Attn: Mr. Barry P. Scott

Alternative Energy Sources

1477 Lomal and, B1dg. A

E1 Paso, TX 79935

Attn: Dr. Vijay Kane

American Society of

Mechanical Engineering

United Engineering Center

345 East 47 th Street

New York, NY 10017

Attn: Ms. Diane Kaylor, News Editor

American Solar Energy Society 203017 th St.

Boulder, CO 80302-5404

Archer Industries

142 South Hale Avenue

Escondido, CA 92025

Attn: Mr. Mike Landry

Mr. Peter Armstrong

715 Peterson Street

Fort Collins, CO 80524

Argonne National Laboratory

Building 362

9700 South Cass Avenue

Argonne, IL 60439

Attn: Mr. William Shertz

Brookhaven National Laboratory

Building 475

Upton, NY 11973

Attn: Mr. William Wilhelm

Business Publishers, Inc.

951 Pershing Drive

Silver Spring, MD 20910

Attn: Mr. Allan L. Frank
California Polytechnic

State University

Agr. Engineering Department

San Luis Obispo, CA 93407

Attn: Professor Ed Carnegie

California State University

6000 "J" Street

Sacramento, CA 95819

Attn: Dr. Jim Berguam

Calmac

150 South Van Brunt Street

Englewood, NJ 07631

Attn: Mr. Brian Silvetti

Centre of Energy Studies

Indian Institute of Technology

New Delhi-16

INDIA

Attn: Dr. Tara Chandra Kandpal

Centre Scientifique et Technique du Batiment

4, Avenue du Recteur Poincare

75782 Paris, FRANCE

Attn: Mr. Luc Bourdeau

Colorado State University

Department of Mechanical Engineering

Fort Collins, CO 80523

Attn: Dr. S. Karaki

Colorado State University

Department of Mechanical Engineering

Fort Collins, CO 80523

Attn: Dr. George Löf

Com Tech

Box 5642

Victoria, BC V8R $6 \mathrm{~S} 4$

CANADA

Attn: Mr. Day Chapin

Mike Connolly

10500 W. Center Ave.

Lakewood, CO 80226

Contemporary Systems, Inc.

Route 12

Walpole, NH 03608

Attn: Mr. John Christopher 
Danish Solar Energy Testing Lab Technological Institute

P.0. Box 141

Taastrup, DENMARK

Attn: Mr. Torkild Vest Hansen, Manager

Davis Energy Group

2655 Portage Bay Avenue, Suite \#1 Davis, CA 95616

Attn: Mr. Jack Androvich

\section{DMNES}

P.0. Box 1830

Limassol, Cyprus

Attn: Mr. Mike Merino

DSET Laboratories

Box 1850 Black Canyon Stage I

Phoenix, AZ 85029

Attn: Mr. Matthew Rupp

EMC Engineering

P.0. Box 36009

Denver, CO 80236

Attn: Mr. Doug Dougherty

Energy Contractors Group

13161 Newhope Street

Garden Grove, CA 92643

Attn: Mr. Guy Rohlfs Voss

Energy Engineering

4616 McLeod Rd., N.E.

Albuquerque, NM 87109

Attn: Dr. Karl Feldman, Jr.

Energy Systems Centre

Ontario Research Foundation

Mississauga, Ontario

CANADA L5K 183

Attn: Mr, Bruce E. Sibbitt

Engineering Staff College of India Visvesvaraya Bhavan

Khairatabad, Hyderabad--500 004

INDIA

Attn: Dr. M. Ramakrishna Rao

ETEC

Rockwell International Corporation P.0. Box 1449

Canoga Park, CA 91304

Attn: Mr. Paul Pekrul
Florida Solar Energy Center

300 State Road 401

Cape Canaveral, FL 32920-4099

Attn: Mr. Charles J. Cromer, P.E.

Florida Solar Energy Center

300 State Road 401

Cape Canaveral, FL 32920-4099

Attn: Ms. Iraida B. Rickling, University Librarian

Florida Solar Energy Center 300 State Road 401

Cape Canaveral, FL 32920-4099

Attn: Mr. Marvin Yarosh

Dr. Jeff M. Gordon

University of Colorado

Civil Engineering Department

Campus Box 428

Boulder, CO 80309

Honeywell, Inc.

Technology Strategy Center

1700 West Highway 36

Roseville, NM 55113

Attn: Mr. Bob Aasen

Industrial Solar Technology

12325 W. 19th Place

Lakewood, CO 80215

Attn: Mr. Ken May

King Saud University

P.O. Box 800

Riyadh

SAUDI ARABIA 11421

Attn: Dr. Ing. H. Sofrata

Korea Institute of Energy and Resources

P.O. Box 339

Taejeon

Chungnam, SOUTH KOREA

Attn: Dr. Paul Auh

Korea Institute of Energy and Resources

P.0. Box 339

Taejeon

Chungnam, SOUTH KOREA

Attn: $\mathrm{Dr}$. Lee Jong Ho 
Lawrence Berkeley Laboratory

University of California

Building 90-2024

Berkeley, CA 94720

Attn: Dr. Mashuri Warren

Los Alamos National Laboratory

Mail Stop J 576

P.0. Box 1663

Los Alamos, NM 87545

Attn: Mr. John Avery

Dr. Peter Lunde

4 Daniel Lane

W. Simsbury, CT 06092

Dr. Ali M. E1 Nashar

Water and Electricity Department

P.O. Box 219

Abu Dhabi

United Arab Emirates

National Bureau of Standards

Thermal Solar Group

Building 226, Room B-322

Gaithersburg, MD 20899

Attn: Dr. Hunter Fanney

National Bureau of Standards

Building 226, Room B-320

Gaithersburg, MD 20899

Attn: Mr. Robert Dikkers

National Research Council of Canada

Low Temperature Laboratory

Division of Mechanical Engineering

Ottawa, Ontario

CANADA K1A 0R6

Attn: Mr. Steven Beale

National Technical University of Athens

School of Chemical Engineering

Thermodynamics and Transport

Phenomena Laboratory

Athens 147, GREECE GR-106 82

Attn: Dr. John Palyvos

Naval Civil Engineering Lab

Port Hueneme, CA 93043

Attn: Mr. Ed Durlak (Code L73)
New Mexico Energy Research and Development Institute

Room 358, Pinon Building

1220 South St. Francis Drive

Santa Fe, NM 87501

Attn: Mr. Steve Parker, Project Scientist

New Mexico Solar Energy Institute Box 3SOL

Las Cruces, NM 88003

Attn: Dr. Roger Farrer

New Mexico State University

Dept. of Mechanical Engineering

Box 3450

Las Cruces, NM 88003

Attn: Dr. George Mulholland

North Carolina A\&T State University Mechanical Engineering Department Greensboro, NC 27420

Attn: Dr. Tony Min

North Carolina A\&T State University Mechanical Engineering Department Greensboro, NC 27411

Attn: Dr. David Klett

Novan Energy, Inc. 1630 North 63rd Street

Boulder, CO 80301

Attn: Mr. Peter Jacobs

Oregon Department of Energy

Labor and Industries Building

Room 102

Salem, OR 97310-0831

Attn: Mr. David Robison

Penn State University

P.0. Box 519

Uniontown, PA 15401

Attn: Prof. David B. Meredith

Public Works Canada

Solar Programs office

Sir Charles Tupper Building

Ottawa, Ontario

CANADA K1A OM2

Attn: Mr. Peter Sauer 
Pyramid Controls

421-16 North Buchanan Circle

Pacheco, CA 94553

Ramada Energy Systems

1421 South McClintock

Tempe, AZ 85281

Attn: Mr. John Gamero-Abarca

Red Rocks Community College

12600 West 6 th Avenue

Golden, CO 80401

Attn: Mr. Jon K1 ima

Reynolds Metals Company

P.0. Box 27003

Richmond, VA 23261

Attn: R. Spears

Rho Sigma/Watsco, Inc.

1800 West Fourth Avenue

Hialeah, FL 33010

Attn: Dr. Joseph Mibelli

Rocky Mountain Solar Electric 1131 South Street

Louisville, CO 80027

Attn: Dr. M. McCray

Royal Scientific Society

P.O. Box 5211

Amman, JORDAN

Attn: Mr. Malek Kabariti

Mr. Bob Schuman

1090 Youngfield Street

Golden, CO 80401

Science Applications

International Corp.

5113 Leesburg Pike

Suite 710

Falls Church, VA 22041

Attn: Mr. William Scholten

Solaron Corporation

1885 West Dartmouth Avenue

Englewood, CO 80110

Attn: Dr. George Lof

Sunbelt Energy Corporation

2686 South Tejon

Englewood, CO 80110

Attn: Mr. Mike Davis
Sun 1 and

1115 Chestnut

Burbank, CA 91506

Attn: Mr. Dick Talbert

Sunmaster Corporation

35 West William Street

P.0. Box 1077

Corning, NY 14830

Attn: Mr. Michael Platt, P.E.

Sunstroke Solar

2406 Doswell Ave.

St. Paul, MN 55108

Swedish Council for

Building Research

Sankt Goransgatan 66

$\mathrm{s}-11233$

Stockholm, SWEDEN

Attn: Mr. Hans E. B. Andersson

Tata Energy Research Institute

7 Jorbagh

New Delhi - 110003

INDIA

Attn: Dr. Veena Joshi

Tennessee Valley Authority

MR 3S-43E

1101 Market Street

Chat tanooga, TN 37402-2801

Attn: Mr. Dale Depew

Tennessee Valley Authority

3S-44D Signal Place

1101 Market Street

Chattanooga, TN 37402-2801

Attn: Mr. Stephen Ira

Tennessee Valley Authority

SP IS-71A-C

1101 Market Street

Chat tanooga, TN 37402-2801

Attn: Mr. Dale Smotherman

Texas Tech University

Department of Mechanical Engineering Lubbock, TX 79409-4289

Attn: Dr. Jerry Dunn 
Trident Energy Systems

1355 Willow Way

Concord, CA 94520

Attn: Mr. David Horne

U.S. Solar Corporation

P.O. Drawer $K$

Hampton, FL 32044

Attn: Dr. W. Farber, Vice President

U.S. Department of Energy

Forrestal Building

1000 Independence Avenue, S.W.

Washington, D.C. 20585

Attn: Mr. Robert Hassett CE-311, 5H-065

U.S. Department of Energy Forrestal Building

1000 Independence Avenue, S.W.

Washington, D.C. 20585

Attn: Dr. Fred Morse

CE-31, 5H-095

U.S. Department of Energy

Forrestal Building

1000 Independence Avenue, S.W.

Washington, D.C. 20585

Attn: Mr. Dave Pellish

$\mathrm{CE}-312,5 \mathrm{H}-047$

Universidad Politecnica

Department: Termodinamica

P.0. Box 22012

Valencia, SPAIN 46071

Attn: Prof. J. Canada Ribera

University of California

Department of Mechanical Engineering

Irvine, CA 92717

Attn: Dr. M. Young

University of Colorado

Civil, Environmental, and

Architectural Engineering

Campus Box 428

Boulder, CO 80309-0428

Attn: Dr. Jan Kreider
University of Colorado

Department of Mechanical Engineering

Campus Box 427

Boulder, CO 80309-0427

Attn: Dr. Mel Branch

University of Houston

Department of Mechanical Engineering

University Park

Houston, TX 77004

Attn: Dr. Rick Bannerot

University of Nebraska

4911 Davenport

Omaha, NE 68132

Attn: Dr. Bing Chen

University of Wisconsin

1343 Engineering Research Building

Madison, WI 53706

Attn: Dr. W. Beckman

Virginia Polytechnic Institute and State University

Department of Mechanical Engineering

Blacksburg, VA 24061

Attn: Dr. William Thomas

Vitro Laboratories

14000 Georgia Avenue

Silver Spring, MD 20910

Attn: Mr. Ed Pollock

Professor John Yellott

901 West El Caminito Drive

Phoenix, AZ 85021

\section{SERI Staff:}

Carl Bingham

Gordon Gross

Frank Kreith

Chuck Kutscher

Al Lewandowski

Paul Notari

Ken 01 sen

Doug Powell

Steve Rubin

Walter Short

Chet Wells 


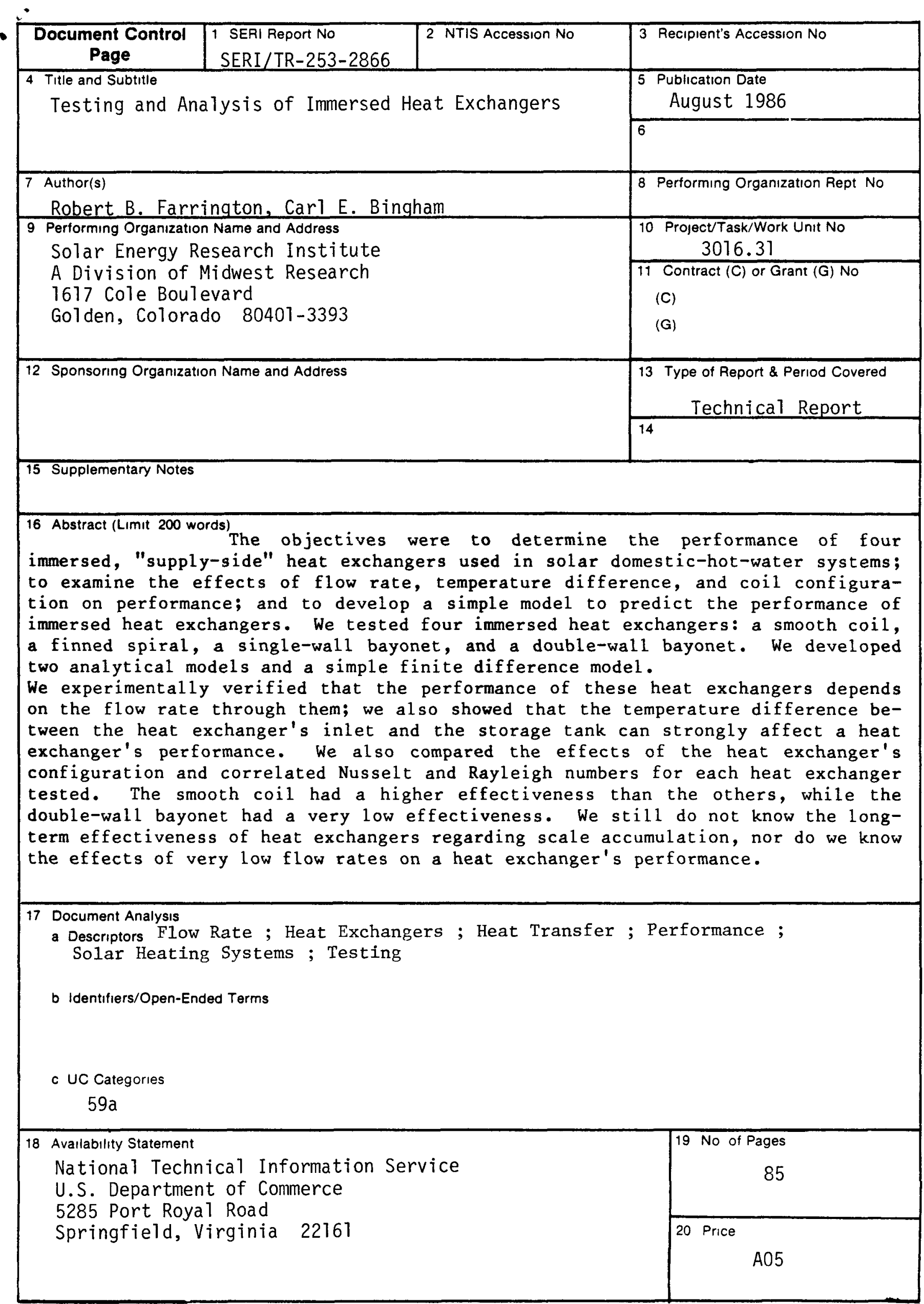

